\title{
Psychological predictors and treatment outcome in chronic pain
}

Citation for published version (APA):

Lamé, I. E. (2008). Psychological predictors and treatment outcome in chronic pain. [Doctoral Thesis, Maastricht University]. Datawyse / Universitaire Pers Maastricht. https://doi.org/10.26481/dis.20081126il

Document status and date:

Published: 01/01/2008

DOI:

10.26481/dis.20081126il

Document Version:

Publisher's PDF, also known as Version of record

\section{Please check the document version of this publication:}

- A submitted manuscript is the version of the article upon submission and before peer-review. There can be important differences between the submitted version and the official published version of record.

People interested in the research are advised to contact the author for the final version of the publication, or visit the DOI to the publisher's website.

- The final author version and the galley proof are versions of the publication after peer review.

- The final published version features the final layout of the paper including the volume, issue and page numbers.

Link to publication

\footnotetext{
General rights rights.

- You may freely distribute the URL identifying the publication in the public portal. please follow below link for the End User Agreement:

www.umlib.nl/taverne-license

Take down policy

If you believe that this document breaches copyright please contact us at:

repository@maastrichtuniversity.nl

providing details and we will investigate your claim.
}

Copyright and moral rights for the publications made accessible in the public portal are retained by the authors and/or other copyright owners and it is a condition of accessing publications that users recognise and abide by the legal requirements associated with these

- Users may download and print one copy of any publication from the public portal for the purpose of private study or research.

- You may not further distribute the material or use it for any profit-making activity or commercial gain

If the publication is distributed under the terms of Article $25 \mathrm{fa}$ of the Dutch Copyright Act, indicated by the "Taverne" license above, 


\section{Psychological Predictors and Treatment Outcome in Chronic Pain}


ISBN 9789052787800

๑ Copyright, IE Lamé, Rotterdam 2008

Omslag ontwerp: Impressie grafische vormgeving (Anja Verhart), Den Haag Layout en druk: Datawyse / Universitaire Pers Maastricht 


\title{
Psychological Predictors and Treatment Outcome in Chronic Pain
}

\author{
PROEFSCHRIFT
}

ter verkrijging van de graad van doctor

aan de Universiteit Maastricht,

op gezag van de Rector Magnificus, Prof. mr. G.P.M.F. Mols,

volgens het besluit van het College van Decanen,

in het openbaar te verdedigen

op woensdag 26 november 2008 om 12.00 uur

door

Ingrid Elisabeth Lamé

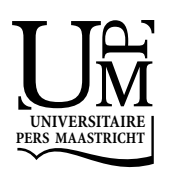




\section{Promotores}

Prof. dr. M. van Kleef

Prof. dr. M.L. Peters

\section{Copromotor}

Dr. J. Patijn

\section{Beoordelingscommissie}

Prof. dr. J. van 0s (voorzitter)

Prof. dr. J. Metsemakers

Prof. dr. K. Vissers (UMC St Radboud, Nijmegen)

Prof. dr. V. Visser-van de Walle

Prof. dr. J. Vles 
Mont Ventoux

Velen zijn mij reeds de berg op voorgegaan

Dichters en wielrenners in bonte stromen

Hebben voor mij de Mont Ventoux gedaan

En ook na mij zullen nog velen komen

$0 m$ te ervaren wat het is: per fiets, te voet

Naar het haast onhaalbare te streven

Niets of niemand zegt dat het echt moet

En toch, of juist daarom, wil je het beleven

Het dagelijkse werk van een fenomeen

Als Armstrong, Kal, Petrarca of Anquetil

Stervelingen zoals ik en iedereen

Gaan drie keer dood omhoog op hun twee wielen

Maar bovenop vervallen de verschillen

Talent is ook een vorm van heel graag willen

Huub van der Lubbe, Geregeld Leven, 2003 



\section{Contents}

Chapter 1 Introduction

Chapter 2 Quality of life in chronic pain is more associated with beliefs about pain than with pain intensity

Chapter 3 Test-retest stability of the pain catastrophizing scale and the tampa scale for kinesiophobia in chronic pain patients over a longer period of time

Chapter 4 Systematic review of the psychological factors that predict treatment outcome in chronic non-cancer pain

Chapter 5 Psychological predictors of treatment outcome in a heterogeneous chronic pain population: depression, fearavoidance beliefs or both? A prospective cohort study

Chapter 6 Can the outcome of spinal cord stimulation in chronic CRPS-I patients be predicted by catastrophizing thoughts?

Chapter 7 General discussion

Chapter 8 Summary

Samenvatting

Dankwoord

Publications 


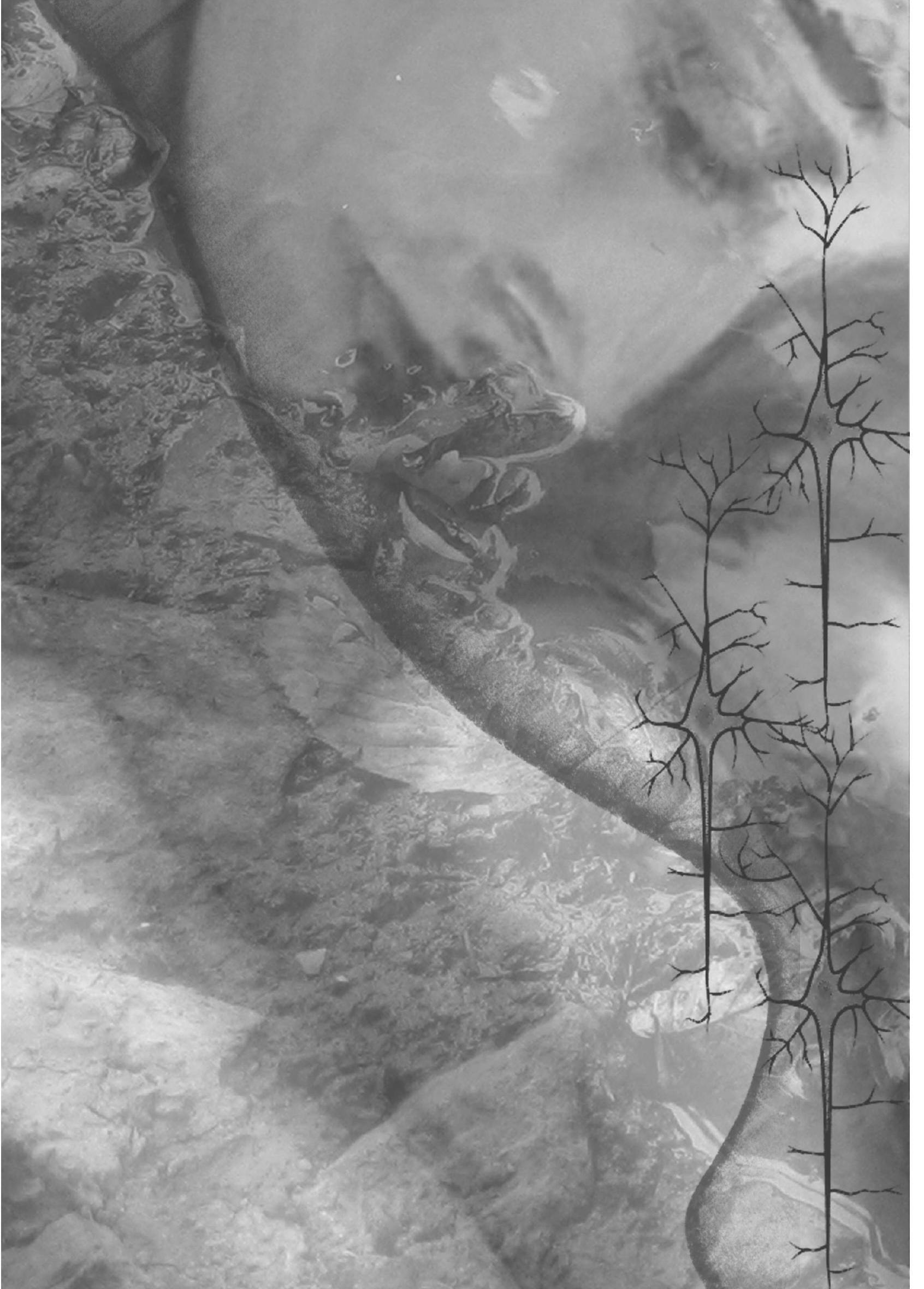




\section{Chapter 1}

\section{Introduction}




\section{INTRODUCTION}

A substantial proportion of chronic pain patients do not benefit enough from treatment (Vlaeyen \& Morley, 2005). Pain patients referred to an academic pain centre may have a long history of complaints, often with multiple pain problems, sometimes of unknown aetiology. These patients are usually exposed to multiple somatic interventions, including medication, which has consequences both for health care and the patient's mental health condition. Therefore, the diagnostic approach and treatment of this pain population should include both somatic and psychological factors.

The pressure on health care and the subsequent economic impact are both huge, mainly due to absence through sickness and long-term disability (Vlaeyen et al., 1995b; Steenstra et al., 2006). Prevalence rates of chronic pain provide an insight into the extent of this problem. Musculoskeletal pain is one of the leading causes of chronic pain world wide (Woolf \& Akesson, 2001). Approximately 85\% of the population suffer from it at some time point during their working career, and an estimated 3-10\% develop long-term disability (Boersma \& Linton, 2005). In the Netherlands, about $44 \%$ of the population aged 25 years and over will report musculoskeletal pain that lasts longer than three months (Picavet \& Schouten, 2003). The most frequently reported pain locations are: low back, shoulder, neck, knee, wrist/hand, upper back, hip, elbow, ankle and foot. Often more than one pain location is involved and causes widespread pain. In Europe, the prevalence rates of chronic pain, with pain lasting for more than six months, vary between $12 \%$ (Spain) and 30\% (Norway) (Breivik et al., 2006). In the Netherlands, $18 \%$ of the population are reported to suffer from chronic pain for more than six months. Although the prevalence of chronic pain is high, pain is under-treated, even in developed countries where patients have access to the best health care (Breivik et al., 2006; Lynch et al., 2008).

There is an increasing impact on mental health when a patient's pain lasts longer. There is evidence that chronic pain is often associated with co-morbid psychiatric disorders and emotional suffering (Gatchel et al., 2007; Weisberg \& Boatwright, 2007). A traditional biomedical approach, where pain is treated as a symptom isomorphically related to the severity of the underlying pathology of the organism, ignores mental factors (Vlaeyen \& Morley, 2005). Despite the successful treatment of many disease processes, some complex and important medical problems, such as non-specific musculoskeletal conditions, have proved to be resistant to purely medical treatment. A more comprehensive model focusing on visible signs of pain and suffering, resulting in behavioural medicine, was initiated by Fordyce (1976). This led to the development and evolution of the biopsychosocial model, in which the interrelationships between psychological, biological, and social factors should be considered (Turk, 1996; Gatchel et al., 2007) (fig 1). 


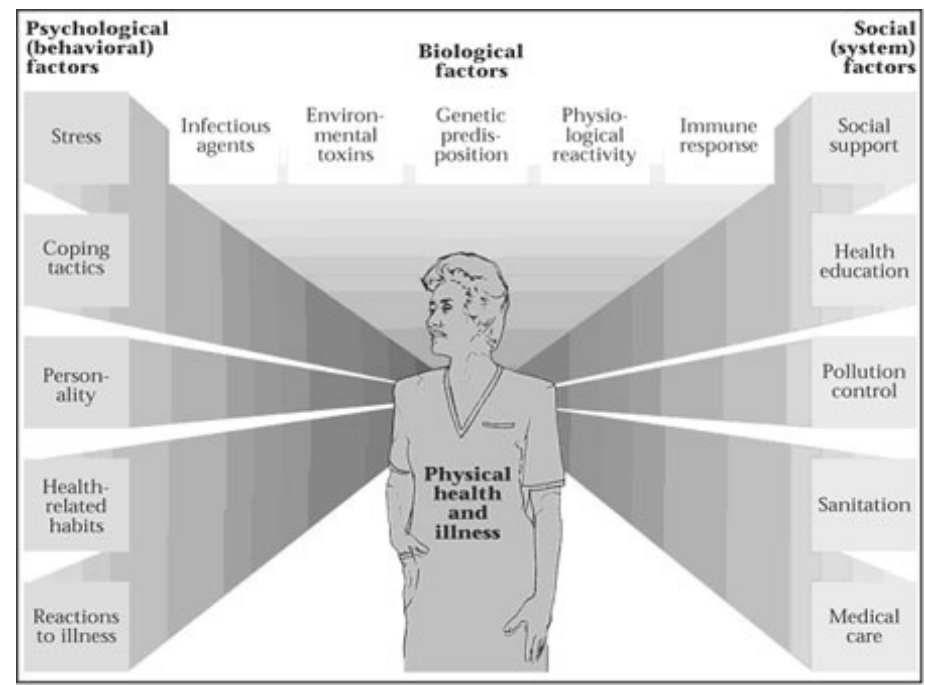

Figure 1. Biopsychosocial model

Currently, the biopsychosocial perspective of pain is a recommended approach for the understanding and treatment of pain syndromes. In particular, when pain persists over time and reaches a chronic state, the interaction between biological, psychological, and social factors with the underlying physical pathology becomes more evident in the patient's report of pain and disability (Gatchel, 2001; Waddell, 2006). The impact of persistent pain will finally influence all aspects of the pain sufferer's life, which can lead to depression, anger, anxiety, self-preoccupation, and isolation (Gatchel et al., 2007). There is growing interest in identifying patients at risk for insufficient treatment outcome within the framework of the biopsychosocial model. This thesis will mainly focus on the psychological factors associated with treatment outcome in chronic pain patients referred to an academic pain centre. Before dealing with the definition of the research questions in this thesis, the relevance of a multidisciplinary treatment approach will be discussed, and the theoretical background of the psychological factors in chronic pain, on which this research is based, will be described.

\section{TREATMENT IMPLICATIONS}

Many people with chronic pain experience moderate to severe pain intensity, are seriously affected in their daily lives, and do not receive adequate conventional treatment (Breivik et al., 2006). About $40 \%$ of chronic pain patients in Europe are not satisfied with the effect of the treatment they are receiving (Breivik et al., 2006). Single-discipline treatment, either somatic or psychological, has proved to 
be effective in subgroups of patients, but not all cases. The effects of somatic treatment, e.g., spinal manipulative therapy (Assendelft et al., 2004), back school (Heymans et al., 2004), transcutaneous electrical nerve stimulation (TENS) (Khadilkar et al., 2005), and interventional techniques (Mailis-Gagnon et al., 2004; Boswell et al., 2005; Malik \& Benzon, 2007; Staal et al., 2008) have recently been reviewed. All these reviews included either chronic non-specific low back pain (Heymans et al., 2004; Mailis-Gagnon et al., 2004; Staal et al., 2008) or a more broader selection of patients with spinal pain (Assendelft et al., 2004; Boswell et al., 2005; Khadilkar et al., 2005) and found limited to moderate evidence of a positive effect of treatment on pain intensity and functional status. Since standard medical care and invasive methods have not led to a decline in the prevalence of chronic pain, the role of psychologically-based treatments for chronic pain has become increasingly important (Gatchel, 2001).

The most commonly used psychological approaches for the management of chronic pain are cognitive-behavioural therapy (CBT), operant behavioural therapy and self-hypnosis training (Molton et al., 2007). Behavioural treatments can be defined as interventions that apply active psychological methods to change the behavioural expressions, thoughts, or feelings of patients with chronic pain, in order to help them experience less distress, and to improve physical functioning (Vlaeyen et al., 1995a; McCracken \& Turk, 2002). 'The severity and debilitating effects of chronic pain should be reduced as a patient comes to view pain and discomfort less as an overwhelming catastrophe and more as a controllable and manageable condition' (Burns et al., 2003). CBT includes both 'cognitive' and 'behavioural' elements, where cognitions (thoughts, attributions, beliefs) can either enhance or interfere with effective behavioural coping (Molton et al., 2007). About a decade ago, the results of a meta-analysis showed that active psychological treatment based on cognitive-behavioural principles, including behavioural treatment and biofeedback, is effective (median value of the effect size for the measurement domains is 0.5 ) compared to waiting-list control conditions for the domains of pain intensity, mood/affect, cognitive coping and appraisal (reduction of negative coping and increase of positive coping), pain behaviour and activity level, and social functioning (Morley et al., 1999). When CBT is compared to other treatments or control conditions, its efficacy is limited to the outcomes of pain intensity, positive coping, and social functioning. Moreover, CBT was shown to be efficacious in rheumatoid arthritis (Carson et al., 2006), patients with temporomandibular disorder (Turner et al., 2006), and elderly patients with chronic pain (Hughes et al., 2006). Although the effectiveness of CBT is dominant in several outcome measures and in several patient groups, a substantial proportion of patients with chronic pain still does not improve sufficiently (McCracken \&Turk, 2002).

The realization that chronic pain and disability are not only influenced by somatic pathology, but also by psychological and social factors has resulted in the devel- 
opment of multidisciplinary treatment programmes, in order to obtain the maximum effects of treatment and to avoid expensive interventions that are likely to fail. This biopsychosocial approach has led to an increasing number of multidisciplinary pain clinics all over the world. Multidisciplinary pain programmes combine elements of behavioural therapy (cognitive, operant, respondent or cognitivebehavioural therapy (CBT)), physical and occupational therapies, and medical management. The efficacy of multidisciplinary treatment programmes for chronic back pain compared to no treatment, waiting list, or single-discipline treatments such as medical treatment or physical therapy, has been reviewed by Flor et al. (1992). The effects of multidisciplinary treatment outcome in terms of mood, behaviour, and pain intensity were greater than those of untreated and unimodallytreated patients. Even on long-term follow-up, patients who were treated in multidisciplinary settings functioned better than $75 \%$ of patients who were either untreated or treated with conventional unimodal therapy. The available evidence for the efficacy of multidisciplinary treatment has recently been reviewed again (Scascighini et al., 2008). This review was more comprehensive and contained an update of former reviews. The results show that the efficacy of multidisciplinary treatment programmes (including individual exercise, relaxation techniques, group therapy led by a clinical psychologist, patient education sessions, physical therapy, medical training therapy, and neuro-physiology information) is better than standard medical treatment and other non-multidisciplinary treatments for chronic pain patients in general. When looking at specific subgroups of patients, the beneficial effect of multidisciplinary treatments appeared to be strongest in patients with chronic low back pain (Bendix et al., 1996; Basler et al., 1997; Jensen et al., 2001) and fibromyalgia (Vlaeyen et al., 1996; Gowans et al., 1999; Cedraschi et al., 2004). Both low back pain and fibromyalgia are strongly associated with behavioural components such as avoidance, over-under activity, and passive coping strategies. Moreover, both groups experienced maladaptive beliefs about the explanation of their pain, such as catastrophic thoughts and affective components, e.g., a high level of depression and distress. The results of this study support the conclusion that multidisciplinary treatment modalities are more promising in the treatment of chronic pain, especially of low back pain and fibromyalgia, compared to unimodal treatment programmes.

\section{THEORETICAL PERSPECTIVES OF PSYCHOLOGICAL FACTORS}

Theoretically, two aspects of psychological factors and chronic pain are of interest. Firstly, psychological factors are important in the persistence of pain, which can lead to the transition from acute to chronic pain. Secondly, psychological factors can influence treatment outcome in chronic pain. 


\section{CHAPTER 1}

\section{Psychological factors and the persistence of pain}

There is growing evidence that psychological variables are risk factors in the development of chronic pain and disability (Linton, 2000; Pincus et al., 2002). In an attempt to find an explanation for the development of persistent pain and disability, Lethem et al. (1983) introduced the 'fear-avoidance' model of musculoskeletal pain. The central concept of this model is 'fear of pain', which is driven by the anticipation of pain and not by the sensory experience of pain itself. Vlaeyen et al. (1995b; 1995c) proposed a more cognitively-oriented framework for pain-related fear, based on the aforementioned model. This postulates two opposing behavioural responses: confrontation and avoidance. The model suggests possible pathways by which injured patients fall into a downward spiral of increasing avoidance of movements or activities, leading to disability and pain. In particular, patients who misinterpret their pain as a sign of serious injury, and tend to see it as a catastrophe, are susceptible to developing pain-related fear and avoidance of movements that they believe to be harmful and to cause (re)injury (Vlaeyen et al., 1995b; Vlaeyen \& Linton, 2000). Pain catastrophizing is a better way of predicting pain-related fear than biomedical status and pain intensity (Vlaeyen et al., 1995b; Vlaeyen et al., 1995c; Crombez et al., 1999). Pain-related fear and pain catastrophizing lead to avoidance behaviour and hypervigilance to bodily sensations, which in turn lead to disability, disuse and depression (fig 2). Injured patients get caught in a downward spiral of increasing avoidance, disability, and pain. Avoidance behaviour is postulated to be one of the mechanisms in sustaining chronic musculoskeletal pain and disability (Vlaeyen et al., 1995b; Boersma \& Linton, 2005).

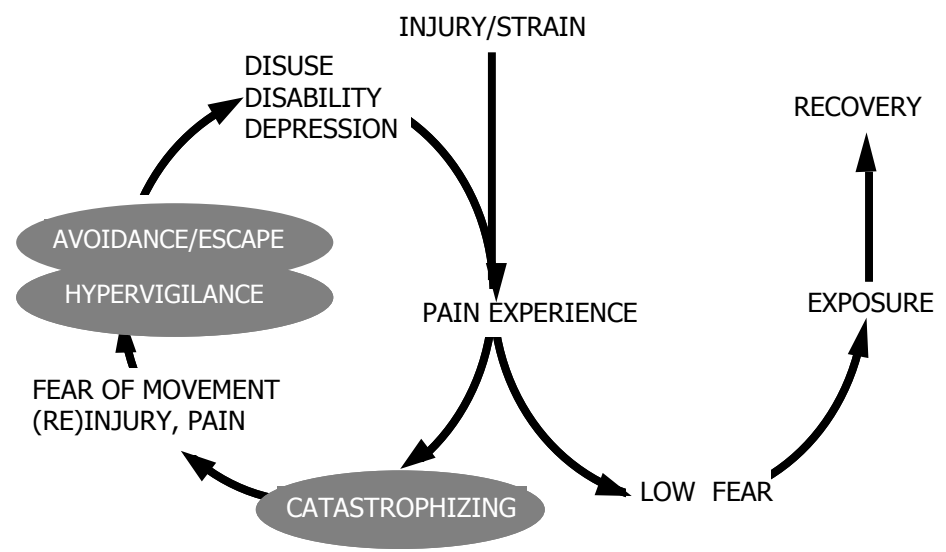

Figure 2. Fear-avoidance model adapted from Vlaeyen, J.W.S., Fear in Musculoskeletal Pain. In: J.0. Dostrovsky, D.B. Carr and M. Koltzenburg (Eds.), Proceedings of the 10th World Congress on Pain, Progress in Pain Research and Management,, Vol. 24, IASP Press, Seattle, 2003, pp. 631-650. 
The concept of pain catastrophizing has been defined as a process of exaggerated negative worrying thoughts brought to bear during the experience of actual or anticipated pain (Sullivan et al., 1995). Pain catastrophizing is consistently associated with heightened pain in clinical and experimental studies in adults and children, and with heightened disability. Pain catastrophizing predicts disability better than disease-related variables or pain (Sullivan \& D'Eon, 1990; Main \& Waddell, 1991; Lefebvre et al., 1995; Vlaeyen \& Linton, 2000; Severeijns et al., 2001; Peters et al., 2005; Sullivan et al., 2005). Moreover, there is evidence of catastrophizing and pain-related fear (together called fear-avoidance beliefs) contributing to the transition from acute to chronic musculoskeletal pain (Leeuw et al., 2007). Linton (2000) concluded that fear-avoidance beliefs were associated with both the inception and continuation of low back pain. More recently, several prospective studies have found support for the value of fear-avoidance beliefs as predictors for the transition to chronic low back pain and for future outcomes such as disability and sick leave (Picavet et al., 2002; Sieben et al., 2002; George et al., 2005; Swinkels-Meewisse et al., 2006). However, others concluded that negative mood, in the form of distress or depression, is prominently associated with the development of chronic pain (Pincus et al., 2002). In this review, evidence of fearavoidance was only noted in one study. Four years later, the same authors conducted a systematic review focusing on the role of fear-avoidance in the transition to chronic states in low back pain, in order to obtain additional evidence (Pincus et al., 2006). Once again, fear-avoidance was not found to be associated with the development of persistent pain. Although a review of nine studies was carried out, none of these discovered any association between baseline measures of fearavoidance and outcome. Moreover, the findings of Boersma and Linton (2005) suggest that both depressed mood and fear-avoidance in a population with acute non-specific back or neck pain may be associated with the development of chronic pain and disability. There still appears to be a lack of consistent findings on the impact of fear-avoidance in the transition from acute to chronic pain, whereas distress and depression seem to be an obstacle on the road to recovery. Future research should include both fear-avoidance beliefs and depression.

\section{Psychological factors and treatment outcome in chronic pain}

In the last few decades, an increasing number of studies examined many different psychological predictors of treatment outcome in chronic pain patients (Turk, 1990). Systematic reviews should reveal consistent findings in this large body of information. However, thus far, no uniform results have been reported. Moreover, the number of reviews dealing with this specific topic would appear to be limited. Only two reported on the psychological predictors of treatment outcome in chronic pain (Feuerstein et al., 1994; van der Hulst et al., 2005). Feuerstein et al. (1994) included studies that investigated demographic, medical, physical and psychological predictive factors of returning to work following multidisciplinary treatment for 
chronic back pain. Evidence for the predictive value of psychological factors was only obtained from one study (Barnes et al., 1989). High levels of hypochondriasis, depression, distrust/stubbornness, premorbid pessimism, and low levels of cooperativeness, predicted the low likelihood of returning to work. Van der Hulst et al. (2005) reviewed the predictors of multidisciplinary or back school treatment outcome in chronic low back pain patients, and found only weak associations between depression or active coping and the outcome of treatment in terms of disability. The reviews mainly focused on multidisciplinary treatment. There is relatively less evidence for the association of depression or fear-avoidance and the efficacy of somatic treatment in chronic pain. We found no systematic reviews on this topic, just a few studies that noted an association between depression and the outcome of spinal cord stimulation (Burchiel et al., 1995), depression and the outcome of conservative treatment (McCreary et al., 1979; Turner et al., 1983), and catastrophizing and the outcome of radiofrequency lesions (Samwel et al., 2000). A more comprehensive review of the psychological predictive factors of treatment outcome, including somatic treatment, will provide insight into the strength of these associations.

A point for consideration in the assessment of literature on this topic and in the understanding of the process of therapeutic change, is to distinguish between mediators, moderators, and non-specific predictors (Kraemer et al., 2002; Turner et al., 2007). A treatment mediator is a variable that changes during treatment and identifies possible mechanisms that are responsible for all or part of the achieved treatment effects. A mediator is associated with treatment and has an effect on the outcome. A treatment moderator specifies for whom, and under which conditions, the treatment works (Baron \& Kenny, 1986). A moderator is a baseline characteristic that is not associated with treatment, but interacts with the treatment to affect the outcome. The effect of an individual's treatment depends on the value of the moderator. A knowledge of moderators is helpful to clinicians when distinguishing between those patients who may be most responsive to treatment and those who may not (Kraemer et al., 2002). A non-specific predictor is a baseline characteristic that predicts response in both treatment and control groups (Turner et al., 2007). As stated earlier, this thesis focuses on the psychological predictors associated with treatment outcome, which could be a help in clinical decision-making. Therefore, its scope is limited to variables that moderate treatment outcome.

Essential in the search for psychological predictors that moderate treatment outcome is the development of appropriate assessment tools. Both screening and outcome measures are influenced by the adoption of the biopsychosocial model. Nowadays, most commonly used outcome measures in chronic pain, such as measures of quality of life or disability, are based on their ability to measure the biopsychosocial status of or change in patients, and have almost completely re- 
placed the former biomedical measures of outcome (Weiner, 2008). For screening purposes, two widely-used assessment tools have been developed to measure fearavoidance, i.e., the Tampa Scale for Kinesiophobia (TSK) and the Pain Catastrophizing Scale (PCS). The TSK is a questionnaire developed to quantify excessive fear of (re)injury due to movement in pain patients (Kori et al., 1990; Vlaeyen et al., 1995b), while the PCS was developed to identify catastrophic thoughts or feelings about the experience of pain (Sullivan et al., 1995; Crombez \& Vlaeyen, 1996). The Beck Depression Inventory (BDI) is one of the most commonly used measures of depressive symptomatology in individuals with chronic pain (Beck et al., 1961; Wesley et al., 1999; Morley et al., 2002). The studies reviewed in this thesis mainly - but not exclusively - focus on the moderating effects of these core dimensions.

\section{RESEARCH OBJECTIVE}

The research described in this thesis is mostly based on the above-mentioned theoretical considerations and experiences at our academic pain centre. Our main objective was to examine whether psychological variables are predictive of treatment outcome in a heterogeneous chronic pain population. In order to do so, we addressed the following research questions:

1. What is the quality of life of patients referred to an academic pain center, and how does this relate to psychological factors?

2. Are the TSK and PCS reliable assessment tools in a chronic pain population over a longer period of time, as is common in clinical practice?

3. Which psychological predictors of treatment outcome can be determined in a heterogeneous chronic pain population?

4. Which predictors of spinal cord stimulation (SCS) can be identified in a specific group of neuropathic pain complaints, i.e., Complex Regional Pain Syndrome type I (CRPS-I)?

\section{FRAMEWORK OF THE THESIS}

In order to address to the main aim of this thesis, the characteristics of chronic pain patients referred to an academic pain centre will first be determined. Chapter 2 presents descriptive data of quality of life in chronic pain patients referred to 
our academic pain centre. The role of demographics, pain cognition and pain coping as predictive variables of the various domains of quality of life will be studied. Although several studies have already examined this association in low back pain patients, the study presented in this chapter will focus on pain patients with more heterogeneous pain complaints. Moreover, it will provide us with information about the characteristics of the specific chronic pain population seen at our academic pain center, and will thus set the stage for subsequent studies in this population. It will illustrate the base level of severity in this population and will shed light on the psychological factors that may play a role in maintaining or aggravating complaints. We speculate that fear-avoidance variables are among the main predictive factors, both for impaired quality of life and for suboptimal treatment outcome. It is therefore vital to have reliable instruments for assessing these factors. Chapter 3 investigates the test-retest stability of the two most commonly used fear-avoidance measuring instruments (i.e., PCS and TSK) in chronic pain patients. Although the stability of these instruments has already been examined, we were interested in this stability over a longer period of time. Due to waiting list procedures in academic pain centres, the time between initial screening and first consultation with a physician can run into months. Instruments that are used for screening purposes in clinical practice have to be stable over these longer periods of time.

The main aim of this thesis, identification of psychological predictors of treatment outcome, is addressed in Chapters 4 to 6. In Chapter 4, a systematic review of the psychological predictors of treatment outcome in chronic pain patients is presented. This review is more comprehensive than previous reviews and incorporates both psychological and somatic treatments. We are particularly interested in the psychological factors predictive of outcome after somatic treatment, and somatic treatment will be the focus of Chapters 5 and 6 . Psychological factors that are identified in this review as being definitely or possibly predictive, will be incorporated in the following study, which is covered in Chapter 5. In Chapter 5, we describe a comprehensive prospective cohort study that tested the predictive value of pain catastrophizing, pain-related fear, depression, pain coping, internal and external control on outcome of somatic treatment, in terms of pain intensity, quality of life, global perceived effect (GPE), and pain interference in our heterogeneous chronic pain population. We also tested whether the same or other predictors would be identified in patients with different diagnoses and/or after either invasive or non-invasive treatment. The final study in this thesis focuses on a homogenous group of patients undergoing uniform treatment. Chapter 6 presents a prospective cohort study in which pain catastrophizing is hypothesized as being predictive of SCS outcome in a population with a well-defined neuropathic pain complaint, i.e., CRPS-I. Finally, the general discussion in Chapter 7 provides a summary of the results and critical reflections on our research. Furthermore, the implications of our results are discussed, suggestions for further research are made, and clinical relevance and recommendations are presented. 


\section{REFERENCES}

Assendelft, W.J., Morton, S.C., Yu, E.I., Suttorp, M.J. \&Shekelle, P.G.(2004). Spinal manipulative therapy for low back pain. Cochrane Database Syst Rev 1): CD000447.

Barnes, D., Smith, D., Gatchel, R.J. \&Mayer, T.G.(1989). Psychosocioeconomic predictors of treatment success/failure in chronic low-back pain patients. Spine 14(4): 427-30.

Baron, R.M. \&Kenny, D.A.(1986). The moderator-mediator variable distinction in social psychological research: conceptual, strategic, and statistical considerations. J Pers Soc Psychol 51(6): 1173-82.

Basler, H.D., Jakle, C. \&Kroner-Herwig, B.(1997). Incorporation of cognitive-behavioral treatment into the medical care of chronic low back patients: a controlled randomized study in German pain treatment centers. Patient Educ Couns 31(2): 113-24.

Beck, A.T., Ward, C.H., Mendelson, M., Mock, J. \&Erbaugh, J.(1961). An inventory for measuring depression. Arch Gen Psychiatry 4(561-71.

Bendix, A.F., Bendix, T., Vaegter, K., Lund, C., Frolund, L. \&Holm, L.(1996). Multidisciplinary intensive treatment for chronic low back pain: a randomized, prospective study. Cleve Clin J Med 63(1): 62-9.

Boersma, K. \&Linton, S.J.(2005). Screening to identify patients at risk: profiles of psychological risk factors for early intervention. Clin J Pain 21(1): 38-43; discussion 69-72.

Boswell, M.V., Shah, R.V., Everett, C.R., Sehgal, N., McKenzie Brown, A.M., Abdi, S., Bowman, R.C., 2nd, Deer, T.R., Datta, S., Colson, J.D., Spillane, W.F., Smith, H.S., Lucas, L.F., Burton, A.W., Chopra, P., Staats, P.S., Wasserman, R.A. \&Manchikanti, L.(2005). Interventional techniques in the management of chronic spinal pain: evidence-based practice guidelines. Pain Physician 8(1): 1-47.

Breivik, H., Collett, B., Ventafridda, V., Cohen, R. \&Gallacher, D.(2006). Survey of chronic pain in Europe: prevalence, impact on daily life, and treatment. Eur J Pain 10(4): 287-333.

Burchiel, K.J., Anderson, V.C., Wilson, B.J., Denison, D.B., Olson, K.A. \&Shatin, D.(1995). Prognostic factors of spinal cord stimulation for chronic back and leg pain. Neurosurgery 36(6): 1101-10; discussion 1110-1.

Burns, J.W., Kubilus, A., Bruehl, S., Harden, R.N. \&Lofland, K.(2003). Do changes in cognitive factors influence outcome following multidisciplinary treatment for chronic pain? A cross-lagged panel analysis. J Consult Clin Psychol 71(1): 81-91.

Carson, J.W., Keefe, F.J., Affleck, G., Rumble, M.E., Caldwell, D.S., Beaupre, P.M., Kashikar-Zuck, S., Sandstrom, M. \&Weisberg, J.N.(2006). A comparison of conventional pain coping skills training and pain coping skills training with a maintenance training component: a daily diary analysis of shortand long-term treatment effects. J Pain 7(9): 615-25.

Cedraschi, C., Desmeules, J., Rapiti, E., Baumgartner, E., Cohen, P., Finckh, A., Allaz, A.F. \&Vischer, T.L.(2004). Fibromyalgia: a randomised, controlled trial of a treatment programme based on self management. Ann Rheum Dis 63(3): 290-6.

Crombez, G., Vlaeyen, J.W., Heuts, P.H. \&Lysens, R.(1999). Pain-related fear is more disabling than pain itself: evidence on the role of pain-related fear in chronic back pain disability. Pain 80(1-2): 329-39.

Crombez, G. \&Vlaeyen, J.W.S.(1996). The Pain Catastrophizing Scale. unpublished Dutch/Flemisch translation.

Feuerstein, M., Menz, L., Zastowney, T.R. \&Barron, B.A.(1994). Chronic pain and disability: Vocational outcomes following multidisciplinary rehabilitation. J Occup Rehabil 4(229-51.

Flor, H., Fydrich, T. \&Turk, D.C.(1992). Efficacy of multidisciplinary pain treatment centers: a metaanalytic review. Pain 49(2): 221-30.

Fordyce, W.E.(1976). Behavioral Methods for Chronic Pain and Illness. St. Louis, MO: Mosby.

Gatchel, R.J.(2001). A biopsychosocial overview of pretreatment screening of patients with pain. Clin J Pain 17(3): 192-9.

Gatchel, R.J., Peng, Y.B., Peters, M.L., Fuchs, P.N. \&Turk, D.C.(2007). The biopsychosocial approach to chronic pain: scientific advances and future directions. Psychol Bull 133(4): 581-624.

George, S.Z., Bialosky, J.E. \&Donald, D.A.(2005). The centralization phenomenon and fear-avoidance beliefs as prognostic factors for acute low back pain: a preliminary investigation involving patients classified for specific exercise. J Orthop Sports Phys Ther 35(9): 580-8. 
Gowans, S.E., deHueck, A., Voss, S. \&Richardson, M.(1999). A randomized, controlled trial of exercise and education for individuals with fibromyalgia. Arthritis Care Res 12(2): 120-8.

Heymans, M.W., van Tulder, M.W., Esmail, R., Bombardier, C. \&Koes, B.W.(2004). Back schools for nonspecific low-back pain. Cochrane Database Syst Rev 4): CD000261.

Hughes, S.L., Seymour, R.B., Campbell, R.T., Huber, G., Pollak, N., Sharma, L. \&Desai, P.(2006). Longterm impact of Fit and Strong! on older adults with osteoarthritis. Gerontologist 46(6): 801-14.

Jensen, I.B., Bergstrom, G., Ljungquist, T., Bodin, L. \&Nygren, A.L.(2001). A randomized controlled component analysis of a behavioral medicine rehabilitation program for chronic spinal pain: are the effects dependent on gender? Pain 91(1-2): 65-78.

Khadilkar, A., Milne, S., Brosseau, L., Robinson, V., Saginur, M., Shea, B., Tugwell, P. \&Wells, G.(2005). Transcutaneous electrical nerve stimulation (TENS) for chronic low-back pain. Cochrane Database Syst Rev 3): CD003008.

Kori, S.H., Miller, R.P. \&Todd, D.D.(1990). Kinesiophobia: a new view of chronic pain behaviour. Pain Manag jan/feb(35-43.

Kraemer, H.C., Wilson, G.T., Fairburn, C.G. \&Agras, W.S.(2002). Mediators and moderators of treatment effects in randomized clinical trials. Arch Gen Psychiatry 59(10): 877-83.

Leeuw, M., Goossens, M.E., Linton, S.J., Crombez, G., Boersma, K. \&Vlaeyen, J.W.(2007). The fearavoidance model of musculoskeletal pain: current state of scientific evidence. J Behav Med 30(1): 77-94.

Lefebvre, J.C., Lester, N. \&Keefe, F.J.(1995). Pain in young adults. II: The use and perceived effectiveness of pain-coping strategies. Clin J Pain 11(1): 36-44.

Lethem, J., Slade, P.D., Troup, J.D. \&Bentley, G.(1983). Outline of a Fear-Avoidance Model of exaggerated pain perception--I. Behav Res Ther 21(4): 401-8.

Linton, S.J.(2000). A review of psychological risk factors in back and neck pain. Spine 25(9): 1148-56.

Lynch, M.E., Campbell, F., Clark, A.J., Dunbar, M.J., Goldstein, D., Peng, P., Stinson, J. \&Tupper, H.(2008). A systematic review of the effect of waiting for treatment for chronic pain. Pain 136(12): $97-116$.

Mailis-Gagnon, A., Furlan, A.D., Sandoval, J.A. \&Taylor, R.(2004). Spinal cord stimulation for chronic pain. Cochrane Database Syst Rev 3): CD003783.

Main, C.J. \&Waddell, G.(1991). A comparison of cognitive measures in low back pain: statistical structure and clinical validity at initial assessment. Pain 46(3): 287-98.

Malik, K. \&Benzon, H.T.(2007). Pulsed radiofrequency: a critical review of its efficacy. Anaesth Intensive Care 35(6): 863-73.

McCracken, L.M. \&Turk, D.C.(2002). Behavioral and cognitive-behavioral treatment for chronic pain: outcome, predictors of outcome, and treatment process. Spine 27(22): 2564-73.

McCreary, C., Turner, J. \&Dawson, E.(1979). The MMPI as a predictor of response to conservative treatment for low back pain. J Clin Psychol 35(2): 278-84.

Molton, I.R., Graham, C., Stoelb, B.L. \&Jensen, M.P.(2007). Current psychological approaches to the management of chronic pain. Curr Opin Anaesthesiol 20(5): 485-9.

Morley, S., Eccleston, C. \&Williams, A.(1999). Systematic review and meta-analysis of randomized controlled trials of cognitive behaviour therapy and behaviour therapy for chronic pain in adults, excluding headache. Pain 80(1-2): 1-13.

Morley, S., Williams, A.C. \&Black, S.(2002). A confirmatory factor analysis of the Beck Depression Inventory in chronic pain. Pain 99(1-2): 289-98.

Peters, M.L., Vlaeyen, J.W. \&Weber, W.E.(2005). The joint contribution of physical pathology, painrelated fear and catastrophizing to chronic back pain disability. Pain 113(1-2): 45-50.

Picavet, H.S. \&Schouten, J.S.(2003). Musculoskeletal pain in the Netherlands: prevalences, consequences and risk groups, the DMC(3)-study. Pain 102(1-2): 167-78.

Picavet, H.S., Vlaeyen, J.W. \&Schouten, J.S.(2002). Pain catastrophizing and kinesiophobia: predictors of chronic low back pain. Am J Epidemiol 156(11): 1028-34.

Pincus, T., Burton, A.K., Vogel, S. \&Field, A.P.(2002). A systematic review of psychological factors as predictors of chronicity/disability in prospective cohorts of low back pain. Spine 27(5): E109-20.

Pincus, T., Vogel, S., Burton, A.K., Santos, R. \&Field, A.P.(2006). Fear-avoidance and prognosis in back pain: a systematic review and synthesis of current evidence. Arthritis Rheum 54(12): 3999-4010. 
Samwel, H., Slappendel, R., Crul, B.J. \&Voerman, V.F.(2000). Psychological predictors of the effectiveness of radiofrequency lesioning of the cervical spinal dorsal ganglion (RF-DRG). Eur J Pain 4(2): 149-55.

Scascighini, L., Toma, V., Dober-Spielmann, S. \&Sprott, H.(2008). Multidisciplinary treatment for chronic pain: a systematic review of interventions and outcomes. Rheumatology (Oxford) 47(5): 670-8.

Severeijns, R., Vlaeyen, J.W., van den Hout, M.A. \&Weber, W.E.(2001). Pain catastrophizing predicts pain intensity, disability, and psychological distress independent of the level of physical impairment. Clin J Pain 17(2): 165-72.

Sieben, J.M., Vlaeyen, J.W., Tuerlinckx, S. \&Portegijs, P.J.(2002). Pain-related fear in acute low back pain: the first two weeks of a new episode. Eur J Pain 6(3): 229-37.

Staal, J.B., de Bie, R., de Vet, H.C.W., Hildebrandt, J. \&Nelemans, P.(2008). Injection therapy for subacute and chronic low-back pain. Cochrane Database Syst Rev 3): CD 001824.

Steenstra, I.A., Verbeek, J.H., Prinsze, F.J. \&Knol, D.L.(2006). Changes in the incidence of occupational disability as a result of back and neck pain in the Netherlands. BMC Public Health 6(190.

Sullivan, M.J. \&D'Eon, J.L.(1990). Relation between catastrophizing and depression in chronic pain patients. J Abnorm Psychol 99(3): 260-3.

Sullivan, M.J., Lynch, M.E. \&Clark, A.J.(2005). Dimensions of catastrophic thinking associated with pain experience and disability in patients with neuropathic pain conditions. Pain 113(3): 310-5.

Sullivan, M.J.L., Bishop, S.R. \&Pivik, J.(1995). The Pain Catastrophizing Scale: Development and Validation. Psych Assess 7(4): 524-32.

Swinkels-Meewisse, I.E., Roelofs, J., Schouten, E.G., Verbeek, A.L., Oostendorp, R.A. \&Vlaeyen, J.W.(2006). Fear of movement/(re)injury predicting chronic disabling low back pain: a prospective inception cohort study. Spine 31(6): 658-64.

Turk, D.C.(1990). Customizing treatment for chronic pain patients: who, what, and why. Clin J Pain 6(4): 255-70.

Turk, D.C., Biopsychosocial perspective on chronic pain. In: Gatchel, R. J. \&Turk, D. C. (Eds.), Psychological approaches to pain management: a practitioner's handbook., Guilford, New York, 1996, pp. 3-32.

Turner, J.A., Holtzman, S. \&Mancl, L.(2007). Mediators, moderators, and predictors of therapeutic change in cognitive-behavioral therapy for chronic pain. Pain 127(3): 276-86.

Turner, J.A., Mancl, L. \&Aaron, L.A.(2006). Short- and long-term efficacy of brief cognitive-behavioral therapy for patients with chronic temporomandibular disorder pain: a randomized, controlled trial. Pain 121(3): 181-94.

Turner, J.A., Robinson, J. \&McCreary, C.P.(1983). Chronic low back pain: predicting response to nonsurgical treatment. Arch Phys Med Rehabil 64(11): 560-3.

van der Hulst, M., Vollenbroek-Hutten, M.M. \&Ijzerman, M.J.(2005). A systematic review of sociodemographic, physical, and psychological predictors of multidisciplinary rehabilitation-or, back school treatment outcome in patients with chronic low back pain. Spine 30(7): 813-25.

Vlaeyen, J.W., Haazen, I.W., Schuerman, J.A., Kole-Snijders, A.M. \&van Eek, H.(1995a). Behavioural rehabilitation of chronic low back pain: comparison of an operant treatment, an operant-cognitive treatment and an operant-respondent treatment. Br J Clin Psychol 34 (Pt 1)(95-118.

Vlaeyen, J.W., Kole-Snijders, A.M., Boeren, R.G. \&van Eek, H.(1995b). Fear of movement/(re)injury in chronic low back pain and its relation to behavioral performance. Pain 62(3): 363-72.

Vlaeyen, J.W., Kole-Snijders, A.M., Rotteveel, A.M., Ruesink, R. \&Heuts, P.H.(1995c). The role of fear of movement/(re)injury in pain disability. J Occup Reh 5(4): 235-52.

Vlaeyen, J.W. \&Linton, S.J.(2000). Fear-avoidance and its consequences in chronic musculoskeletal pain: a state of the art. Pain $85(3): 317-32$.

Vlaeyen, J.W. \&Morley, S.(2005). Cognitive-behavioral treatments for chronic pain: what works for whom? Clin J Pain 21(1): 1-8.

Vlaeyen, J.W., Teeken-Gruben, N.J., Goossens, M.E., Rutten-van Molken, M.P., Pelt, R.A., van Eek, H. \&Heuts, P.H.(1996). Cognitive-educational treatment of fibromyalgia: a randomized clinical trial. I. Clinical effects. J Rheumatol 23(7): 1237-45. 


\section{CHAPTER 1}

Waddell, G.(2006). Preventing incapacity in people with musculoskeletal disorders. Br Med Bull 7778(55-69.

Weiner, B.K.(2008). Spine update: the biopsychosocial model and spine care. Spine 33(2): 219-23.

Weisberg, J.N. \&Boatwright, B.A.(2007). Mood, anxiety and personality traits and states in chronic pain. Pain 133(1-3): 1-2.

Wesley, A.L., Gatchel, R.J., Garofalo, J.P. \&Polatin, P.B.(1999). Toward more accurate use of the Beck Depression Inventory with chronic back pain patients. Clin J Pain 15(2): 117-21.

Woolf, A.D. \&Akesson, K.(2001). Understanding the burden of musculoskeletal conditions. The burden is huge and not reflected in national health priorities. Bmj 322(7294): 1079-80. 


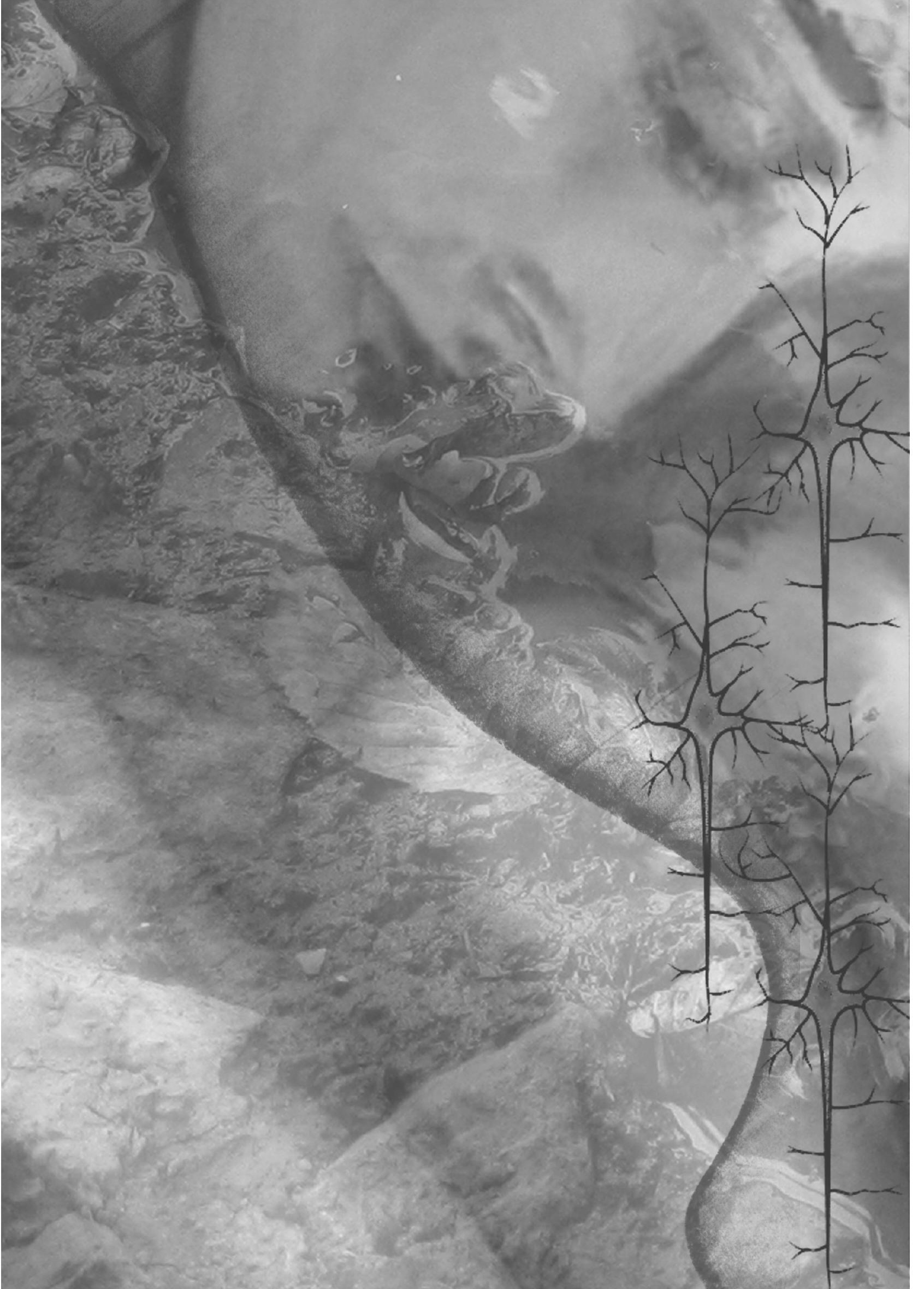




\section{Chapter 2}

\section{Quality of life in chronic pain is more associated with beliefs about pain than with pain intensity}

Inge E. Lamé, Madelon L. Peters, Johan W.S. Vlaeyen,

Maarten van Kleef, Jacob Patijn 


\section{CHAPTER 2}

\section{ABSTRACT}

The objectives of this study were to investigate pain cognition and quality of life of chronic pain patients referred to an academic pain clinic, and to search for predictors of quality of life.

A heterogeneous group of 1208 chronic pain patients referred to the Maastricht University Hospital pain clinic participated in this cross-sectional study. On initial assessment, all patients completed a set of questionnaires on demographic variables, cause, location, pain intensity (McGill Pain Questionnaire (MPQ)), pain coping and beliefs (Pain Coping and Cognition List (PCCL)), pain catastrophizing (Pain Catastrophizing Scale (PCS) and eight dimensions of quality of life (Rand-36). The results showed that the present sample of heterogeneous pain patients reported low quality of life for each domain and significantly lower scores compared to previous studies in other Dutch chronic pain populations. Patients with low back pain and multiple pain localizations experienced the most functional limitations. Women reported more pain, more catastrophizing thoughts about pain, more disability, and low vitality and general health. When tested in a multiple regression analysis, pain catastrophizing turned out to be the single most important predictor of quality of life. In particular, social functioning, vitality, mental health and general health are significantly associated with pain catastrophizing.

Patients from academic pain clinics experience strikingly low quality of life, and of these, low back pain patients and patients with multiple pain localizations have the lowest quality of life. Pain catastrophizing showed the strongest association with quality of life, stronger even than pain intensity.

\section{INTRODUCTION}

It is generally accepted that chronic pain has a negative impact on quality of life (Kempen et al., 1997; Schlenk et al., 1998; Stewart et al., 1989). Chronic pain has negative consequences for general health (Becker et al., 1997), as well as for social and psychological well-being (Gureje et al., 1998). Nowadays, psychodiagnostic procedures are considered indispensable tools in the diagnosis and management of chronic non-malignant pain. The prevailing model of chronic pain is based on a bio-psycho-social approach, in which depression, pain-related fear and catastrophizing play a prominent role. Chronic pain is related to high levels of anxiety, depression, and social and occupational dysfunction (Crombez et al., 1999b; Romano et al., 1985; Sullivan et al., 1992; Turk et al., 1996). Fearavoidance models have been developed to describe this relationship (Lethem et al., 1983; Vlaeyen et al., 2000; Vlaeyen et al., 1995b). These models assume that pain catastrophizing promotes the fear of movement/(re)injury. In turn, the latter leads to avoidance behaviour, disuse, disability and depression. 
Pain catastrophizing has been broadly defined as an exaggerated negative orientation towards pain stimuli and pain experience (Sullivan et al., 1995). There is increasing evidence for the role of catastrophizing and fear of movement in the transition from acute to chronic pain, whereby the importance of early detection by means of screening and early intervention is endorsed (Buer et al., 2002; Linton, 2002). The relationship between pain catastrophizing, pain-related fear and disability described in the literature is mainly seen in low back pain patients (Buer et al., 2002; Crombez et al., 1999b; Hout van den et al., 2001; Sieben et al., 2002; Vlaeyen et al., 1995a; Vlaeyen et al., 1995b), although some researchers have found evidence in other diagnosis groups as well (Keefe et al., 1989; Keefe et al., 2000; Sullivan et al., 1998).

A different aspect of pain catastrophizing and pain-related fear concerns the potential negative influence on the medical treatment of chronic pain patients. Samwel et al. (2000) found a negative correlation between pain catastrophizing and the effect of a radiofrequency lesion on the dorsal root ganglion in a population with cervical brachialgia. They hypothesized that a psychological treatment strategy focusing on decreasing the level of catastrophizing, could have a positive effect on medical treatment. If indeed psycho-diagnostic procedures can provide better insight into planned treatment strategies in chronic pain patients (Morley et al., 1999), it is important that these psychological factors are diagnosed at an early stage. General use of a combination of quality of life and psychological measuring instruments for screening would be a first step in obtaining better insight into the psychological starting point of a chronic pain population.

The first aim of this study was to present descriptive data of quality of life for patients presenting with heterogeneous chronic pain complaints at a university hospital pain management clinic. In order to place these data in proper perspective, comparisons with previous Dutch studies on other chronic pain populations and with healthy controls are made. Moreover, quality of life is presented for different pain locations, and for males and females separately. The second aim of the study was to search for predictors of quality of life. The role of pain cognition and pain coping in explaining the various domains of quality of life was studied, checking for pain intensity and demographic variables.

\section{MATERIALS AND METHODS}

\section{Patients}

A cross-sectional study was performed in a population at the outpatient's clinic for Pain and Pain Management at the University Hospital Maastricht, the Netherlands. This population is a heterogeneous group of chronic pain patients with various 
pain localizations, such as low back, neck, shoulder, different forms of headache, complex regional pain syndrome types I and II (CRPS I and II), neuropathic pain syndrome, central pain and abdominal pain. Questionnaires were mailed to each new non-malignant pain patient between February 2000 and March 2002 ( $n=$ 1333). Patients were requested to return their completed questionnaire before their first appointment with the physician. Finally, 91\% $(n=1208)$ returned the questionnaire and were included in the study.

\section{Measuring instruments}

The screening questionnaire was in two parts. The first part requested demographic information and information on cause, localization and duration of pain. The second part consisted of four standard measuring instruments: Rand-36, PCCL, PCS, and $M P Q$.

Rand-36: This instrument was developed during medical outcome studies at the Rand Corporation and measures general health and quality of life (Van der Zee et al., 1993). The items in the Dutch version of Rand-36 are identical to the Dutch translation of the SF-36 (Aaronson et al., 1992). It contains 36 items, measuring eight aspects of health (domains): physical functioning (PF), social functioning $(\mathrm{SF})$, role limitations physical (RP), role limitations emotional (RE), mental health $(\mathrm{MH})$, vitality (VI), bodily pain (BP), and general health perception (GH). Perceived health change over the previous year is measured with one item. All raw scale scores are linearly converted to a 0 -100 scale, with higher scores indicating higher levels of functioning or well being (Aaronson et al., 1998). Psychometric properties of the Dutch version of Rand-36 were found to be adequate (Aaronson et al., 1998; Essink Bot et al., 1997; Van der Zee et al., 1993; Van der Zee et al., 1996).

PCCL: The Pain Coping and Cognition List was developed by the Pain Management and Research Centre (PKC) at the University Hospital, Maastricht, the Netherlands (Stomp-van den Berg et al., 2001). It is constructed out of the Pain Cognition List (Vlaeyen et al., 1990), Locus of Pain Control questionnaire (Engstrom, 1983); Dutch version: (Kuile ter et al., 1993), and the Coping Strategies Questionnaire (Spinhoven et al., 1994). PCCL includes all the unique information from the original lists and consists of 42 items, subdivided into four scales: pain catastrophizing (higher scores denote a higher degree of catastrophizing), pain coping (low scores denote a low degree of pain coping), internal pain control (low scores denote less internal pain control), and external pain control (higher scores denote less external pain control, i.e., more health control by others). Stomp-van den Berg et al. (2001) found support for the internal consistency and construct validity of PCCL. 
PCS: This instrument measures the degree of catastrophic thoughts about pain (Crombez et al., 1996; Sullivan et al., 1995). PCS is a 13-item five-point scale, mostly used as a total score. Sullivan et al. (1995) proposed three dimensions of pain catastrophizing: rumination, magnification and helplessness. As well as total score values, subscale scores can also be measured. Higher scores denote a higher degree of catastrophizing. The psychometric properties of PCS appeared to be adequate in previous studies (Crombez et al., 1998; Crombez et al., 1999b; Van Damme et al., 2000; Vlaeyen et al., 1990). PCS has been shown to have good reliability and validity in a clinical population (Crombez et al., 1998) and in a student population (Crombez et al., 1999b).

MPQ: MPQ measures three dimensions of pain experience: the sensory, affective and evaluative dimensions of pain. The instrument consists of a list of adjectives, divided into 12 sensory, five affective, and three evaluative subclasses. It groups various pain adjectives (descriptions) according to their pain quality and ranks the adjectives of a certain quality according to their intensity. Two major measurements are extracted from the adjective list: the number of words chosen (NWC) and the pain-rating index (PRI). The present study only uses the PRI total score. The PRI adds the rankings of all words chosen. Higher scores denote more pain. The psychometric properties of the Dutch language version of MPQ, put together by Verkes et al. (1989), were found to be encouraging.

\section{Statistical analysis}

Student's t-test was used to calculate differences between population characteristics, psychological characteristics and differences with other populations. The assumption of equal variance between the various sites of pain was tested by Levene's test for equality of variance, after which differences between the groups were tested using ANOVA. More conservative post hoc tests (Bonferroni and LSD) were used to specify the differences. The predictors of quality of life were calculated using a hierarchical stepwise regression analysis, in which the demographic variables (gender, age, education) and pain intensity were entered in the first step, and the predictors of interest (four PCCL subscale scores: catastrophizing, pain coping, internal and external pain control) in the second. For each domain of quality of life, the additional variance explained by significant predictors was shown in the final model, after checking for demographic variables and pain intensity. In order to exclude the influence of multicollinearity, we calculated the VIF value for every independent variable. The variable was included if $\mathrm{VIF}<3$. 


\section{RESULTS}

\section{Population characteristics}

The characteristics of the study population are summarized in Table 1 . The population had a mean age of 49.9 years (sd 14.7 ), $51.5 \%$ had a relatively low education level (low vocational education or less), and $62 \%$ of the patients were female. The location of the pain was diverse and was classified into five pain clusters: headache $(2.4 \%)$, including all different types of headache, i.e., migraine, tension type, cervicogenic and cluster; neck pain and/or brachialgia (23.3\%), including arm pain and combinations of arm and neck pain; back pain and/or sciatica $(27.9 \%)$, including leg pain and combinations of leg and back pain; other pain, such as CRPS I en II, neuropathic pain syndrome, trigeminus neuralgia, fibromyalgia and rheumatoid arthritis (15.7\%), and finally a cluster containing all possible combinations of the first four clusters (multiple pain locations) $(30.1 \%)$. In all clusters, there was an overrepresentation of females (headache $(55.2 \%)$, neck pain $(59.5 \%)$, back pain $(59.3 \%)$, other pain $(66.6 \%)$, and multiple pain locations $(65.7 \%))$. There were no differences between the five clusters in age, gender or education.

Table 1: Population characteristics

\begin{tabular}{lll}
\hline & Male & Female \\
\hline $\mathrm{N}(\%)$ & $461(38)$ & $743(62)$ \\
Age (mean(sd)[range]) & $50,2(13,5)[15-94]$ & $49,6(15,3)[14-88]$ \\
\hline
\end{tabular}

$\mathrm{Sd}=$ standard deviation; Range = minimum age-maximum age

\section{Descriptive data on quality of life}

Quality of life in relation to pain localization and demographic variables

Rand-36 mean domain scores are summarized in Table 2. Due to missing values in Rand-36 item scores, a varying number of patients was excluded from the eight domains. Differences between the pain clusters were found in all domains, with the exception of role limitations emotional. Patients with back pain, other pain, and multiple pain locations experience more functional limitations (physical functioning and role limitations physical) than the other clusters. In addition, patients with multiple pain localizations scored significantly low on mental health, vitality, and general health. Patients with other pain showed significantly lower scores on bodily pain than the other clusters. Gender differences were found for physical functioning, role limitations physical, vitality, bodily pain, and general health, whereby females reported lower scores than males (Table 3). 
QUALITY OF LIFE IN CHRONIC PAIN

Table 2: Quality of life domain total mean scores and mean scores of the different pain clusters.

\begin{tabular}{|c|c|c|c|c|c|c|c|}
\hline & $\mathrm{n}$ & $\begin{array}{l}\text { Total } \\
\text { Score } \\
(\mathrm{sd}) \\
\end{array}$ & $\begin{array}{l}\text { Headache } \\
(1)\end{array}$ & $\begin{array}{l}\text { Neck Pain } \\
(2)\end{array}$ & $\begin{array}{l}\text { Back Pain } \\
(3)\end{array}$ & $\begin{array}{l}\text { Other Pain } \\
(4)\end{array}$ & $\begin{array}{l}\text { Multiple Pain } \\
\text { Localizations } \\
\text { (5) }\end{array}$ \\
\hline \multicolumn{8}{|l|}{ Rand-36 } \\
\hline Physical Functioning & 1119 & $41.3(26.3)$ & $66.2(27.3)^{\star 3,4,5}$ & $55.1(23.1)^{\star 3,5}$ & $31.0(21.1)^{\star 1,2,4}$ & $49.8(31.0)^{\star 1,3,5}$ & $34.0(23.0)^{\star 1,2,4}$ \\
\hline Social Functioning & 1191 & $39.9(27.0)$ & $41.0(27.3)$ & $43.7(27.7)^{\star 5}$ & $38.3(27.2)$ & $43.7(26.8)$ & $36.4(25.8)^{\star 2}$ \\
\hline \multicolumn{8}{|l|}{ Role Limitations } \\
\hline Physical & 1104 & $9.7(24.3)$ & $8.9(22.8)$ & $9.9(25.0)$ & $8.6(22.5)^{\star 4}$ & $16.7(31.3)^{\star 3,5}$ & $7.4(20.8)^{\star 4}$ \\
\hline \multicolumn{8}{|l|}{ Role Limitations } \\
\hline Emotional & 1061 & $46.6(46.1)$ & $60.7(46.3)$ & $47.0(46.4)$ & $47.8(45.9)$ & $49.4(47.0)$ & $42.5(45.5)$ \\
\hline Mental Health & 1125 & $56.7(22.6)$ & $56.9(18.9)$ & $57.7(22.9)$ & $60.1(22.2)^{* 5}$ & $57.6(21.4)$ & $52.4(23.0)^{\star 3}$ \\
\hline Vitality & 1142 & $39.8(20.4)$ & $40.9(19.3)$ & $43.5(21.1)^{\star 5}$ & $41.4(19.2)^{* 5}$ & $40.6(21.2)$ & $35.2(19.8)^{\star 2,3}$ \\
\hline Bodily Pain & 1185 & $24.6(17.9)$ & $24.6(17.0)$ & $24.9(18.3)^{\star 4}$ & $22.7(17.3)^{\star 4}$ & $30.2(19.5)^{* 2,3,5}$ & $23.2(16.5)^{\star 4}$ \\
\hline General Health & 1109 & $44.7(21.4)$ & $53.7(21.6)^{\star 5}$ & $48.8(20.8)^{\star 5}$ & $47.3(21.7)^{\star 5}$ & $46.8(21.9)^{\star 5}$ & $37.4(19.7)^{\star 1,2,3,4}$ \\
\hline
\end{tabular}

$\mathrm{n}=$ number of patients; * significant difference $(\mathrm{p}<0.05)$ with pain clusters corresponding to the numbers in superscript.

Table 3: Gender characteristics of quality of life domains.

\begin{tabular}{|c|c|c|c|c|c|}
\hline & Male (sd) & Female (sd) & $\mathrm{t}$ & df & $\mathrm{p}$-value \\
\hline \multicolumn{6}{|l|}{ Rand-36 } \\
\hline Physical Functioning & $44.0(26.2)$ & $39.6(26.2)$ & 2.714 & 1116 & 0.007 * \\
\hline Social Functioning & $41.4(27.0)$ & $39.0(27.0)$ & 1.470 & 1188 & 0.142 \\
\hline Role Limitations Physical & $12.3(26.7)$ & $8.2(22.5)$ & 2.606 & 1101 & 0.009 * \\
\hline Role Limitations Emotional & $47.2(45.6)$ & $46.3(46.5)$ & 0.298 & 1059 & 0.765 \\
\hline Mental Health & $57.7(21.8)$ & $56.1(23.0)$ & 1.143 & 1122 & 0.253 \\
\hline Vitality & $42.5(20.4)$ & $38.1(20.2)$ & 3.631 & 1138 & $<0.0001^{*}$ \\
\hline Bodily Pain & $27.0(18.4)$ & $23.1(17.3)$ & 3.629 & 1181 & $<0.0001^{*}$ \\
\hline General Health & $46.4(21.0)$ & $43.6(21.7)$ & 2.108 & 1106 & 0.035 * \\
\hline
\end{tabular}

Mean scale scores, standard deviations (sd) and degrees of freedom (df)

Quality of life compared to other patient populations

Figure 1 shows quality of life domains obtained in the present study compared to the results found in other chronic pain populations in the Netherlands, using the Dutch version of SF-36, i.e., migraine and cancer pain (Aaronson et al., 1998). Moreover, data from a healthy reference population, using Rand-36, are presented (Van der Zee et al., 1993). This reference population was derived from a random sample survey from the population register in Emmen $(n=1063)$, a city in the east of the Netherlands. A group of 292 patients with no chronic disease was taken from this sample and used as a healthy reference population (Van der Zee et al., 1993). The population with migraine ( $n=423,40.4$ years ( $s d 12.8)$ [16-88], 84\% females) consisted of patients who had been identified as migraine sufferers in an earlier study, in accordance with the International Headache Society (Essink Bot et al., 1997). The population with cancer pain $(n=485,57.3$ years (sd 12.1) [22-86], $58 \%$ females) was a heterogeneous sample of cancer patients, primarily with breast, colorectal or lung cancer, recruited from the outpatient clinics at the An- 


\section{CHAPTER 2}

toni van Leeuwenhoek Hospital, a cancer treatment centre located in Amsterdam (Aaronson et al., 1998). Another Dutch investigation, using the Dutch version of SF-36 (not shown in the figure), comprised a chronic pain population presenting to a general practitioner $(n=305,48.6$ years (sd 12.7)[19-87], 71.5\% females) (Verhaak et al., 2000). These authors only presented the mean domain scores on physical functioning, role limitations physical, mental health, and vitality. We tested Rand-36 scores for all domains obtained in our patient group against each of the other four Dutch samples. As can be seen from Table 4, chronic pain patients from the multi-disciplinary university pain clinic scored significant lower for all domains than any of the other groups.

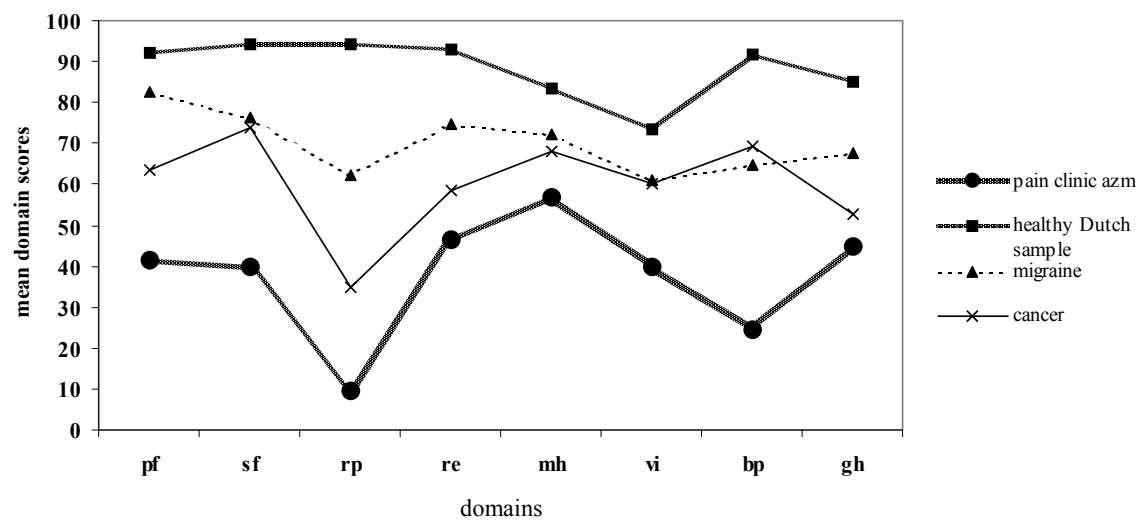

Figure 1: Quality of Life of the population at a pain clinic compared with other patient populations and a healthy Dutch reference group ( $\mathrm{pf}=$ physical functioning; $\mathrm{sf}=\mathrm{social}$ functioning; $\mathrm{r} p=$ role limitations physical; re=role limitations emotional; $\mathrm{mh}=$ mental health; vi=vitality; bp=bodily pain; gh=general health).

Prediction of quality of life

Table 5 summarizes the final regression models showing the significant predictors that were retained after hierarchical stepwise regression analysis. In the first step, demographic variables and pain intensity were entered. Age and education showed a substantial (i.e., > 0.10) association with physical functioning only. It is interesting to note that gender was not significantly related (or only very weakly) to any of the quality of life domains when other predictors were taken into account. Pain intensity showed a significant negative association with each of the quality of life domains, although this association was not very strong (beta values between 0.06 and 0.20 ). Step 2 shows the additional variance explained by pain coping and cognition after controlling for demographic variables and pain. Only significant predictors were retained in the model. As can be seen from Table 5, pain catastrophizing was, without exception, most strongly related to each of the quality of life domains, more strongly than pain intensity or the demographic 
variables. Patients with high catastrophizing cognition had a lower quality of life than patients who catastrophized less. In particular, social functioning, vitality, mental health, and general health demonstrated very prominent associations with catastrophizing ${ }^{1}$. Low internal pain control was further associated with low emotional role functioning, lower mental health and lower general health, but with higher scores on quality of life in relation to bodily pain. External pain control and pain coping showed only weak and inconsistent relationships with the various quality of life domains. 
Table 4: Quality of life of the population of the pain clinic compared to other Dutch populations. (Migraine/cancer: Aaronson et al. (1998); chronic pain group: Verhaak et al. (2000) and a healthy Dutch sample: Van der Zee et al. (1996)).

\begin{tabular}{|c|c|c|c|c|}
\hline Variable & Study & $\begin{array}{c}\text { Mean score } \\
\text { (sd) }\end{array}$ & $\begin{array}{c}\text { Degree of } \\
\text { Freedom } \\
\text { (df) }\end{array}$ & $\mathrm{t}$ \\
\hline \multirow[t]{5}{*}{ Physical Functioning } & Pain Clinic azM & $41.3(26.3)$ & & \\
\hline & Migraine & $82.4(21.3)$ & 1540 & $28.984^{* \star *}$ \\
\hline & Cancer & $63.6(25.1)$ & 1602 & $15.979^{* * *}$ \\
\hline & Chronic pain group & $53.7(25.1)$ & 1422 & $7.425^{\star \star \star}$ \\
\hline & Healthy Dutch sample & $92.2(13.0)$ & 1409 & $32.136^{* * *}$ \\
\hline \multirow[t]{4}{*}{ Social Functioning } & Pain Clinic azM & $39.9(27.0)$ & & \\
\hline & Migraine & $76.2(20.9)$ & 1612 & $25.139^{* \star *}$ \\
\hline & Cancer & $73.9(24.1)$ & 1674 & $24.139^{* * *}$ \\
\hline & Healthy Dutch sample & $94.2(12.3)$ & 1481 & $33.535^{* * *}$ \\
\hline \multirow[t]{5}{*}{ Role Limitations Physical } & Pain Clinic azM & $9.7(24.3)$ & & \\
\hline & Migraine & $62.2(40.8)$ & 1525 & $31.522^{* * *}$ \\
\hline & Cancer & $35.0(40.3)$ & 1587 & $15.807^{* * *}$ \\
\hline & Chronic pain group & $22.6(34.2)$ & 1407 & $7.570^{* * *}$ \\
\hline & Healthy Dutch sample & $94.3(19.4)$ & 1394 & $55.378^{* \star *}$ \\
\hline Role Limitations & Pain Clinic azM & $46.6(46.1)$ & & \\
\hline \multirow[t]{3}{*}{ Emotional } & Migraine & $74.5(37.8)$ & 1482 & $11.199^{\star * *}$ \\
\hline & Cancer & $58.4(43.6)$ & 1544 & $4.835^{*}$ \\
\hline & Healthy Dutch sample & $93.1(21.6)$ & 1351 & $16.796^{* * *}$ \\
\hline \multirow[t]{5}{*}{ Mental Health } & Pain Clinic azM & $56.7(22.6)$ & & \\
\hline & Migraine & $72.0(18.7)$ & 1546 & $12.505^{* \star *}$ \\
\hline & Cancer & $68.0(19.8)$ & 1608 & $9.627^{\star \star \star}$ \\
\hline & Chronic pain group & $59.7(20.2)$ & 1428 & $2.115^{* *}$ \\
\hline & Healthy Dutch sample & $83.3(13.3)$ & 1415 & $19.320^{* * *}$ \\
\hline \multirow[t]{5}{*}{ Vitality } & Pain Clinic azM & $39.8(20.4)$ & & \\
\hline & Migraine & $61.1(18.6)$ & 1563 & $18.899^{* * *}$ \\
\hline & Cancer & $60.1(22.3)$ & 1625 & $18.015^{* * *}$ \\
\hline & Chronic pain group & $44.2(18.6)$ & 1445 & $3.425^{*}$ \\
\hline & Healthy Dutch sample & $73.4(13.5)$ & 1432 & $26.764^{* * *}$ \\
\hline \multirow[t]{4}{*}{ Bodily Pain } & Pain Clinic azM & $24.6(17.9)$ & & \\
\hline & Migraine & $64.9(22.4)$ & 1606 & $37.212^{* * *}$ \\
\hline & Cancer & $69.3(26.6)$ & 1668 & $40.039^{* * *}$ \\
\hline & Healthy Dutch sample & $91.8(16.1)$ & 1475 & $58.671^{* \star *}$ \\
\hline \multirow[t]{4}{*}{ General Health } & Pain Clinic azM & $44.7(21.4)$ & & \\
\hline & Migraine & $67.5(20.5)$ & 1530 & $19.063^{* * *}$ \\
\hline & Cancer & $52.5(21.4)$ & 1592 & $6.780^{*}$ \\
\hline & Healthy Dutch sample & $85.1(13.0)$ & 1399 & $30.910^{* * *}$ \\
\hline
\end{tabular}

All differences are significant between the quality of life domains of the population of the pain clinic and all other populations. ${ }^{*} p<0.01 ;{ }^{* *} p<0.001 ;{ }^{* * *} p<0.0001$ 
Table 5: Summary of the hierarchical regression analyses for quality of life domains with step 1, demographic variables (age, gender and education) and pain intensity and step 2, the psychometric predictors (catastrophizing, pain coping, internal pain control and external pain control) as independent variables.

\begin{tabular}{|c|c|c|c|}
\hline Variable & Summary of the model & Predictors & \\
\hline Physical & $\mathrm{R}^{2}=.25(F(7,998)$ & Step 1: Gender & $\beta=0.05, p=0.07$ \\
\hline \multirow[t]{6}{*}{ Functioning } & $=46.2, p<0.0001)$ & Age & $\beta=-0.20, p<0.0001$ \\
\hline & & Education & $\beta=0.19, p<0.0001$ \\
\hline & & Total pain rating index & $\beta=-0.16, p<0.0001$ \\
\hline & & Step 2: Catastrophizing & $\beta=-0.32, p<0.0001$ \\
\hline & & Pain coping & $\beta=-0.09, p=0.001$ \\
\hline & & External pain control & $\beta=0.08, p=0.01$ \\
\hline Social & $\mathrm{R}^{2}=.32(\mathrm{~F}(5,1098)$ & Step 1: Gender & $\beta=-0.02, p=0.36$ \\
\hline \multirow[t]{4}{*}{ Functioning } & $=104.2, p<0.0001)$ & Age & $\beta=-0.06, p=0.03$ \\
\hline & & Education & $\beta=-0.02, p=0.40$ \\
\hline & & Total pain rating index & $\beta=-0.15, p<0.0001$ \\
\hline & & Step 2: Catastrophizing & $\beta=-0.50, p<0.0001$ \\
\hline Role limitations & $\mathrm{R}^{2}=.15(\mathrm{~F}(6,1023)$ & Step 1: Gender & $\beta=0.04, p=0.23$ \\
\hline \multirow[t]{5}{*}{ Physical } & $=30.8, p<0.0001)$ & Age & $\beta=0.02, p=0.60$ \\
\hline & & Education & $\beta=0.04, p=0.17$ \\
\hline & & Total pain rating index & $\beta=-0.07, p=0.03$ \\
\hline & & Step 2: Catastrophizing & $\beta=-0.36, p<0.0001$ \\
\hline & & Pain Coping & $\beta=-0.10, p=0.001$ \\
\hline Role Limitations & $\mathrm{R}^{2}=.27(\mathrm{~F}(7,953)$ & Step 1: Gender & $\beta=-0.02, p=0.57$ \\
\hline \multirow[t]{6}{*}{ Emotional } & $=49.3, p<0.0001)$ & Age & $\beta=-0.05, p=0.06$ \\
\hline & & Education & $\beta=0.10, p=0.001$ \\
\hline & & Total pain rating index & $\beta=-0.10, p=0.001$ \\
\hline & & Step 2: Catastrophizing & $\beta=-0.40, p<0.0001$ \\
\hline & & Internal pain control & $\beta=-0.17, p<0.0001$ \\
\hline & & External pain control & $\beta=-0.13, p<0.0001$ \\
\hline \multirow[t]{8}{*}{ Mental Health } & $\mathrm{R}^{2}=.46(\mathrm{~F}(8,997)$ & Step 1: Gender & $\beta=-0.03, p=0.30$ \\
\hline & $=104.8, p<0.0001)$ & Age & $\beta=-0.10, p<0.0001$ \\
\hline & & Education & $\beta=0.06, p=0.01$ \\
\hline & & Total pain rating index & $\beta=-0.13, p<0.0001$ \\
\hline & & Step 2: Catastrophizing & $\beta=-0.58, p<0.0001$ \\
\hline & & Pain Coping & $\beta=0.08, p=0.003$ \\
\hline & & Internal pain control & $\beta=-0.11, p<0.0001$ \\
\hline & & External pain control & $\beta=-0.06, p=0.02$ \\
\hline \multirow[t]{5}{*}{ Vitality } & $\mathrm{R}^{2}=.37(F(5,1065)$ & Step 1: Gender & $\beta=0.04, p=0.12$ \\
\hline & $=125.5, p<0.0001)$ & Age & $\beta=-0.01, p=0.73$ \\
\hline & & Education & $\beta=0.00, p=0.99$ \\
\hline & & Total pain rating index & $\beta=-0.07, p=0.006$ \\
\hline & & Step 2: Catastrophizing & $\beta=-0.58, p<0.0001$ \\
\hline
\end{tabular}




\begin{tabular}{|c|c|c|c|}
\hline Variable & Summary of the model & Predictors & \\
\hline \multirow[t]{6}{*}{ Bodily Pain } & $R^{2}=.31(F(6,1070)$ & Step 1: Gender & $\beta=0.05, p=0.05$ \\
\hline & $=79.6, p<0.0001)$ & Age & $\beta=-0.01, p=0.62$ \\
\hline & & Education & $\beta=0.05, p=0.08$ \\
\hline & & Total pain rating index & $\beta=-0.20, p<0.0001$ \\
\hline & & Step 2: Catastrophizing & $\beta=-0.37, p<0.0001$ \\
\hline & & Internal pain control & $\beta=0.15, p<0.0001$ \\
\hline \multirow[t]{7}{*}{ General Health } & $\mathrm{R}^{2}=.34(\mathrm{~F}(7,1020)$ & Step 1: Gender & $\beta=0.01, p=0.78$ \\
\hline & $=73.5, p<0.0001)$ & Age & $\beta=-0.01, p=0.64$ \\
\hline & & Education & $\beta=0.05, p=0.07$ \\
\hline & & Total pain rating index & $\beta=-0.06, p=0.02$ \\
\hline & & Step 2: Catastrophizing & $\beta=-0.56, p<0.0001$ \\
\hline & & Pain Coping & $\beta=0.09, p=0.004$ \\
\hline & & Internal pain control & $\beta=-0.13, p<0.0001$ \\
\hline
\end{tabular}

\section{DISCUSSION}

The primary aim of this study was to provide descriptive data on quality of life in a heterogeneous group of chronic pain patients from a multi-disciplinary university pain clinic in the Netherlands. The influence of demographic variables, pain intensity and pain cognition on the various domains of quality of life was also explored. Noteworthy results were found for all quality of life domains. Chronic pain patients from the multi-disciplinary university pain clinic scored significantly lower for all domains than any other Dutch reference groups, including a heterogeneous sample of cancer patients with metastases and a heterogeneous chronic pain population presenting to a general practitioner (Aaronson et al., 1998; Verhaak et al., 2000). When the different pain clusters are taken into account, in particular patients with low back pain and multiple pain localizations score low. Kempen et al. (1997) obtained similar results in an elderly Dutch population. In that study, eight chronic medical conditions were identified (asthma/chronic bronchitis, heart condition, hypertension, diabetes mellitus, back problems lasting at least three months, rheumatoid arthritis/other joint complaints, migraine/chronic headache, and serious dermatological disorders (psoriasis and eczema)). The results showed that, in particular, physical functioning, role limitations physical and bodily pain were strongly affected by rheumatoid arthritis/other joint problems and back pain.

Independent of pain location and when corrected for pain intensity, demographic variables and pain cognition also influence quality of life. The gender differences found in connection with physical functioning, role limitations physical, vitality, bodily pain, and general health are consistent with other studies (Brazier et al., 1992; Severeijns et al., 2001; Sullivan et al., 1998). Females score lower than 
males, implying that females are more disabled by pain than males. However, when other variables were taken into account in the regression analysis, gender no longer proved to be a significant predictor of quality of life. Females proved to be significantly more catastrophizing than males in the present patient sample (i.e., 3.8 versus $3.6 \mathrm{p}=0.001$ ), and it could be that their low quality of life is due to their higher scores on catastrophizing. Indeed, in step 1 of the regression analysis, when catastrophizing was not yet entered into the model, gender did appear to be a significant predictor for most of the domains (physical functioning, role limitations physical, vitality, bodily pain, and general health).

The second aim of the present study was to search for predictors of quality of life. The results of this study show that pain catastrophizing is by far the most prominent predictor of social functioning, mental health, vitality, and general health. The association between catastrophizing and the physical aspects of quality of life (physical functioning, role limitations physical, and bodily pain) is less prominent, but is still relatively strong and is stronger than the association of these domains of quality of life with pain intensity. These results agree with findings of Severeijns et al. (2002), and expand on previous findings in low back pain patients (Crombez et al., 1999a; Severeijns et al., 2002; Severeijns et al., 2001; Vlaeyen et al., 1995b). Vlaeyen et al. (1995b) introduced the fear of movement/injury model, which shows that disability is related to fear of movement and catastrophizing. As fear of movement seems to be important for patients with musculo-skeletal pain in particular, and because we studied a group of heterogeneous pain patients, we focused on catastrophizing in this study. Our findings are in accordance with those of Severeijns et al. (2002). Those authors analyzed data from a Dutch survey on the prevalence and course of musculoskeletal complaints. They examined five patient groups with different musculoskeletal pain localizations and one patient group without pain. They found that pain catastrophizing is best associated with the social and psychological aspects of quality of life (social functioning, mental health, vitality, and general health).

The results reported in this study are based on catastrophizing scored with PCCL. In previous studies, catastrophizing was usually measured with either the Pain Catastrophizing Scale (PCS) or the catastrophizing subscale of the Coping Strategies Questionnaire (CSQ) (Crombez et al., 1999a; Severeijns et al., 2002; Severeijns et al., 2001; Vlaeyen et al., 1995b). The present study also included PCS. There was a high correlation between PCCL and PCS (pearsons $r=.64, p<0.0001$ ). Vlaeyen et al. (1990) also reported a strong correlation $(r=.73)$ between PCS and the Pain Cognition List (PLC), the questionnaire from which PCCL was developed. Moreover, when regression analyses were performed with PCS scores instead of the PCCL catastrophizing scale, similar results were found as those reported above. While for PCCL there are no comparative data, the scores on PCS show that, compared to previous studies, including back pain patients, our population scored very high on 


\section{CHAPTER 2}

catastrophizing (PCS total mean score $=31.0$ ). Other authors found low total mean scores of PCS, e.g., Van den Hout et al. (2001) found a total mean score of 16.8 for low back pain patients; Van Damme et al. (2002) a total mean score of 22.0 for chronic low back pain patients and 25.5 for fibromyalgia patients; and Crombez et al. (2002) a total mean score of 23.6 for back pain patients. Thus, the low quality of life in a multidisciplinary university pain population found in this study, in relation to other studies in chronic pain patients, may originate from the higher level of catstrophizing in our patient population. We hypothesize that the university pain clinic population is a highly catastrophizing group, with a high medical consumption, which explains the relatively low scores on all quality of life domains.

From a medical point of view, the results of the present study are very important. An adequate screening method, which concentrates on psychological predictors before treatment to identify patients with psychological suffering, can better guarantee that the most efficient treatment strategy is selected, either medical and/or cognitive behavioural. Recently, Holdcroft \& Power (2003) reviewed the literature on the management of pain in multidisciplinary pain clinics, and noted that there is more willingness to consider psychosocial factors when medical treatment and/or physical interventions fail. Increasingly, there is evidence of the important effect of cognitive behavioural therapy. Pain catastrophizing, as a predictor of the psychological burden of illness, could imply that cognitive behavioural treatment should first be offered, after which medical treatment may be more effective, or is perhaps no longer necessary. This leads to the hypothesis that treatment focusing on decreasing the level of catastrophizing, may increase the effect of medical treatment. Studies showing that pain catastrophizing is associated with the outcome of invasive pain treatments, support this hypothesis (Samwel et al., 2000).

There are a number of limitations to the present study that should be taken into account. Firstly, due to the cross-sectional study design, causal inferences cannot be made. Secondly, the mail-out methodology used may contain several kinds of bias. However, the strength of this study is its very high response rate, since returning the screening questionnaire was a condition of the first medical visit. Finally, the description of the five pain clusters is based on self-reports. A fairly global classification was made, based on how patients answered the question: 'What pain complaints do you have?'. Future studies in pain groups based on medical diagnosis should be carried out, in particular to discover whether the associations found in this study also apply to these pain complaints. 


\section{REFERENCES}

Aaronson NK, Acquadro C, Alonso J, Apolone G, Bucquet D, Bullinger M, Bungay K, Fukuhara S, Gandek B, Keller S and et al. (1992). "International Quality of Life Assessment (IQOLA) Project." Quality of life research an international journal of quality of life aspects of treatment, care and rehabilitation 1(5): 349-51.

Aaronson NK, Muller M, Cohen PD, Essink-Bot ML, Fekkes M, Sanderman R, Sprangers MA, te Velde A and Verrips E (1998). "Translation, validation, and norming of the Dutch language version of the SF-36 Health Survey in community and chronic disease populations." J Clin Epidemiol 51(11): 1055-68.

Becker N, Bondegaard Thomsen A, Olsen AK, Sjogren P, Bech P and Eriksen J (1997). "Pain epidemiology and health related quality of life in chronic non-malignant pain patients referred to a Danish multidisciplinary pain center." Pain 73(3): 393-400.

Brazier JE, Harper R, Jones NM, O'Cathain A, Thomas KJ, Usherwood T and Westlake L (1992). "Validating the SF-36 health survey questionnaire: new outcome measure for primary care." BMJ 305(6846): 160-4.

Buer N and Linton SJ (2002). "Fear-avoidance beliefs and catastrophizing: occurrence and risk factor in back pain and ADL in the general population." Pain 99(3): 485-91.

Crombez G, Eccleston C, Baeyens F and Eelen P (1998). "When somatic information threatens, catastrophic thinking enhances attentional interference." Pain 75(2-3): 187-98.

Crombez G, Eccleston C, Baeyens F, van Houdenhove B and van den Broeck A (1999a). "Attention to chronic pain is dependent upon pain-related fear." J Psychosom Res 47(5): 403-10.

Crombez G, Eccleston C, Vlaeyen JW, Vansteenwegen D, Lysens R and Eelen P (2002). "Exposure to physical movements in low back pain patients: restricted effects of generalization." Health psychology official journal of the Division of Health Psychology, American Psychological Association 21(6): 573-8.

Crombez G, Vlaeyen JW, Heuts PH and Lysens R (1999b). “Pain-related fear is more disabling than pain itself: evidence on the role of pain-related fear in chronic back pain disability." Pain 80(1-2): 32939.

Crombez G and Vlaeyen JWS (1996). “The pain catastrophizing scale. Unpublished Dutch/Flemish translation."

Engstrom D (1983). Cognitive behavioral therapy methods in chronic pain treatments. Advances in Pain research and therapy. J. J. Bonica. New York, Raven Press: 829-838.

Essink Bot ML, Krabbe PF, Bonsel GJ and Aaronson NK (1997). “An empirical comparison of four generic health status measures. The Nottingham Health Profile, the Medical Outcomes Study 36-item ShortForm Health Survey, the COOP/WONCA charts, and the EuroQol instrument." Med Care 35: 522-37.

Gureje 0, Von Korff M, Simon GE and Gater R (1998). "Persistent pain and well-being: a World Health Organization Study in Primary Care." JAMA the journal of the American Medical Association 280(2): 147-51.

Holdcroft A and Power I (2003). "Recent developments: management of pain." BMJ Clinical research ed 326(7390): 635-9.

Hout van den JHC, Vlaeyen JWS, Heuts PHTG, Sillen WJT and Willen AJEHL (2001). "Functional Disability in nonspecific low back pain: The role of pain-related fear and problem-solving skills." Int J Behav Med 8(2): 134-48.

Keefe FJ, Brown GK, Wallston KA and Caldwell DS (1989). “Coping with rheumatoid arthritis pain: catastrophizing as a maladaptive strategy." Pain 37(1): 51-6.

Keefe FJ, Lefebvre JC, Egert JR, Affleck G, Sullivan MJ and Caldwell DS (2000). “The relationship of gender to pain, pain behavior, and disability in osteoarthritis patients: the role of catastrophizing." Pain 87(3): 325-34.

Kempen GI, Ormel J, Brilman EI and Relyveld J (1997). “Adaptive responses among Dutch elderly: the impact of eight chronic medical conditions on health-related quality of life." Am J Public Health 87(1): 38-44. 
Kuile ter MM, Linssen ACG and Spinhoven P (1993). “The development of the Multidimensional Locus of Pain Control Questionnaire (MLPC): Factor Structure, reliability and validity." J Psychopat and Beh Ass 15: 387-404.

Lethem J, Slade PD, Troup JDG and Bentley G (1983). “Outline of a fear-avoidance model of exaggerated pain perception." Behav Res Ther 21: 401-408.

Linton SJ (2002). "Early identification and intervention in the prevention of musculoskeletal pain." Am J Ind Med 41(5): 433-42.

Morley S, Eccleston C and Williams A (1999). "Systematic review and meta-analysis of Randomized controlled trials of cognitive behaviour therapy and behaviour therapy for chronic pain in adults, excluding headache." Pain 80(1-2): 1-13.

Romano JM and Turner JA (1985). "Chronic pain and depression: does the evidence support a relationship?" Psychological bulletin 97(1): 18-34.

Samwel H, Slappendel R, Crul BJ and Voerman VF (2000). "Psychological predictors of the effectiveness of radiofrequency lesioning of the cervical spinal dorsal ganglion (RF-DRG)." Eur J Pain 4(2): 14955.

Schlenk EA, Erlen JA, Dunbar Jacob J, McDowell J, Engberg S, Sereika SM, Rohay JM and Bernier MJ (1998). "Health-related quality of life in chronic disorders: a comparison across studies using the MOS SF-36." Quality of life research an international journal of quality of life aspects of treatment, care and rehabilitation 7(1): 57-65.

Severeijns R, van den Hout MA, Vlaeyen JW and Picavet HS (2002). “Pain catastrophizing and general health status in a large Dutch community sample." Pain 99(1-2): 367-76.

Severeijns R, Vlaeyen JW, van den Hout MA and Weber WE (2001). "Pain catastrophizing predicts pain intensity, disability, and psychological distress independent of the level of physical impairment." Clin J Pain 17(2): 165-72.

Sieben JM, Vlaeyen JW, Tuerlinckx S and Portegijs PJ (2002). “Pain-related fear in acute low back pain: the first two weeks of a new episode." Eur J Pain 6(3): 229-37.

Spinhoven P, Kuile ter MM and Linssen ACG (1994). Coping met Pijn Vragenlijst (CPV) handleiding/experimentele versie. Lisse, Swets and Zeitlinger.

Stewart AL, Greenfield S, Hays RD, Wells K, Rogers WH, Berry SD, McGlynn EA and Ware JE, Jr. (1989). "Functional status and well-being of patients with chronic conditions. Results from the Medical Outcomes Study." JAMA the journal of the American Medical Association 262(7): 907-13.

Stomp-van den Berg SGM, Vlaeyen JWS, Kuile ter MM, Spinhoven P, Breukelen van G and Kole-Snijders AMJ (2001). Meetinstrumenten chronische pijn: deel 2 Pijn Coping en Cognitie Lijst (PCCL). Maastricht, Pijn Kennis Centrum, AZM.

Sullivan M and Karlsson J (1998). “The Swedish SF-36 Health Survey III. Evaluation of criterion-based validity: results from normative population." J Clin Epidemiol 51(11): 1105-13.

Sullivan MD and Loeser JD (1992). "The diagnosis of disability. Treating and rating disability in a pain clinic." Archives of internal medicine 152(9): 1829-35.

Sullivan MJL, Bishop SR and Pivik J (1995). "The pain catastrophizing scale: Development and Validation." Psych Ass 7(4): 524-32.

Turk DC and Okifuji A (1996). "Perception of traumatic onset, compensation status, and physical findings: impact on pain severity, emotional distress, and disability in chronic pain patients." Journal of behavioral medicine 19(5): 435-53.

Van Damme S, Crombez G, Bijttebier P, Goubert L and Van Houdenhove B (2002). "A confirmatory factor analysis of the Pain Catastrophizing Scale: invariant factor structure across clinical and non-clinical populations." Pain 96(3): 319-24.

Van Damme S, Crombez G, Vlaeyen JWS, Goubert L, Van den Broeck A and Van Houdenhove B (2000). "De Pain Catastrophizing Scale: psychometrische karakteristieken en normering." Gedragstherapie 3: 211-22.

Van der Zee K, Sanderman R and Heyink J (1993). “De psychometrische kwaliteiten van de MOS 36-item Short Form Health Survey (SF-36) in een Nederlandse populatie." T Soc Gez 71: 183-91.

Van der Zee K, Sanderman R, Heyink JW and Haes dH (1996). "Psychometric qualities of the Rand 36item health survey 1.0: a multidimensional measure of general health status." Int $\mathrm{J}$ Behav Med 3: 104-22. 
Verhaak PFM, Kerssens JJ, Bensing JM, Sorbi MJ, Peters ML and Kruise DA (2000). “Medical help-seeking by different types of chronic pain patients." Psych and Health 15: 771-86.

Verkes J, Vanderiet K, Vertommen H, Van der Kloot WA and Van der Meij J (1989). De MPQ-DLV: een standaard Nederlandstalige versie van de Mc Gill Pain Questionnaire voor Belgie en Nederland. De MPQ-DLV: een standaard Nederlandstalige versie van de Mc Gill Pain Questionnaire. Achtergronden en handleiding. W. A. Van der Kloot. Lisse, Swets \& Zeitlinger: 59-67.

Vlaeyen JW, Kole-Snijders AM, Boeren RG and van Eek H (1995a). "Fear of movement/(re)injury in chronic low back pain and its relation to behavioral performance." Pain 62(3): 363-72.

Vlaeyen JW and Linton SJ (2000). "Fear-avoidance and its consequences in chronic musculoskeletal pain: a state of the art." Pain 85(3): 317-32.

Vlaeyen JWS, Geurts SM, Kole-Snijders AMJ, Schuerman JA, Groenman NH and Eek van H (1990). "What do chronic pain patients think of their pain? Towards a pain cognition questionnaire." Brit J Clin Psych 28: 383-94.

Vlaeyen JWS, Kole Snijders AMJ, Rotteveel AM and Ruesink R (1995b). "The role of fear of movement/(re)injury in pain disability." J 0ccup Rehab 5: 235-52. 


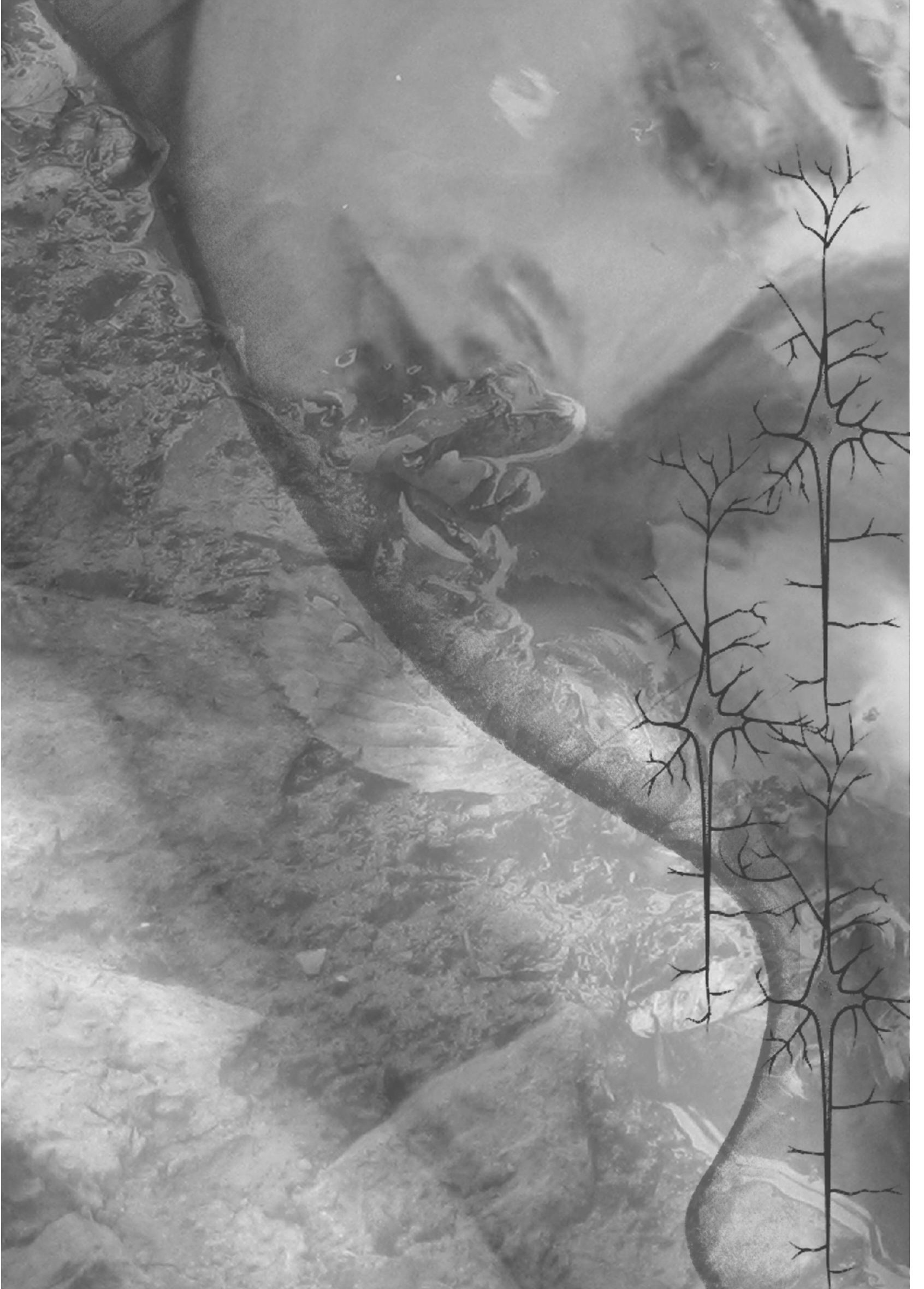




\section{Chapter 3}

\section{Test-retest stability of the pain catastrophizing scale and the tampa scale for kinesiophobia in chronic pain patients over a longer period of time}

Inge E. Lamé, Madelon L. Peters, Alfons G. Kessels, Maarten van Kleef, Jacob Patijn 


\section{CHAPTER 3}

\section{ABSTRACT}

The objective of this study was to investigate the test-retest stability of the Pain Catastrophizing Scale (PCS), the Tampa Scale for Kinesiophobia (TSK) and their subscales in chronic pain patients over a relatively long period of time, such as those most often seen in clinical practice. Fifty non-malignant chronic pain patients filled out PCS and TSK twice, with a mean interval between testing of 52 days. Both assessment instruments showed sufficient test-retest stability, even with long time intervals between testing.

\section{INTRODUCTION}

Psychological screening measures may be useful in clinical settings for improving the matching of specific treatments to subgroups of pain patients with similar characteristics (Crombez et al., 1998; Vlaeyen et al., 2001; Vlaeyen et al., 2002; Boersma et al., 2004; de Jong et al., 2005a; de Jong et al., 2005b). Due to factors such as waiting lists, there may be a delay of several weeks to months between screening and a first consultation with the physician. Screening instruments with diagnostic consequences should be stable over periods of time that are in accordance with this interval between screening and the start of treatment. Two instruments that are frequently used for screening psychological aspects of chronic pain are the Pain Catastrophizing Scale (PCS) and the Tampa Scale for Kinesiophobia (TSK). These measure related constructs: pain catastrophizing and pain related fear. Pain catastrophizing and pain related fear have emerged as the most reliable psychological predictors of disability and impaired quality of life in chronic pain patients (Vlaeyen et al., 1995; Sullivan et al., 2002; Lame et al., 2005). Although several studies have previously investigated the test-retest stability of PCS and TSK (Miller et al., 1991; Sullivan et al., 1995; Swinkels-Meewisse et al., 2003; Woby et al., 2005), none of these studies has examined test-retest stability over an extended period of time in patients with chronic pain. To the best of our knowledge, the test-retest stability of PCS has only been established once, in the original publication which introduced it. Test-retest stability appeared to be adequate ( 0.75 after six weeks and 0.70 after ten weeks), but this was assessed in a healthy student population (Sullivan et al., 1995). It cannot be ruled out that the results will be different in individuals who actually experience pain, compared to those who responded to the questions by imaging how they usually respond to pain.

The presence of pain is essential for pain catastrophizing to manifest itself (Keefe et al., 2000; Severeijns et al., 2005), and pain catastrophizing may vary in time with fluctuating pain intensity. The test-retest stability of TSK has already been assessed several times in chronic pain patients, but always over a relatively short period of time, varying from 24 hours to eight days (Miller et al., 1991; Swinkels- 
Meewisse et al., 2003; Woby et al., 2005). Miller et al. (1991) found a correlation of 0.66 at an interval of eight days, in contrast to other studies testing shorter time intervals, which noted correlations close to 0.80 (Swinkels-Meewisse et al., 2003; Woby et al., 2005). When the time interval between the first and second administration is short, a high test-retest correlation could be due to recall. Therefore, the current study explores the test-retest stability of PCS and TSK in patients with chronic pain complaints, using time intervals that reflect common practice in most out-patient pain management facilities.

Thus far, no studies have examined the test-retest stability of the subscales of PCS and TSK. In previous studies, PCS consisted of three subscales: rumination, magnification, and helplessness (Sullivan et al., 1995; Osman et al., 2000; Severeijns et al., 2002; Van Damme et al., 2002). Vlaeyen et al. (1995) examined the factor structure of TSK and identified a four-factor model, with the subscales harm, fear of (re)injury, importance of exercise, and avoidance of activity. However, most recently, two subscales of TSK have been identified: somatic focus (SF) and activity avoidance (AA) (Clark et al., 1996). These were confirmed in subsequent studies (Clark et al., 1996; Geisser et al., 2000; Goubert et al., 2004; Roelofs et al., 2004). Moreover, these studies indicated that the four reversed key items showed weak associations with the total TSK score, and that deleting these items increased internal consistency and test-retest stability (Swinkels-Meewisse et al., 2003). The current study additionally explores the test-retest stability of the subscales of PCS and TSK and the test-retest stability of total TSK, without the four reversed key items in chronic pain patients.

In summary, the objectives of the current study are: (1) to investigate the testretest stability of PCS and TSK in chronic pain patients over a longer period of time; and (2) to explore the stability of PCS and TSK subscales.

\section{METHODS}

\section{Participants and procedure}

The subjects included in this study were selected from the Outpatient Clinic for Pain and Pain Management at the University Hospital Maastricht, the Netherlands. This population has been described in detail elsewhere, but briefly, it consists of a heterogeneous group of chronic non-malignant pain patients characterized by low scores on quality of life and high scores on catastrophizing (Lame et al., 2005). Questionnaires - including PCS and TSK - were mailed to each new referral to the pain clinic, as part of the standard intake procedure. These questionnaires had to be returned and evaluated before a first appointment could be made with a physician. On the day of their first appointment at the clinic, 50 consecutive non- 


\section{CHAPTER 3}

malignant chronic pain patients were asked to fill out a retest of PCS and TSK. No treatment was given between the first and second questionnaires.

Registration of demographic variables (gender and age) was part of the standard questionnaire.

\section{Measures}

\section{Tampa Scale for Kinesiophobia}

The Dutch version of TSK (Miller et al., 1991; Vlaeyen et al., 1995) (originally developed by Miller et al., 1991) is a 17-item questionnaire developed to identify fear of (re)injury due to movement or activity. The items are scored on a fourpoint Likert scale with scoring possibilities ranging from 'strongly disagree' (score $=1$ ) to 'strongly agree' (score =4). The scores on items 4, 8, 12 and 16 are reversed, and total scores range from 17 to 68 . High scores indicate more fear of pain/(re)injury due to movement or activity. Two factors were identified, somatic focus (SF) (items 3, 5, 6, 7 and 11) and activity avoidance (AA) (items 1, 2, 9, 10, 13, 14, 15 and 17) (Goubert et al., 2004; Roelofs et al., 2004). The questionnaire has been validated, with sufficient internal consistency $(\alpha=0.77)$ and validity (Vlaeyen et al., 1995).

\section{Pain Catastrophizing Scale}

The Dutch version of PCS (Sullivan et al., 1995; Crombez \& Vlaeyen, 1996) is a 13item questionnaire developed to identify catastrophic thoughts or feelings in relation to painful experiences. The items are scored on a five-point Likert scale with scoring possibilities ranging from 'not at all' (score $=0)$ to 'always' (score $=4)$. The total score ranges from 0 to 52 , and high scores indicate that more catastrophic thoughts or feelings are experienced. Three factors were identified, rumination (items 8, 9, 10 and 11), magnification (items 6, 7 and 13), and helplessness (items $1,2,3,4,5$ and 12) (Sullivan et al., 1995). The psychometric properties of PCS appeared to be adequate. The internal consistency measured in a student sample (Crombez et al., 1998), and in two samples of chronic low back pain patients (Van Damme et al., 2000), was adequate (Cronbach's $\alpha=0.85,0.88$, and 0.91, respectively).

\section{Data analysis}

Student's t test was used to calculate differences between the mean PCS and TSK scores on the first and second questionnaire. The test-retest stability of PCS, TSK and the subscales was determined using the Intraclass Correlation Coefficient (ICC) (Shrout \& Fleiss, 1979). ICC values above 0.75 indicate good reliability (Nunnally \& Bernstein, 1994), and we defined ICCs of between 0.70 and 0.75 as having sufficient reliability. ICCs of PCS and TSK total scores and subscale scores are mutually statistically dependent. A bootstrap technique was used to test for differences 
between these ICCs (Efron \&Tibshiram, 1993). This technique provides a way to obtain confidence intervals and standard deviations when no appropriate formula is otherwise available. Data were analyzed by using the SPSS Statistical Package, version 12.0 for Windows and Stata Statistical Package Release 8.

\section{RESULTS}

\section{Description of sample}

The mean age of the patients was 54.7 years $(s d=13.1), 40 \%$ were male (mean age 51.9 years, $s d=13.2$ ) and $60 \%$ female (mean age 56.6 years, $s d=12.8$ ). Pain duration varied between three months and 38 years. Seventy-eight percent of patients reported musculoskeletal pain, $50 \%$ of whom suffered from low back pain $(\mathrm{LBP})$. Mean VAS at baseline was $7.2(s d=1.9)$. Forty-eight patients completed the retest of PCS and 46 patients the retest of TSK. Due to the waiting list procedure at our pain clinic, the mean test-retest interval was 51.7 days $(s d=21.7$; median = 44.0; range 14-135). There were no significant differences between males $(n=20)$ and females $(n=30)$ in PCS $(p=0.41)$ and TSK total scores $(p=0.45)$. Baseline and retest information on PCS and TSK total and subscale scores is presented in Table 1 . The scores found reflect scores that are common in chronic pain populations (Lamé et al., 2005; Vlaeyen et al., 1995). Apart from the magnification subscale of PCS $(p=0.02)$, there were no significant differences in total or subscale scores between the first and second questionnaires. The internal consistency (Cronbach's ) was sufficient (TSK total score, TSK subscale somatic focus and PCS subscale magnification) to good (PCS total score, PCS subscales rumination, helplessness and TSK subscale activity avoidance; Table 1).

Table 1: Internal consistency (Cronbach's $\alpha$ ), test-retest mean and ICC values of the PCS and TSK total and subscale scores.

\begin{tabular}{|c|c|c|c|c|c|c|}
\hline & $\mathrm{N}$ & Cronbach's a & $\begin{array}{l}\text { First } \\
\text { administration } \\
\text { mean }(\mathrm{sd})\end{array}$ & $\begin{array}{l}\text { Second } \\
\text { administration } \\
\text { mean (sd) }\end{array}$ & ICC & $\begin{array}{l}95 \% \text { confidence } \\
\text { interval }\end{array}$ \\
\hline PCS Total & 48 & 0.92 & $30.2(11.7)$ & $31.4(13.3)$ & 0.73 & $0.56-0.84$ \\
\hline Rumination & 47 & 0.84 & $11.1(3.6)$ & $10.4(4.2)$ & 0.63 & $0.42-0.78$ \\
\hline Magnification & 46 & 0.74 & $4.5(3.3)$ & $5.3(3.5)^{*}$ & 0.71 & $0.51-0.83$ \\
\hline Helplessness & 46 & 0.87 & $14.9(5.9)$ & $15.9(6.1)$ & 0.65 & $0.44-0.79$ \\
\hline TSK Total & 46 & 0.73 & $41.0(7.8)$ & $41.3(9.5)$ & 0.72 & $0.54-0.83$ \\
\hline Somatic Focus & 47 & 0.73 & $10.7(3.6)$ & $11.3(4.2)$ & 0.67 & $0.47-0.80$ \\
\hline Activity Avoidance & 45 & 0.81 & $18.9(5.8)$ & $19.3(7.2)$ & 0.68 & $0.49-0.81$ \\
\hline
\end{tabular}

${ }^{*} p=0.02$ 


\section{CHAPTER 3}

\section{Test-retest stability}

The test-retest ICCS of PCS (0.67) and TSK (0.63) were moderate. Visualization of the difference between baseline and retest scores plotted against the time interval between both moments, showed a range of between -28 and 20 for PCS difference scores and of between -12 and 20 for TSK difference scores (difference of retest minus baseline scores; Figs. $1 \mathrm{a}$ and $1 \mathrm{~b}$ ). No relationship was found between the ICCs and the length of the interval. After standardizing the dataset (z-scores), two outliers defined as deviating 2.5 sd or more from the mean value were found for both PCS and TSK total scores. ICC improved when the outliers were omitted from the dataset $($ ICCPCs $=0.73(n=48)$, and ICCtsk $=0.72(n=46))$, thus demonstrating sufficient test retest stability. After omitting the reversed key items of TSK from the dataset, ICCtsk increased slightly to 0.74 (the outliers were omitted from the dataset).
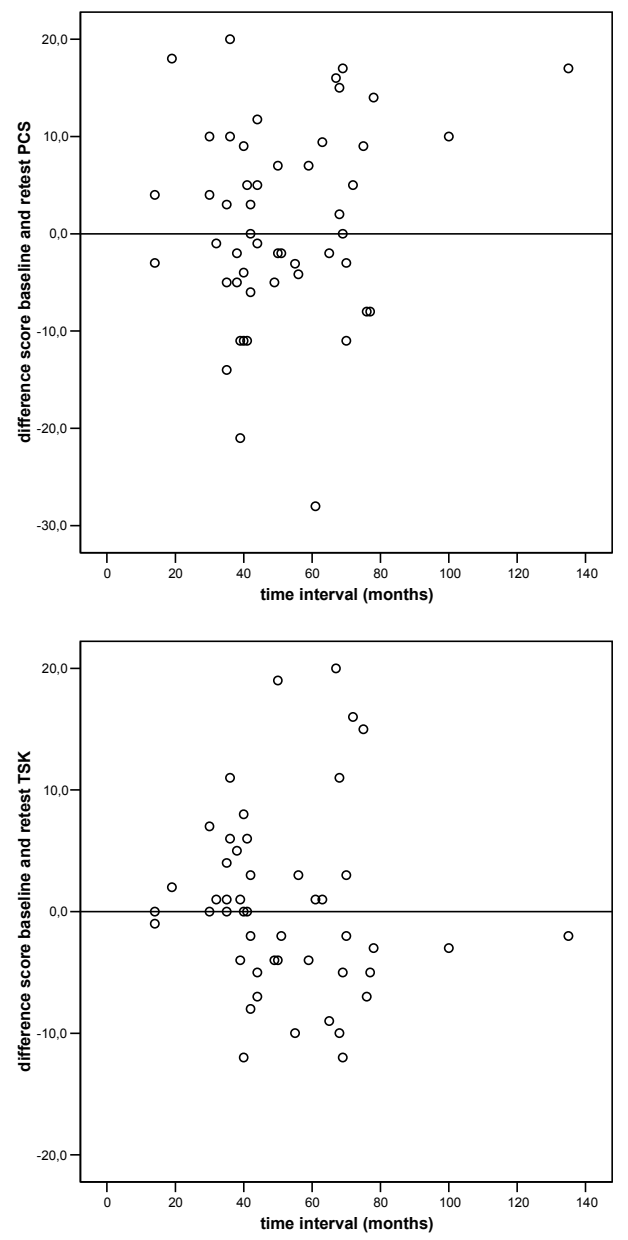

Figure 1a: Scatter plot of differences in retest and baseline PCS scores and the time interval

Figure 1b: Scatter plot of differences in retest and baseline TSK scores and the time interval 
Table 1 summarizes the test-retest stability of the subscales of PCS and TSK. All ICCs were measured without the outliers. Bootstrap statistics indicated that the test-retest correlation of the TSK subscales did not differ significantly from that of total TSK. However, for PCS, test-retest stability of the subscales rumination ( $p=$ 0.01 ) and helplessness $(p=0.02)$ was significantly lower than that of the total score, and only magnification proved to have similar test-retest stability.

\section{DISCUSSION}

The main aim of the current study was to investigate the test-retest stability of PCS and TSK in chronic pain patients over a longer period of time. In order to establish test-retest stability, we used time intervals between completing first and second questionnaires on screening instruments that reflect common practice in most out-patient pain management facilities. Although the time interval between the baseline and retest measuring moment was quite long, and varied considerably between individuals, both ICCpcs and ICCtsk appeared to be stable over time, especially after removing two patients who appeared to be outliers. No relationship was found between ICCs and the time interval.

Previously, it had been noted that omitting the reversed key items improved internal consistency (Swinkels-Meewisse et al., 2003; Goubert et al., 2004; Roelofs et al., 2004) and the test-retest stability (Swinkels-Meewisse et al., 2003). However, the current study only noted a moderate increase in test-retest stability when omitting the reversed key items. Nevertheless, since the reversed key items often seem to be misinterpreted, and patients need to be helped to be more alert when answering these questions (Swinkels-Meewisse et al., 2003; Roelofs et al., 2004), we recommend that TSK is used without the reversed key items for screening purposes.

A secondary objective of this study was to explore the test-retest stability of PCS and TSK subscales. The results indicate that the PCS subscale magnification has similar test-retest stability to PCS total score. However, the subscales rumination and helplessness appeared to be less stable with time. Therefore, for screening purposes, it is recommended that the PCS total score be used. Indeed, thus far, the subscales have not often been used. However, some studies found evidence of both a one-factor and a three-factor model of PCS, with high correlations between the subscales (Osman et al., 2000; Severeijns et al., 2002). Further research is required in order to discover whether the predictive validity of the subscales can be guaranteed. Both TSK subscales were found to have similar test-retest stability as the total TSK scale. The interrelationship between the two subscales was found to be strong (0.74) (Goubert et al., 2004; Roelofs et al., 2004). However, it remains to be determined whether the two subscales have differential predictive 


\section{CHAPTER 3}

validity, and whether both subscales should be used separately for screening purposes, or whether the total score is enough.

A limitation of the present study is that the sample size is somewhat small. This increases the range of the confidence intervals, and the lower limits of these ranges contain ICCs that many would interpret as being poor (e.g., .42). A further limitation is the fact that pain intensity was not asked for in the second questionnaire. We assumed that pain intensity will remain relatively stable in patients with chronic pain, but have not put this to the test. Furthermore, TSK was originally developed for use in patients with low back pain. However, recently some studies have shown that TSK has predictive value for pain outcomes in populations with other musculoskeletal pain complaints, such as osteoarthritis (Heuts et al., 2004; Kvist et al., 2005) and fibromyalgia (Goubert et al., 2004; Roelofs et al., 2004; Burwinkle et al., 2005). Our sample mainly consisted of patients with musculoskeletal pain $(78 \%), 50 \%$ of whom reported back pain.

In conclusion, this study suggests that both instruments possess sufficient testretest stability, over extended period of times, in a clinical population awaiting treatment in a hospital clinic, and can be recommended for use as a screening tool for selecting patients eligible for cognitive behavioural treatment or exposure training, in order to reduce pain catastrophizing and pain-related fear. Nevertheless, it is important to remember that, although the measure is stable and for most patients scores will not vary greatly over time, in some individuals they will. Therefore, whenever possible, multiple assessments are preferable. 


\section{REFERENCES}

Boersma, K., Linton, S., Overmeer, T., Jansson, M., Vlaeyen, J. \&de Jong, J.(2004). Lowering fearavoidance and enhancing function through exposure in vivo. A multiple baseline study across six patients with back pain. Pain 108(1-2): 8-16.

Burwinkle, T., Robinson, J.P. \&Turk, D.C.(2005). Fear of movement: factor structure of the tampa scale of kinesiophobia in patients with fibromyalgia syndrome. J Pain 6(6): 384-91.

Clark, M.E., Kori, S.H. \&Brockel, J.(1996). Kinesiophobia and chronic pain: psychometric characteristics and factor analysis of the Tampa Scale. Am Pain Soc Abstr 77(

Crombez, G., Eccleston, C., Baeyens, F. \&Eelen, P.(1998). When somatic information threatens, catastrophic thinking enhances attentional interference. Pain 75(2-3): 187-98.

Crombez, G. \&Vlaeyen, J.W.S.(1996). The Pain Catastrophizing Scale. unpublished Dutch/Flemisch translation.

de Jong, J.R., Vlaeyen, J.W., Onghena, P., Cuypers, C., den Hollander, M. \&Ruijgrok, J.(2005a). Reduction of pain-related fear in complex regional pain syndrome type I: the application of graded exposure in vivo. Pain 116(3): 264-75.

de Jong, J.R., Vlaeyen, J.W., Onghena, P., Goossens, M.E., Geilen, M. \&Mulder, H.(2005b). Fear of movement/(re)injury in chronic low back pain: education or exposure in vivo as mediator to fear reduction? Clin J Pain 21(1): 9-17; discussion 69-72.

Efron, B. \&Tibshiram, R.J.(1993). An introduction to the bootstrap. New York, USA: Chapman and Halk.

Geisser, M.E., Hang, A.J. \&Theisen, M.E.(2000). Activity avoidance and function in persons with chronic back pain. J Occup Rehab 10(3): 215-227.

Goubert, L., Crombez, G., Van Damme, S., Vlaeyen, J.W., Bijttebier, P. \&Roelofs, J.(2004). Confirmatory factor analysis of the Tampa Scale for Kinesiophobia: invariant two-factor model across low back pain patients and fibromyalgia patients. Clin J Pain 20(2): 103-10.

Heuts, P.H., Vlaeyen, J.W., Roelofs, J., de Bie, R.A., Aretz, K., van Weel, C. \&van Schayck, 0.C.(2004). Pain-related fear and daily functioning in patients with osteoarthritis. Pain 110(1-2): 228-35.

Keefe, F.J., Lefebvre, J.C., Egert, J.R., Affleck, G., Sullivan, M.J. \&Caldwell, D.S.(2000). The relationship of gender to pain, pain behavior, and disability in osteoarthritis patients: the role of catastrophizing. Pain 87(3): 325-34.

Kvist, J., Ek, A., Sporrstedt, K. \&Good, L.(2005). Fear of re-injury: a hindrance for returning to sports after anterior cruciate ligament reconstruction. Knee Surg Sports Traumatol Arthrosc 13(5): 393-7.

Lame, I.E., Peters, M.L., Vlaeyen, J.W., Kleef, M. \&Patijn, J.(2005). Quality of life in chronic pain is more associated with beliefs about pain, than with pain intensity. Eur J Pain 9(1): 15-24.

Miller, R.P., Kori, S.H. \&Todd, D.D.(1991). The Tampa Scale for Kinesiophobia. unpublished report.

Nunnally, J. \&Bernstein, I.(1994). Psychometric theory. New York: McGraw Hill.

Osman, A., Barrios, F.X., Gutierrez, P.M., Kopper, B.A., Merrifield, T. \&Grittmann, L.(2000). The Pain Catastrophizing Scale: further psychometric evaluation with adult samples. J Behav Med 23(4): 351-65.

Roelofs, J., Goubert, L., Peters, M.L., Vlaeyen, J.W. \&Crombez, G.(2004). The Tampa Scale for Kinesiophobia: further examination of psychometric properties in patients with chronic low back pain and fibromyalgia. Eur J Pain 8(5): 495-502.

Severeijns, R., van den Hout, M.A., Vlaeyen, J.W. \&Picavet, H.S.(2002). Pain catastrophizing and general health status in a large Dutch community sample. Pain 99(1-2): 367-76.

Severeijns, R., Vlaeyen, J.W., van den Hout, M.A. \&Picavet, H.S.(2005). Pain catastrophizing and consequences of musculoskeletal pain: a prospective study in the Dutch community. J Pain 6(2): 12532.

Shrout, P.E. \&Fleiss, J.L.(1979). Intraclass Correlations: Uses in Assessing Rater Reliability. Psychological Bulletin 86(2): 420-428.

Sullivan, M.J., Rodgers, W.M., Wilson, P.M., Bell, G.J., Murray, T.C. \&Fraser, S.N.(2002). An experimental investigation of the relation between catastrophizing and activity intolerance. Pain 100(1-2): 47-53. 


\section{CHAPTER 3}

Sullivan, M.J.L., Bishop, S.R. \&Pivik, J.(1995). The Pain Catastrophizing Scale: Development and Validation. Psych Assess 7(4): 524-32.

Swinkels-Meewisse, E.J.C.M., Swinkels, R.A.H.M., Verbeek, A.L.M., Vlaeyen, J. \&0ostendorp, R.A.B.(2003). Psychometric properties of the Tampa Scale for Kinesiophobia and the fear-avoidance beliefs questionnaire in acute low back pain. Man Ther 8(1): 29-36.

Van Damme, S., Crombez, G., Bijttebier, P., Goubert, L. \&Van Houdenhove, B.(2002). A confirmatory factor analysis of the Pain Catastrophizing Scale: invariant factor structure across clinical and nonclinical populations. Pain 96(3): 319-24.

Van Damme, S., Crombez, G., Vlaeyen, J., Goubert, L., Van den Broeck, A. \&Van Houdenhove, B.(2000). De Pain Catastrophizing Scale: psychometrische karakteristieken en normering. Gedragstherapie 3(211-22.

Vlaeyen, J.W., de Jong, J., Geilen, M., Heuts, P.H. \&van Breukelen, G.(2001). Graded exposure in vivo in the treatment of pain-related fear: a replicated single-case experimental design in four patients with chronic low back pain. Behav Res Ther 39(2): 151-66.

Vlaeyen, J.W., de Jong, J., Geilen, M., Heuts, P.H. \&van Breukelen, G.(2002). The treatment of fear of movement/(re)injury in chronic low back pain: further evidence on the effectiveness of exposure in vivo. Clin J Pain 18(4): 251-61.

Vlaeyen, J.W., Kole-Snijders, A.M., Boeren, R.G. \&van Eek, H.(1995). Fear of movement/(re)injury in chronic low back pain and its relation to behavioral performance. Pain 62(3): 363-72.

Woby, S.R., Roach, N.K., Urmston, M. \&Watson, P.J.(2005). Psychometric properties of the TSK-11: a shortened version of the Tampa Scale for Kinesiophobia. Pain 117(1-2): 137-44. 


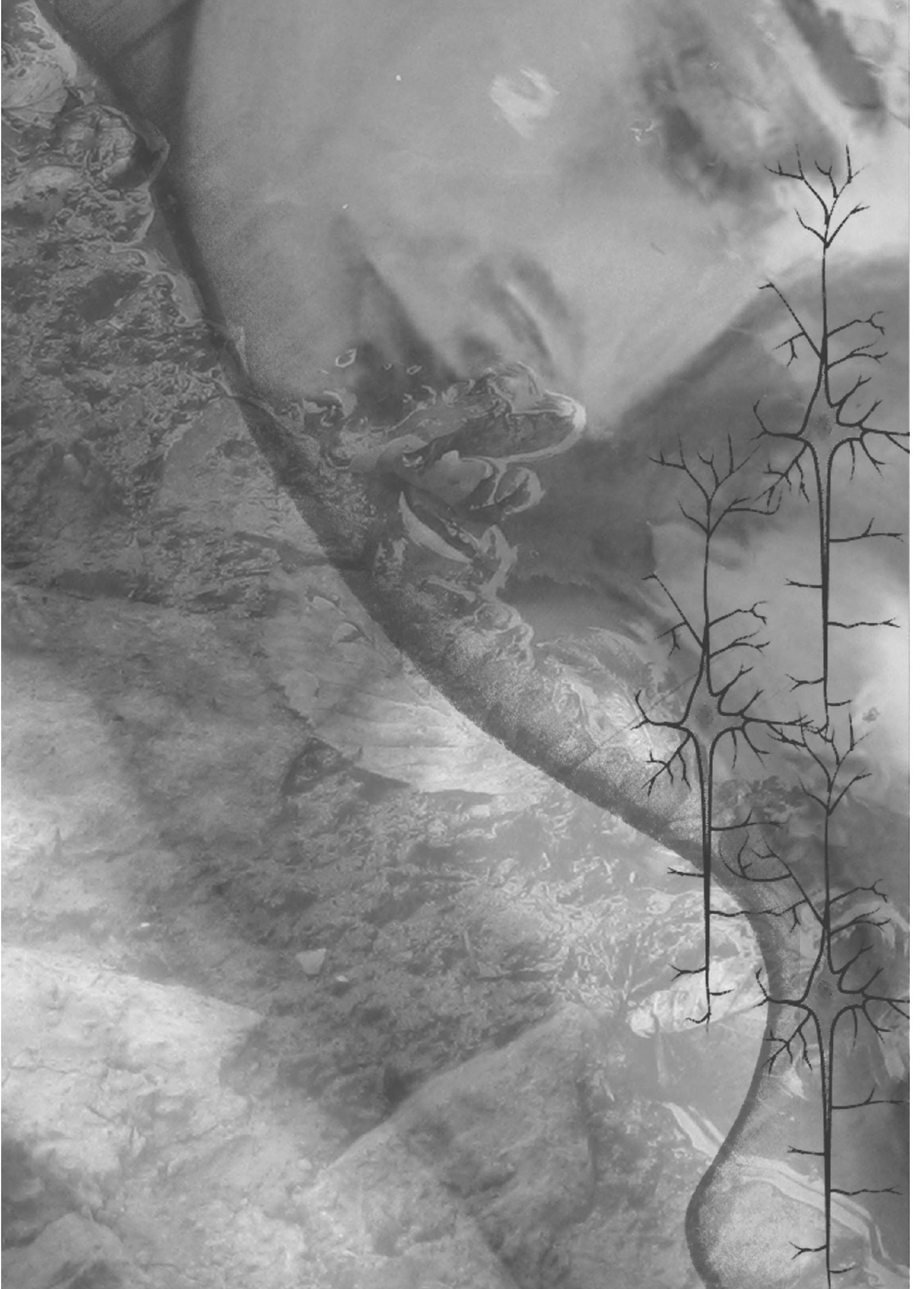




\section{Chapter 4}

Systematic review of the psychological factors that predict treatment outcome in chronic non-cancer pain

Inge Lamé, José Geurts, Alfons Kessels, Madelon Peters,

Albère Köke, Maarten van Kleef, Jacob Patijn 


\section{ABSTRACT}

The current study presents a systematic review of prospective cohort studies. Its aim was to assess the psychological predictive factors associated with treatment outcome in all manifestations of chronic pain. The review process began with a systematic, computerized search of Medline, Psychinfo, Cinahl, Embase, and the Cochrane Library up to September 2006. Reference lists of retrieved studies were checked by hand. Studies were selected if they met the predefined inclusion criteria. Thirty-seven studies were included in the review. Two reviewers independently assessed the methodological quality of the 37 studies, using a standard criteria list with a maximum score of 38 . Studies qualified as high if at least $50 \%$ of the maximum score was obtained. Finally 28 studies qualified as high. Heterogeneity of the studies did not allow statistical pooling, and evidence was provided by qualitative summary. The results were grouped per treatment: cognitive behavioural treatment (CBT), rehabilitation, and somatic treatment. Consistent evidence was found for depression and fear-avoidance as negative predictors of pain intensity after treatment. Consistent evidence was found for depression and external locus of control as negative predictors of disability after treatment. Levels of pain intensity and disability improved in patients typified as dysfunctional, especially after CBT. It was concluded that the choice of assessment instrument is relevant, profiles with a combination of different separate predictive variables probably have more predictive value, and the interaction of the predictor variable with the type of treatment is not substantiated.

\section{INTRODUCTION}

The biopsychosocial perspective of pain has resulted in the most heuristic approach to the understanding and treatment of pain syndromes (Gatchel, 2004b; Gatchel, 2004a). Pain is viewed as a complex and dynamic interaction between biological, psychological and social factors (Gatchel, 2001). When pain persists and becomes chronic, affective factors may become more prominent and can have an influence on all aspects of quality of life (Gatchel et al., 2007). Affective factors relevant in chronic pain are depression, anger, anxiety, self-preoccupation, and isolation, resulting in an overall sense of demoralization. All factors interact with and augment each other over time.

Over the last decades, in accordance with the biopsychosocial model, treatment strategies have turned to multidisciplinary programmes that focus on the restoration of functional activity. Notwithstanding the multidimensional character of these treatments, not every patient is responsive to the intervention and the outcome could be influenced by individual differences. Some patients with specific 
personality, environmental or behavioural factors, may be predisposed towards poorer intervention outcome (Gatchel, 2001).

An increasing number of studies has examined possible psychological predictors of treatment outcome in chronic pain patients (Turk, 1990). However, thus far, no uniform results have been reported as to which psychological factors are predictive of the outcome of a specific treatment. Systematic reviews may be able to shed more light on the relationship between psychological factors and treatment outcome. A number of investigators conducted a systematic review of the literature looking into predictive factors in chronic pain (Feuerstein et al., 1994; Hudak et al., 1996; Borghouts et al., 1998; Borge et al., 2001; Scholten-Peeters et al., 2003; Kuijpers et al., 2004; van der Hulst et al., 2005). Some of these studies focused on the predictors of the clinical course of various pain problems, independent of treatment (e.g., non-specific neck pain (Borghouts et al., 1998), whiplashassociated disorder (Scholten-Peeters et al., 2003), and shoulder pain (Kuijpers et al., 2004)). Other studies have examined physical examination findings as predictors of treatment prognosis in chronic low back pain (Borge et al., 2001) or as demographic predictors of treatment outcome in lateral elbow pain (Hudak et al., 1996). Only two reviews reported on the psychological predictors of treatment outcome in chronic pain (Feuerstein et al., 1994; van der Hulst et al., 2005). However, the scope of both these studies was limited. The review by Feuerstein et al. (1994) only included studies that focused on the outcome measure of rate of return to work in low back pain patients, while van der Hulst et al. (2005) limited their review to multidisciplinary or back school treatment in low back pain patients. Moreover, the latter review followed a new conceptual framework adapted from Côté et al. (2001), which covers the application of the quality criteria to assess internal validity in whiplash-associated disorders (WAD). Although this methodology is well-accepted, it resulted in a high amount of rejected studies in this review. There is no general consensus as to how methodological quality should be assessed in predictive studies, and the debate continues (Freeman et al., 1998; Cote et al., 2001).

In this systematic review, our goal was to perform a more comprehensive study of the psychological predictors of treatment outcome in all manifestations of chronic pain. According to the IMMPACT recommendations (Dworkin et al., 2005), outcome measures of pain intensity, pain interference, quality of life, and global ratings of improvement were included. The different psychological predictors were clustered into meaningful constructs that reflected a similar underlying theoretical dimension. 


\section{CHAPTER 4}

\section{MATERIAL AND METHODS}

\section{Review process:}

The review process consisted of three stages:

- search strategy

- selection strategy

- methodological quality

The selection procedure and methodological quality were completed by two reviewers independently (J.G. and I.E.L.). Disagreements concerning the inclusion of studies and the selection of studies for the final review were discussed and resolved during a consensus meeting. When disagreement persisted, a third reviewer (A.K.) was consulted to make the final decision.

\section{Search strategy}

The review process began with a systematic, computerized search of Medline (1966-September 2006), Psychinfo (1967-September 2006), Cinahl (1982September 2006), Embase (1991-September 2006) and Cochrane Library databases up to September 2006. The most relevant keywords used (MeSH and text words) were: cohort, RCT, follow-up studies, prospective studies, observational studies, chronic pain, pain, widespread pain, treatment, outcome, prediction*, prognosis* and course, in the title, abstract or keywords. The article had to be a full report published in English, German, or Dutch. Duplicate studies were excluded from the database. An initial screening of the titles and abstracts of all studies was used to identify relevant studies. Reference lists of all relevant studies retrieved were checked by hand in order to identify studies that were not found during the computerized search. Neither abstracts nor unpublished studies were included.

\section{Selection strategy}

An article was eligible for the final review if it met the following selection criteria:

- the study design was a randomized controlled trial (RCT) or a prospective cohort study;

- the study population consisted of patients with chronic non-cancer pain, specific as well as non-specific, with a pain duration of three months or more;

- the association of one or more psychological predictive variable(s) with treatment outcome had to be present; 
- the predictive variable had to be a moderator, i.e., a baseline characteristic, not associated with treatment, but that had an interactive effect with treatment on the outcome. ${ }^{2}$ (Kraemer et al., 2002; Turner et al., 2007).

All kinds of treatment common in chronic pain were included. Studies that included surgery as an intervention were excluded from the review.

\section{Methodological quality}

There are no widely agreed criteria for assessing the methodological quality of predictive studies (Altman, 2001; Egger et al., 2001). We constructed an instrument, adapted from suggestions by Egger et al. (2001) and Hudak et al. (1996), and supplemented by relevant criteria from checklists used in earlier systematic reviews of predictive factors (Scholten-Peeters et al., 2003; Kuijpers et al., 2004; van der Hulst et al., 2005) (Appendix I).

The checklist was based on the framework according to Altman (2001), for assessing the internal validity of articles dealing with prediction. The checklist consisted of 19 criteria, subdivided into eight categories, namely: study design, patient selection, response, follow-up, treatment, predictive factors, outcome, and analysis (Appendix 1). Each criterion was graded as: yes, all information provided (2 points), not clear or only partial information provided (1 point) and no information provided ( 0 points). The maximum total methodological quality score obtainable was 38 points. The criteria were scored independently by two reviewers (J.G. and I.E.L.). Disagreements between the two reviewers were resolved during a consensus meeting.

\section{Data extraction}

In order to classify and compare results, data were taken from studies on study design, source population, response, type of psychological predictive factors, and treatment, outcomes, follow-up period, and data on associations. Psychological predictive factors were classified according to the underlying theoretical construct that they were supposed to measure. Factors that measured the same construct were combined. Treatment was subdivided into three main domains: multidisciplinary treatment including cognitive-behavioural treatment (CBT), rehabilitation, and somatic treatment. Treatment was coded as CBT if at least one part of it was cognitive-behavioural. Rehabilitation included active treatment without cognitivebehavioural elements. Somatic treatment included therapies such as invasive techniques, rest, medication, braces, corsets, and instruction.

2 Two other predictive variables can be distinguished Kraemer, H.C., Wilson, G.T., Fairburn, C.G. \& Agras, W.S.(2002). Mediators and moderators of treatment effects in randomized clinical trials. Arch Gen Psychiatry 59(10): 877-83, Turner, J.A., Holtzman, S. \& Mancl, L.(2007). Mediators, moderators, and predictors of therapeutic change in cognitive-behavioral therapy for chronic pain. Pain 127(3): 27686.: 1. A mediator is a variable that changes during treatment, is correlated with treatment and has an interactive effect on the outcome. 2. A non-specific predictor is a baseline characteristic that has a main effect on outcome, but no interactive effect. 


\section{CHAPTER 4}

Outcome measures were categorized into pain intensity, pain interference and disability, global perceived effect (GPE), and quality of life.

\section{Data analysis}

Studies were classified into high and low quality studies. A study was classified as 'high quality' if the total methodological quality score obtained was 19 points or more ( $\geq 50 \%$ of the maximum score). First of all, the heterogeneity of the study population, predictive factors, treatment, outcomes, and analysis in the selected studies were examined, in order to consider statistical pooling. When a pooled estimate could not be computed, a qualitative analysis of a best evidence synthesis for prognosis with outcome was assessed by defining four levels of evidence (Ariens et al., 2000; van Tulder et al., 2003) (Table 1). Qualitative analysis deals with the outcome of treatment, taking into account the source population, interventions, outcomes, and methodological quality of the original studies (van Tulder et al., 2003). A reported non-significant association between a prognostic factor and treatment outcome, with no mention of risk estimate or direction of the association, was disregarded (Ariens et al., 2000).

Table 1: Levels of evidence for predictive factors on treatment outcome in chronic pain

\begin{tabular}{ll}
\hline Level of evidence \\
\hline Strong & Consistent findings* in at least 2 high quality cohorts \\
Moderate & Consistent findings in at least two cohorts of which one high quality cohort \\
Limited & $\begin{array}{l}\text { Net number of high quality cohorts } \geq 1 \text { or consistent findings in at least } 3 \text { or more low } \\
\text { quality cohorts } \\
\text { Inconclusive }\end{array}$ \\
& $\begin{array}{l}\text { Inconsistent findings irrespective of study quality or less than } 3 \text { low quality cohorts } \\
\text { available }\end{array}$
\end{tabular}

${ }^{*}$ Consistent findings: $\geq 75 \%$ of the studies analyzing the association of a predictive factor and treatment outcome will pointed out the same direction.

\section{RESULTS}

\section{Study selection}

The results of the search and selection process are summarized in the flow chart in Fig. 1. Overall, the initial search yielded 1265 citations. After a first screening of the abstracts, 109 non-duplicate studies were selected and the full papers were retrieved. Fifty-one of these studies were potentially suitable for inclusion. The two reviewers (J.G. and I.E.L.) disagreed regarding the inclusion of 17 studies. After agreement, 13 of these studies were excluded according the criteria, and two were left undecided. Following a consensus meeting with the third reviewer (A.K.), one other study was included, making a total of 37 studies in the review. There 
were several reasons for exclusion: pain duration unclear (Brandwin \& Kewman, 1982; Barnes et al., 1989; Goldberg \& Maciewicz, 1994), cancer pain (Brandwin \& Kewman, 1982; Dworkin et al., 1986), use of changed scores between baseline and follow-up as a predictor of treatment outcome (mediator) (Dolce et al., 1986), outcome was sick leave or return to work (Haldorsen et al., 1998a; Haldorsen et al., 1998b), unclear whether the predictive factor was measured before treatment (Hamburgen et al., 1985), not just chronic pain (Jarvikoski et al., 1986; Heikkila et al., 1998; Sinclair \& Wallston, 2001), no treatment or unclear (Lee et al., 1989; Lacroix et al., 1990), and no psychological predictors (Daniel et al., 1985).

The results of the methodological quality assessment are presented in Appendix II. The quality score range varied between 9 (24\% of the total score) (Cairns et al., 1984 ) and 30 points (79\% of the total score) (Harkapaa et al., 1991; Niemisto et al., 2004). The cut-off point was set at 19 points ( $\geq 50 \%$ of the total score). Finally, 28 studies were qualified as high, with 19 points or more.

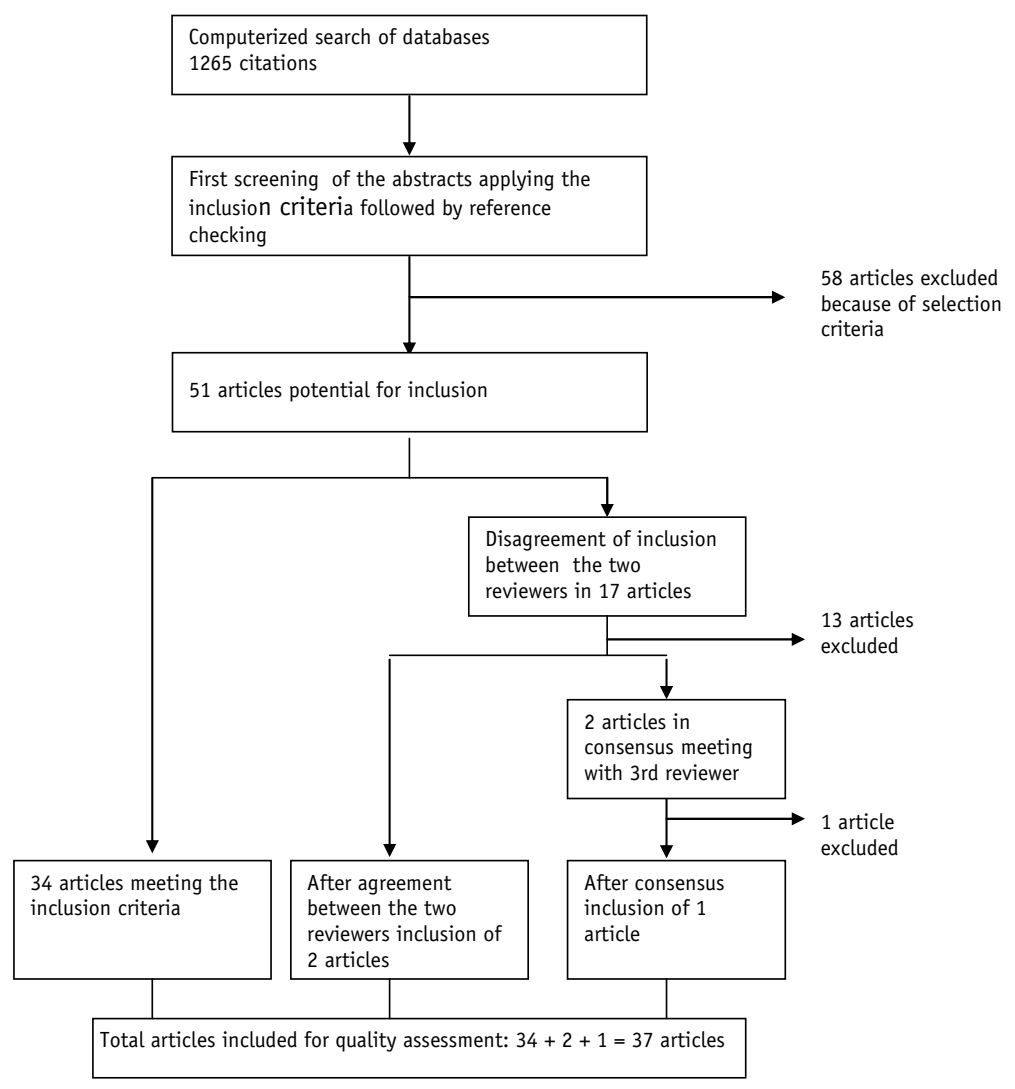




\section{Study characteristics}

The main study characteristics of all 37 studies are presented in Appendix III. The studies are listed alphabetically.

\section{Study design}

Twenty-four studies were prospective cohort studies and nine were RCTs. In two of the nine RCTs, patients were randomized to different treatment groups, while analysis of the predictive variables was performed for the group as a whole (Gale \& Funch, 1984; King et al., 2002). The study by Grahn et al. (2000) was based on a rehabilitation group and a matched control group, analyzing them independently. In the present review, we included the rehabilitation group only. Haazen et al. (1994) assigned patients to three treatment groups, based on a time criterion, and considered the group as a whole when analyzing the predictive variables.

\section{Treatment setting}

Twelve studies were performed in inpatient settings, seven of which were located in a rehabilitation centre (Trief \& Yuan, 1983; Kleinke \& Spangler, 1988; Haazen et al., 1994; Talo et al., 1994; Grahn et al., 2000; Bergstrom et al., 2001; Michaelson et al., 2004), and three in a hospital (Moore et al., 1986; Burchiel et al., 1995; Clark, 1996). Twenty-one studies were performed in outpatient settings, nine of which in a hospital setting (McCreary et al., 1979; Turner et al., 1983; Nelson et al., 1991; ter Kuile et al., 1995; North et al., 1996; Samwel et al., 2000; Hartrick et al., 2004; Niemisto et al., 2004; Riipinen et al., 2005), and eight in a rehabilitation setting (Rudy et al., 1995; Turk et al., 1998; Vendrig et al., 1999; Vendrig et al., 2000; Hutten et al., 2001; Gatchel et al., 2002; King et al., 2002). Two studies referred to the same cohort (Vendrig et al., 1999; Vendrig et al., 2000). The five remaining studies used both inpatient and outpatient settings.

\section{Study population}

The sample size varied from $n=20$ (Hartrick et al., 2004) to $n=476$ (Harkapaa et al., 1991). All studies included chronic pain patients with a pain duration of three months or more, a minimum mean pain duration of 20 months (Hartrick et al., 2004). and a maximum of 209 months (Clark, 1996). The mean age of the patients varied from 32.4 years (Rudy et al., 1995) to 54.9 years (Gatchel et al., 2002). Two studies included females only (Julkunen et al., 1988; King et al., 2002) and one study only males (Moore et al., 1986).

\section{Type of pain}

Most studies $(n=20)$ examined patients with chronic low back pain (LBP). Others examined temporomandibular pain $(n=2)$, musculoskeletal pain $(n=1)$, complex regional pain syndrome $(n=1)$, fibromyalgia $(n=2)$, back and neck pain $(n=1)$, 
cervico-brachialgia $(n=1)$, headache $(n=1)$. and a group of mixed pain diagnoses $(n=7)$.

\section{Treatment}

Subdivision of the treatment into three treatment groups resulted in 22 CBT studies, seven rehabilitation studies, and eight somatic treatment studies. Uniformity within the treatment groups was low. For example, CBT varied from mainly cognitive-behavioural therapy (Gale \& Funch, 1984; Kerns \& Haythornthwaite, 1988; Haazen et al., 1994; ter Kuile et al., 1995; Clark, 1996; Hildebrandt et al., 1997; Gatchel et al., 2002) to interdisciplinary pain treatment, with CBT as part of the programme (Trief \& Yuan, 1983; Moore et al., 1986; Kleinke \& Spangler, 1988; Harkapaa et al., 1991; Tota-Faucette et al., 1993; Chapman \& Pemberton, 1994; Rudy et al., 1995; Harkapaa et al., 1996; Turk et al., 1998; Vendrig et al., 1999; Vendrig et al., 2000; Michaelson et al., 2004). Rehabilitation studies included programmes focused on active exercises such as a work hardening programme (Bergstrom et al., 2001), aerobic exercise (Cairns et al., 1984; King et al., 2002), back school (Julkunen et al., 1988; Hutten et al., 2001), and a functional activation/physical exercise programme (Talo et al., 1994; Riipinen et al., 2005). Somatic treatment included invasive techniques (Samwel et al., 2000; Hartrick et al., 2004), spinal cord stimulation (Burchiel et al., 1995; North et al., 1996), or conservative treatment such as rest, analgesic medication, and instructions= (McCreary et al., 1979; Turner et al., 1983; Nelson et al., 1991).

\section{Follow-up}

In ten studies, there was no follow-up period and treatment outcome was measured at discharge (Aronoff \& Evans, 1982; Moore et al., 1986; Kerns \& Haythornthwaite, 1988; Kleinke \& Spangler, 1988; Tota-Faucette et al., 1993; Clark, 1996; Turk et al., 1998; Hutten et al., 2001; Gatchel et al., 2002; King et al., 2002). The shortest follow-up time was three months (Fredrickson et al., 1988; Harkapaa et al., 1991; Burchiel et al., 1995; Samwel et al., 2000) and the longest 66 months (Chapman \& Pemberton, 1994).

A percentage loss to follow-up of less than $20 \%$ was reported in 12 studies (Trief \& Yuan, 1983; Julkunen et al., 1988; Harkapaa et al., 1991; Talo et al., 1994; Rudy et al., 1995; Vendrig et al., 1999; Samwel et al., 2000; Vendrig et al., 2000; Bergstrom et al., 2001; Hutten et al., 2001; Niemisto et al., 2004). The other studies reported more loss to follow-up, or were inconsistent in mentioning loss to followup. 


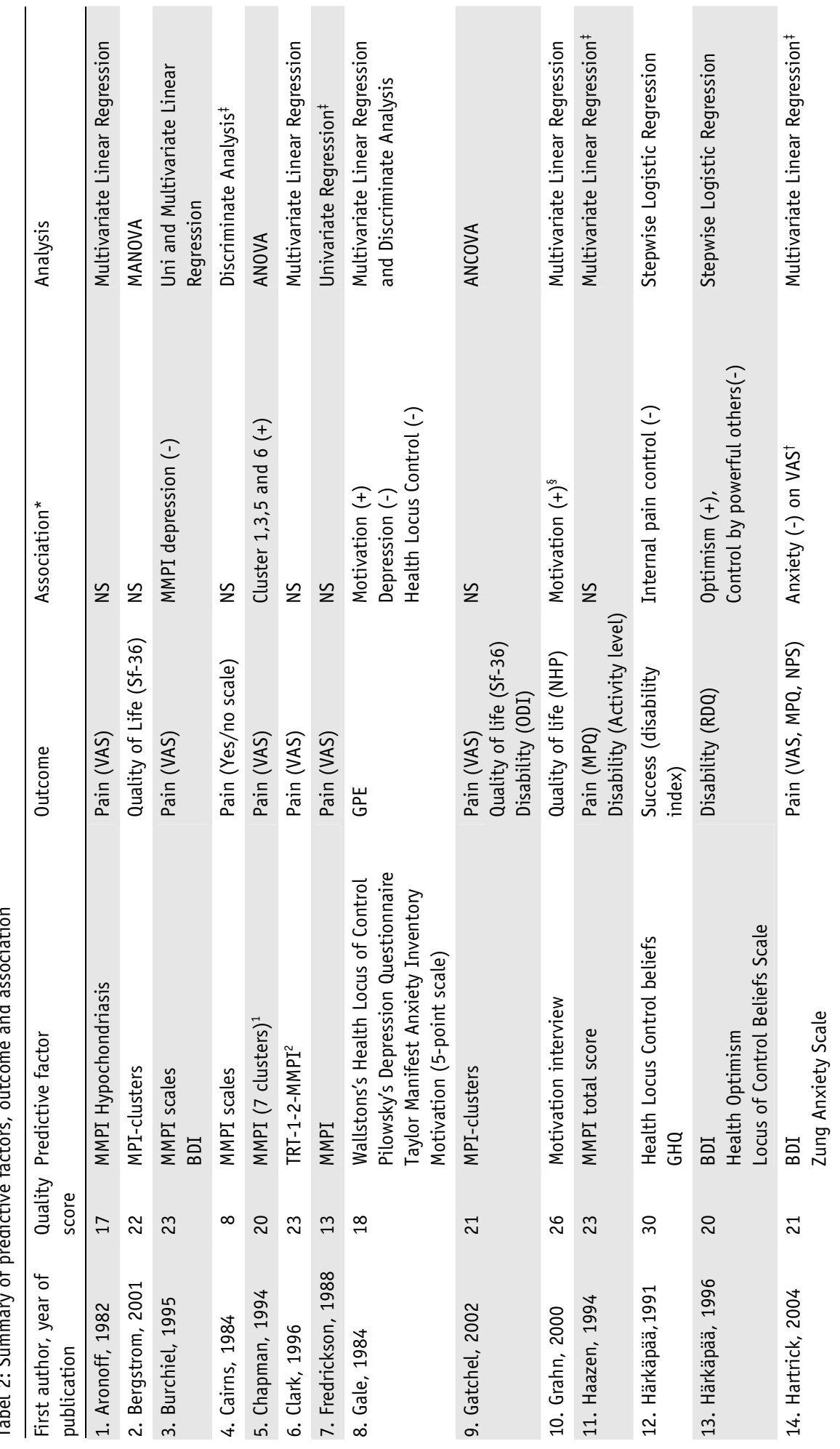




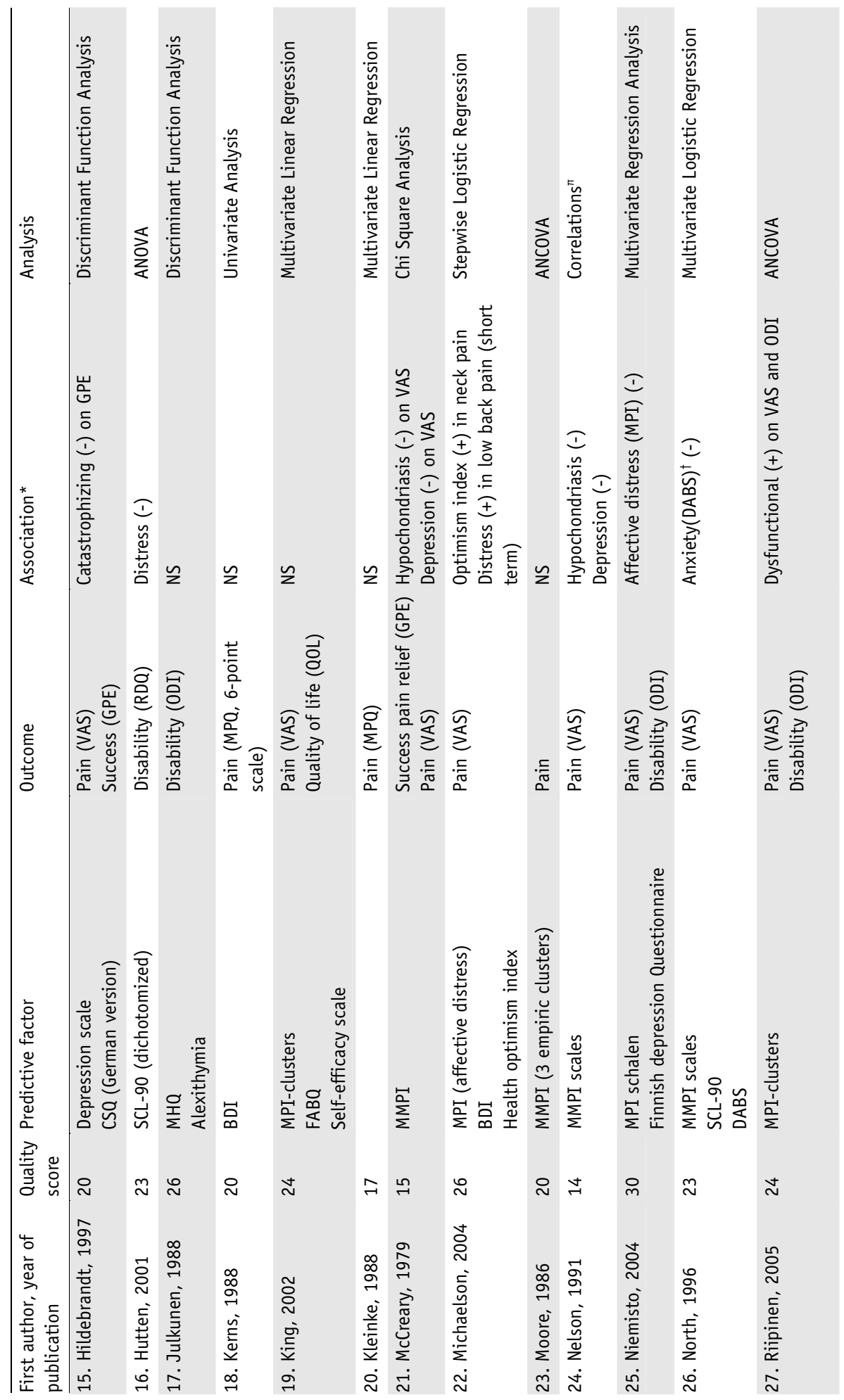




\section{CHAPTER 4}

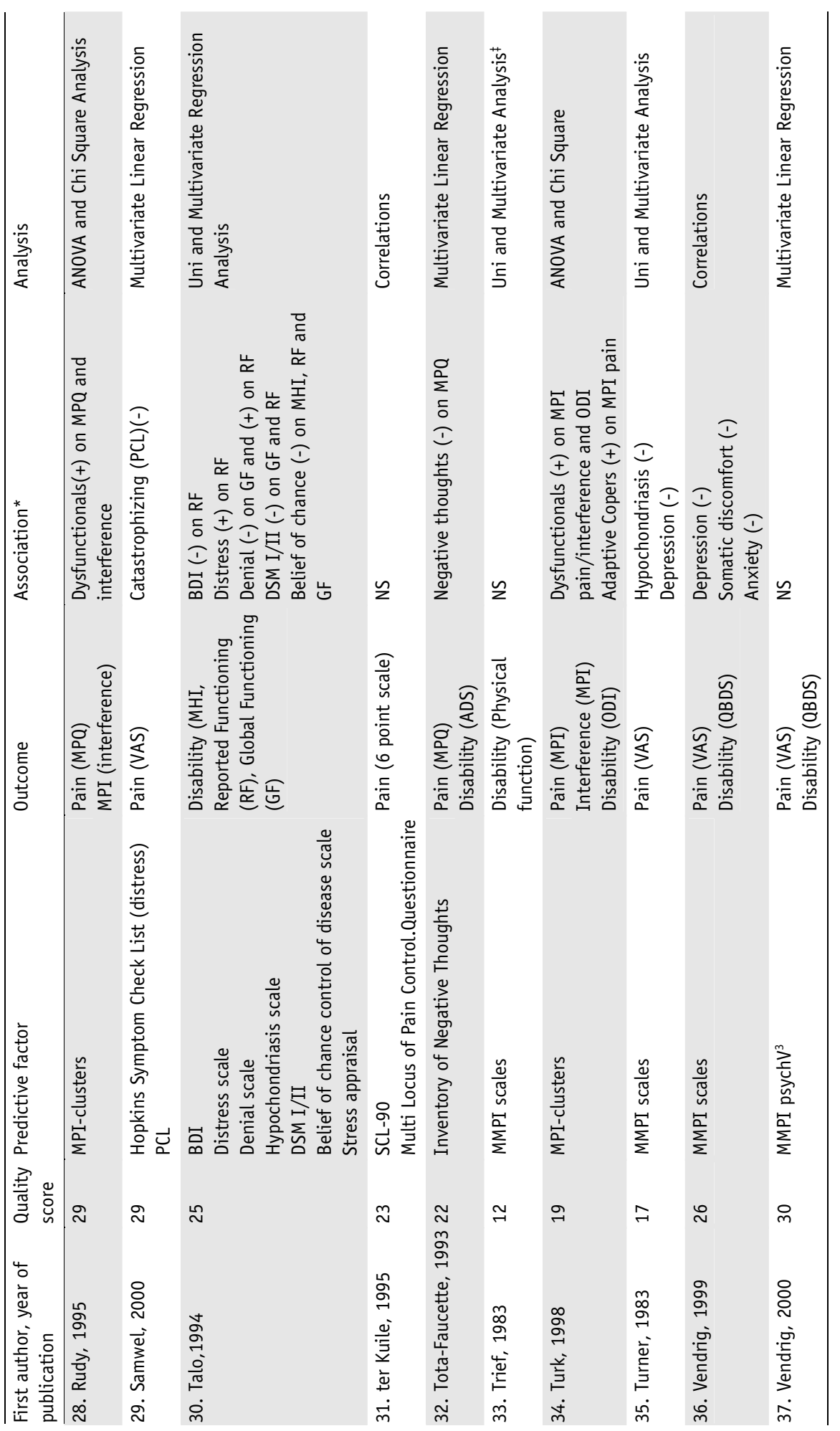




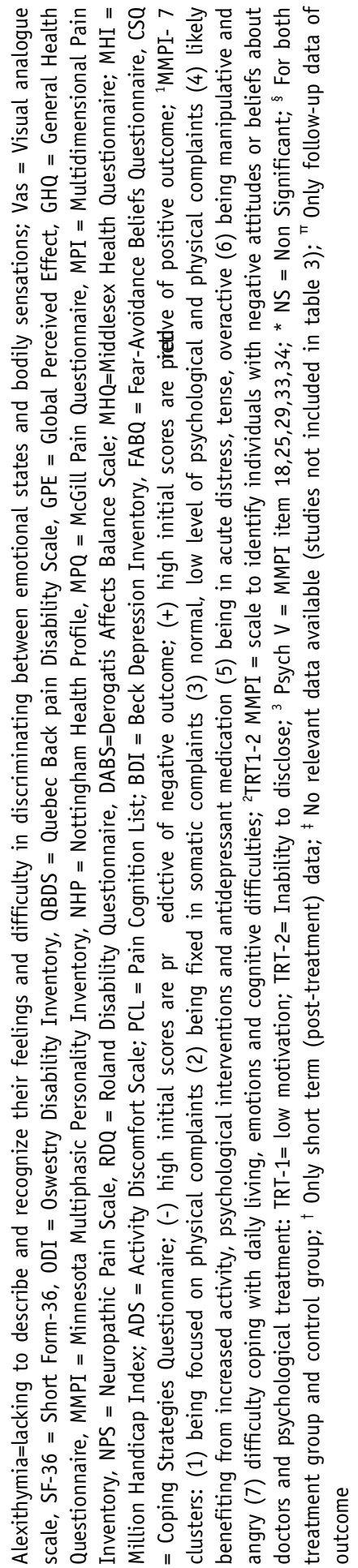




\section{Predictive variables and treatment outcome}

Table 2 presents a summary of the psychological predictors, treatment outcome, and association between predictors and outcome. Most studies analyzed a combination of sociodemographic, physical, and psychological predictors of treatment outcome. Approximately 34 different psychological measuring instruments were used to measure eight prognostic constructs (e.g., depression, somatic focus/hypochondriasis, general distress/general anxiety, fear-avoidance, pain control, motivation, optimism, and psychopathology) and one profile (dysfunctional type of patient), which already included a combination of factors (Appendix IV). In order to draw an accurate conclusion on the level of evidence, we merged all instruments that measured the same construct. Similar merging was carried out to form constructs of the outcome measures. Twenty different outcome measures were used to measure the constructs pain intensity, disability, success of treatment, and quality of life (Appendix V). In ten articles, two different constructs of outcome were measured (Turner et al., 1983; Tota-Faucette et al., 1993; Haazen et al., 1994; Rudy et al., 1995; Hildebrandt et al., 1997; Vendrig et al., 1999; Vendrig et al., 2000; King et al., 2002; Niemisto et al., 2004; Riipinen et al., 2005). Only two articles measured three different constructs (Turk et al., 1998; Gatchel et al., 2002).

The heterogeneity of the study populations, prognostic factors, treatments, outcomes and analyses did not enable statistical pooling of the results. Therefore, the evidence in this study was provided by a qualitative summary of the results, using the four levels of evidence (Table 1). The overall level of evidence of the predictor constructs per outcome construct is presented in Table 3. Only predictor constructs with at least two different studies available were included. Therefore, four predictors were removed from the final summary of results, namely self-efficacy (King et al., 2002), negative thoughts (Tota-Faucette et al., 1993), MMPI psychV (Vendrig et al., 2000), and empirically derived clusters MMPI (Moore et al., 1986).

In the qualitative analysis, studies that presented unclear information on the use of the total score or subscale scores were excluded (Fredrickson et al., 1988). Four studies were not added to the final overall level of evidence, for various reasons, as follows: no data of association provided (Trief \& Yuan, 1983; Cairns et al., 1984; Hartrick et al., 2004), or no moment when the baseline outcome was measured (Nelson et al., 1991).

\section{Overall level of evidence}

Finally, seven studies were rejected and qualitative analysis of the results was carried out in 30 articles (Table 3). The results are grouped per treatment (CBT, rehabilitation and somatic). High-quality studies were considered to be the most predictive and strongly contributed to the overall level of evidence. Low-quality 
studies, shown in italics, gave little weight to the evidence. Details of the various studies and their contribution to the level of evidence are summarized in Appendix VI.

\section{Depression}

The predictive value of depression on the outcome pain intensity was examined in nine studies, on GPE in four studies, and on disability in five studies. Strong evidence was found for the predictive value of depression on treatment outcome in terms of pain intensity and disability. High pre-treatment scores of depression predicted high pain intensity and disability on follow-up. In two studies, there was no follow-up and outcome was measured at discharge (Kerns \& Haythornthwaite, 1988; Kleinke \& Spangler, 1988). A detailed examination of the various treatment groups provided only limited evidence of depression on pain intensity and disability after CBT and somatic treatment, and on disability after a rehabilitation program.

A discrepancy was found between the MMPI depression scale (Turner et al., 1983; Kleinke \& Spangler, 1988; Burchiel et al., 1995; North et al., 1996; Vendrig et al., 1999) and the BDI (Kerns \& Haythornthwaite, 1988; Burchiel et al., 1995; Michaelson et al., 2004). The MMPI depression scale was highly associated with pain, with high scores predicting high pain intensity. The results found with the BDI were inconclusive.

\section{Somatic focus and hypochondriasis}

Ten studies examined the predictive value of somatic focus and/or hypochondriasis. No consistent results were found for either the total group or the various treatment groups, with the exception of the outcome disability and pain interference, where limited evidence was found in the CBT group. Patients who exhibit hypochondriac behaviour were predisposed to being more disabled after treatment.

\section{General distress/general anxiety}

Eleven studies examined general distress and/or general anxiety as a predictor of treatment outcome. In one study, both general distress (SCL-90) and anxiety (DABS) as predictors of treatment outcome in terms of pain intensity were studied (North et al., 1996). Only anxiety measured with DABS was negatively associated with pain intensity after treatment. With regard to the treatment group as a whole, the results showed limited evidence of high pre-treatment anxiety/distress predicting high pain intensity after treatment. However, with regard to the somatic treatment group alone, strong evidence was found that high pre-treatment anxiety/distress predicted high pain intensity. Contrasting results were found in the CBT group, where limited evidence was found that high pre-treatment anxiety/distress predicted an improvement in pain intensity. 
CHAPTER 4

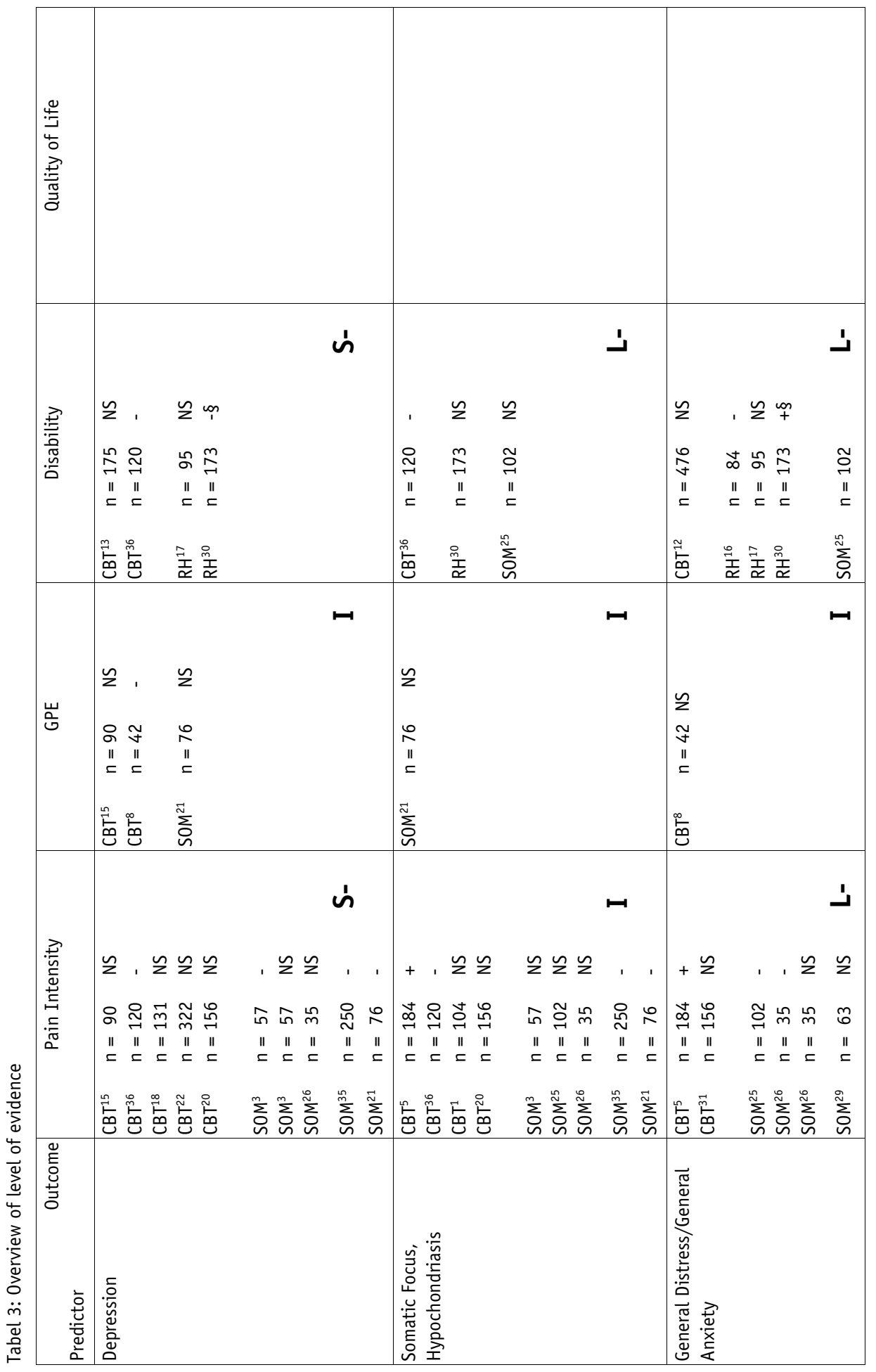




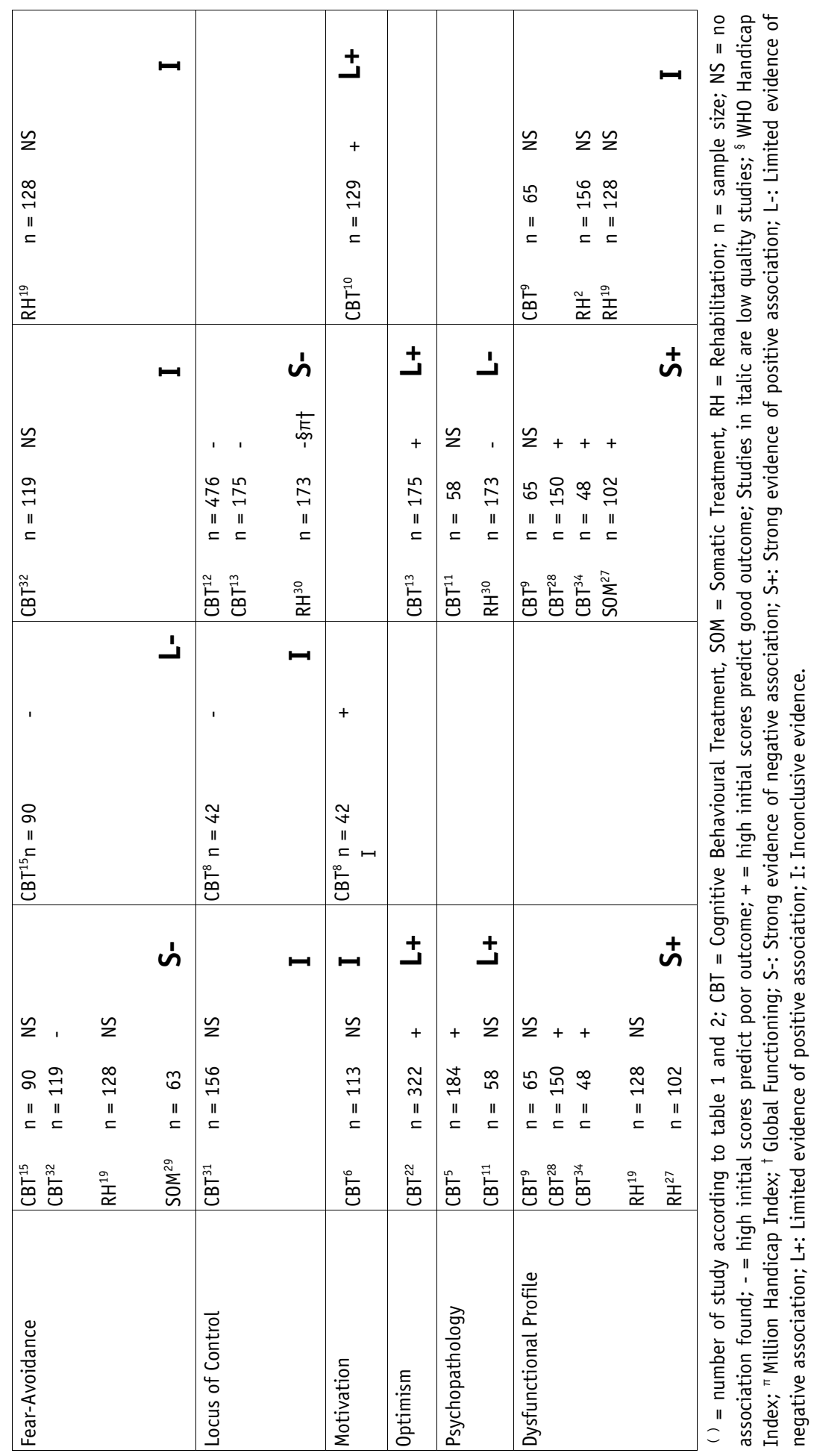




\section{CHAPTER 4}

\section{Fear avoidance}

The construct fear avoidance includes fear of movement and catastrophizing thoughts about pain. The predictive value of fear avoidance was examined in four studies. Overall, strong evidence was found for the predictive value of fear avoidance on pain intensity after treatment, i.e., high scores on catastrophizing predicted high pain intensity (Tota-Faucette et al., 1993; Hildebrandt et al., 1997; Samwel et al., 2000). With regard to the treatment groups, only limited evidence was found for the predictive value of fear avoidance on the outcome pain intensity in the CBT and somatic treatment groups.

\section{Locus of control}

Locus of control could either be related to the control of pain or refer more generally to the health locus of control; the main categories were internal locus of control and external locus of control (Gale \& Funch, 1984; Harkapaa et al., 1991; Talo et al., 1994; ter Kuile et al., 1995; Harkapaa et al., 1996). Strong evidence was found for internal locus of control as a predictor of disability. More internal control was predictive of less disability after treatment. With regard to the various treatment groups, only limited evidence was found for the predictive value of internal pain control on the outcome disability in the CBT and rehabilitation groups.

\section{Motivation}

Motivation as a predictor of treatment outcome was examined in three studies. Only limited evidence was found for the predictive value of high motivation on the improvement of quality of life after CBT.

\section{Optimism}

The predictive value of optimism on CBT outcome in terms of pain intensity and disability was examined in two studies. For both outcome variables, there was limited evidence that optimism is a positive predictor of treatment outcome.

Psychopathology

Psychopathology was measured in three studies. Two studies examined the predictive value of psychopathology on the level of pain intensity after treatment. Limited evidence was found for a positive association between psychopathology and the level of pain intensity after CBT, i.e., high scores on psychopathology predicted less pain after CBT. Limited evidence was found for a negative association between psychopathology and the level of disability after rehabilitation, i.e., high scores on psychopathology predicted more disability after rehabilitation.

\section{Dysfunctional profile}

The predictive value of the dysfunctional profile was examined in five studies. There was strong evidence that the dysfunctional type of patient had a better 
outcome in terms of pain intensity and disability. Furthermore, there was strong evidence that the dysfunctional type of patient predicted pain intensity - and disability reduction after CBT. Only limited evidence was found for pain reduction in the rehabilitation group and for disability reduction in the somatic treatment group.

\section{DISCUSSION}

To the best of our knowledge, this study is the first that systematically reviewed psychological predictive factors of treatment outcome in chronic non-cancer pain. Thirty studies suitable for the final overall evidence were identified. The heterogeneity of factors such as study population, predictive factors, and the applied treatments used in the various studies, did not allow for meta analysis. Therefore, the conclusions of this review are based on a qualitative analysis of the studies.

\section{Predictive factors}

The results of this review provided strong evidence for the predictive value of depression and fear avoidance on the level of pain intensity after treatment. High initial levels of depression and fear avoidance were predictive of high levels of pain intensity after treatment. Strong evidence was found for depression and locus of control as predictors of the level of disability after treatment. High levels of depression and of external locus of control were predictive of high levels of disability after treatment. There is strong evidence that the level of pain intensity and disability improved after treatment in patients typified as dysfunctional, especially after CBT. Limited evidence was found for general distress/anxiety, optimism, and psychopathology as predictors of treatment outcome in terms of pain intensity. Patients who score low on optimism and high on general distress and psychopathology have high levels of pain after treatment. There was limited evidence that a high level of fear avoidance was predictive of unsuccessful treatment outcome, measured with GPE. There was limited evidence that less optimism and high levels of somatic focus/hypochondriasis, general distress/anxiety, and psychopathology were predictive of high levels of disability after treatment. Limited evidence was found that high motivation levels predicted improvement on quality of life after treatment.

\section{Depression}

In our review, the inconsistencies found in studies that used the BDI (Kerns \& Haythornthwaite, 1988; Burchiel et al., 1995; Michaelson et al., 2004), and those that used the MMPI depression scale (McCreary et al., 1979; Turner et al., 1983; Kleinke \& Spangler, 1988; Burchiel et al., 1995; North et al., 1996; Vendrig et al., 1999), were worthy of note. The BDI did not appear to be a predictor of treatment 
outcome, while there was strong evidence that the MMPI depression scale had predictive value. Van der Hulst et al. (2005) reached a similar conclusion, but were unable to explain this finding. We propose that the divergent results may be related to the specific content of the scales. Originally, the BDI was developed and tested in normal and psychiatric populations (Steer et al., 1985). Those authors warned about a somatic component measured with the BDI, which could overestimate depression in patients with medical problems. Factor analysis of BDI scores obtained from chronic pain patients revealed separate factors assessing physical and somatic function, versus negative effect and cognitive functioning (Novy et al., 1995; Morley et al., 2002). Chronic pain patients seem to be especially prone to high scores on physical and somatic dimensions, which can artificially inflate the depression score (Williams \& Richardson, 1993). The MMPI depression scale applies more to the affective and cognitive components than to the somatic component of depression and, therefore, may show less contradiction of somatic and psychological problems. If depression is the most important, an unbiased instrument has more predictive power than an instrument that measures not only depression, but also the severity of the physical complaints.

\section{Fear avoidance}

According to the cognitive-oriented 'fear-avoidance model', catastrophizing, painrelated fear and depression are closely related in chronic pain patients (Vlaeyen et al., 1995a; Vlaeyen et al., 1995b). High levels of pain catastrophizing lead to painrelated fear, resulting in depression, disability and disuse. According to this model, it can be expected that the construct fear avoidance should have a similar predictive value to its intermediate factor depression. The results of this review showed that, as expected, fear avoidance was a strong predictor of pain intensity after treatment (Tota-Faucette et al., 1993; Samwel et al., 2000). Both these studies found that a negative orientation towards pain (catastrophizing) was predictive of high levels of pain intensity after treatment. Several studies have found that fear avoidance contributes in an important way to disability, suffering, and health care use in patients with chronic pain, often more than pain intensity (Vlaeyen et al., 1995b; McCracken et al., 1996; Asmundson et al., 1997; Crombez et al., 1999). It may therefore be an important target for intervention (McCracken \& Turk, 2002).

\section{Locus of control}

Locus of control is closely related to depression, fear avoidance, and pain. Feelings of helplessness have been shown to be associated with internal control and difficulty in performing daily activities (Harkapaa et al., 1991). Patients seem to be at risk for an unsatisfactory treatment outcome if they take little effort to control pain through active cognitive and behavioural strategies (Harkapaa et al., 1991; Tota-Faucette et al., 1993). The results of this review support this theory. 
Dysfunctional profile

The West Haven-Yale Multidimensional Pain Inventory (MPI) was developed to be able better to match treatment to different subgroups of patients with chronic pain (Turk, 2005). MPI clusters pain patients into three homogeneous psychosocial subgroups: dysfunctional patients; interpersonally distressed patients; and adaptive copers (Turk \& Rudy, 1988). The present review specifically focused on the predictive value of the dysfunctional profile, i.e., a profile characterized by a high level of pain, high interference of symptoms with life activities, high affective distress, low level of activity, and low feelings of life control (Rudy et al., 1989; Turk \& Rudy, 1990).

Our results show that patients typified as dysfunctional showed greater improvement after treatment of the outcomes pain intensity and disability. One interpretation of these results could be that this group of patients is most in need of treatment; they have the highest pain and disability levels, and there is greater room for improvement than in more functional patients (Carmody, 2001). In that sense, the dysfunctional profile would not be qualified as a pure psychological predictor; it consists of a combination of physical and psychological complaints and symptoms. It should be noted that studies assessing the predictive value of the two psychological components in this cluster separately, i.e., distress and control, reached different conclusions: if anything, high distress or low control predicted less effect of the intervention. Therefore, it cannot be excluded that the predictive value of the dysfunctional profile has its origins in it being an approximation of the baseline severity of the condition.

\section{Limitations}

Several limitations with regard to this review should be taken into account. Firstly, a review of cohort studies can contain several biases, which could over- or underestimate the final level of evidence. Although carefully conducted, a search strategy is not exhaustive and there is always a chance that not all studies were retrieved. The search strategy was limited to the English, Dutch, and German literature and we did not look at unpublished studies, but we are convinced that most of the relevant studies were included. Another source of bias can be the decision on which the level of evidence is based. Non-significant associations between a prognostic factor and treatment outcome, with no mention of the direction of the association, were disregarded. The exclusion of studies with insufficient information on non-significant prognostic factors could contribute to an overestimation of the strength of the evidence. Furthermore, despite attempting to evaluate studies of all types of pain, we ended up with 17 of 30 studies being on low back pain. In the same way, 18 of the 30 treatments were CBT. Thus, the qualitative results are biased towards those psychological factors that influence low back pain and towards those using CBT as the intervention. Care has to be taken when generalizing 
the results of all types of pain and treatment. Future research is necessary to confirm the conclusions of all pain states.

Secondly, when choosing cut-off points for the inclusion or exclusion of studies, the overall level of evidence remains arbitrary (van Tulder et al., 2003). When establishing a more comprehensive overview of the prognostic factors in chronic pain, a cut-off point of $50 \%$ was chosen, so that 30 of 37 studies were suitable for the overall level of evidence. After detailed examination of the data, we do not believe that this decision had a strong impact on the results of the review.

Thirdly, the overall level of evidence in this review disregarded the sub-grouping of patients, for example, on the basis of pain location and the specific treatment offered. This may have biased interpretation of the evidence. With regard to treatment, we tried to account for different types of intervention by clustering them into three categories: CBT, somatic treatment, and rehabilitation. Although numbers were small, there did not appear to be any major differences in the conclusion when looking at these separate clusters of treatment, with one exception: strong evidence was found that higher distress before treatment hampered the results of somatic interventions, while CBT seemed to be more effective in highly distressed patients. It may be speculated that CBT more specifically targets distress, and that a reduction of distress had a beneficial effect on other pain outcomes. Moreover, various trends should be mentioned, namely it seemed that CBT was more effective in terms of pain intensity in patients with high levels of anxiety/distress and psychopathology. No differences between treatments were observed in the other predictors. But again, numbers were too small to allow for definite conclusions and, moreover, it should be admitted that our categorization was, by necessity, very crude. Patients with certain psychological profiles could benefit more from CBT, but this will depend on the particular focus and/or components of the treatment. For example, highly depressed patients who are part of a CBT programme that includes a component aimed at reducing depression, may benefit more from this treatment than patients who are less depressed. On the other hand, highly depressed patients starting on somatic treatment, or a CBT treatment not specifically aimed at depression reduction, may not benefit as much. However, this kind of fine-grained analysis conflicts with the pooling of data that is the defining element of systematic reviews. Moreover, most studies did not provide detailed information about the exact components of the cognitive behavioural part of the treatment.

\section{Clinical relevance and recommendations}

Since the success rates of treatment in chronic pain populations still are inadequate, there is a need to identify patient-related factors that are predictive of treatment outcome. In this review, an attempt was made to discover the psycho- 
logical predictors of outcome, as a first step in the process of tailoring treatment to individual patients. Several comments can be made with regard to the findings.

Firstly, the choice of psychological assessment instrument is relevant. We encountered inconsistent results with two different measures of depression, and speculated that this might have been due to the inclusion of physical components in the BDI. Therefore, we recommend using an instrument for measuring depression that does not confound symptoms of depression with somatic complaints that may be due to the underlying medical condition.

Secondly, individual measures illustrate one aspect of the pain experience. The complexity of the pain experience in chronic pain calls for a more comprehensive approach. In order to account for this complexity, the use of multifactor biopsychological profiles as predictors of treatment outcome could be considered. The classification developed by Turk and Rudy of chronic pain patients into dysfunctionals, interpersonally distressed, and adaptive copers, is a first attempt to identify subgroups of patients that potentially require different treatment approaches (Turk \& Rudy, 1988). Indeed, this review showed that patients with a dysfunctional profile benefitted most from treatment. However, as previously discussed, it is as yet unclear which components in this cluster account for this effect.

Another potentially important profile could be based on the fear-avoidance conceptualization of chronic pain. The fear-avoidance model has become influential in the explanation of the transition from acute to chronic pain, and the persistence of pain and disability. Factors such as catastrophizing, fear of movement/(re)injury and depression are closely related and are highly interactive in chronic pain patients. This review found strong evidence for the predictive value of fear-avoidance variables as well as of depression, and the combination of these factors could constitute another promising profile. Moreover, the control that patients experience over their pain seems to be a relevant factor in the prediction of treatment outcome, and could thus be another relevant component in this profile. Future studies should establish whether such a profile does have more predictive value than the separate components of the profile.

Finally, this review was inconclusive with regard to the interaction between predictor variable and type of treatment. Although other studies support the idea that interventions that target cognitive factors would produce better outcomes than interventions that do not (de Jong et al., 2005a; de Jong et al., 2005b; Woby et al., 2007), the results of this review could not substantiate this finding. However, it is unclear from our review whether CBT treatments specifically targeted the psychological factors we were examining. Many treatment outcome studies into chronic pain use a multi-package approach, and the exact content of the intervention is not always clear. Future treatment outcome studies should be very specific regarding the focus of the various elements of the intervention. 


\section{REFERENCES}

Altman, D.G.(2001). Systematic reviews of evaluations of prognostic variables. Bmj 323(7306): $224-8$.

Ariens, G.A., van Mechelen, W., Bongers, P.M., Bouter, L.M. \&van der Wal, G.(2000). Physical risk factors for neck pain. Scand J Work Environ Health 26(1): 7-19.

Aronoff, G.M. \&Evans, W.0.(1982). The prediction of treatment outcome at a multidisciplinary pain center. Pain 14(1): 67-73.

Asmundson, G.J., Norton, G.R. \&Allerdings, M.D.(1997). Fear and avoidance in dysfunctional chronic back pain patients. Pain 69(3): 231-6.

Barnes, D., Smith, D., Gatchel, R.J. \&Mayer, T.G.(1989). Psychosocioeconomic predictors of treatment success/failure in chronic low-back pain patients. Spine 14(4): 427-30.

Bergstrom, G., Jensen, I.B., Bodin, L., Linton, S.J. \&Nygren, A.L.(2001). The impact of psychologically different patient groups on outcome after a vocational rehabilitation program for long-term spinal pain patients. Pain 93(3): 229-37.

Borge, J.A., Leboeuf-Yde, C. \&Lothe, J.(2001). Prognostic values of physical examination findings in patients with chronic low back pain treated conservatively: a systematic literature review. J Manipulative Physiol Ther 24(4): 292-5.

Borghouts, J.A., Koes, B.W. \&Bouter, L.M.(1998). The clinical course and prognostic factors of nonspecific neck pain: a systematic review. Pain 77(1): 1-13.

Brandwin, M.A. \&Kewman, D.G.(1982). MMPI indicators of treatment response to spinal epidural stimulation in patients with chronic pain and patients with movement disorders. Psychol Rep 51(3 Pt 2): 1059-64.

Burchiel, K.J., Anderson, V.C., Wilson, B.J., Denison, D.B., Olson, K.A. \&Shatin, D.(1995). Prognostic factors of spinal cord stimulation for chronic back and leg pain. Neurosurgery $36(6)$ : 1101-10; discussion 1110-1.

Cairns, D., Mooney, V. \&Crane, P.(1984). Spinal pain rehabilitation: inpatient and outpatient treatment results and development of predictors for outcome. Spine 9(1): 91-5.

Carmody, T.P.(2001). Psychosocial Subgroups, Coping, and Chronic Low-Back Pain. J Clin Psychol Med Set 8(3): 137-48.

Chapman, S.L. \&Pemberton, J.S.(1994). Prediction of treatment outcome from clinically derived MMPI clusters in rehabilitation for chronic low back pain. Clin J Pain 10(4): 267-76.

Clark, M.E.(1996). MMPI-2 Negative Treatment Indicators Content and Content Component Scales: Clinical Correlates and Outcome Prediction for Men With Chronic Pain. Psychol Assess 8(1): 32-38.

Cote, P., Cassidy, J.D., Carroll, L., Frank, J.W. \&Bombardier, C.(2001). A systematic review of the prognosis of acute whiplash and a new conceptual framework to synthesize the literature. Spine 26(19): E445-58.

Crombez, G., Vlaeyen, J.W., Heuts, P.H. \&Lysens, R.(1999). Pain-related fear is more disabling than pain itself: evidence on the role of pain-related fear in chronic back pain disability. Pain $80(1-2)$ : 329-39.

Daniel, M.S., Long, C., Hutcherson, W.L. \&Hunter, S.(1985). Psychological factors and outcome of electrode implantation for chronic pain. Neurosurgery 17(5): 773-7.

de Jong, J.R., Vlaeyen, J.W., Onghena, P., Cuypers, C., den Hollander, M. \&Ruijgrok, J.(2005a). Reduction of pain-related fear in complex regional pain syndrome type I: the application of graded exposure in vivo. Pain 116(3): 264-75.

de Jong, J.R., Vlaeyen, J.W., Onghena, P., Goossens, M.E., Geilen, M. \&Mulder, H.(2005b). Fear of movement/(re)injury in chronic low back pain: education or exposure in vivo as mediator to fear reduction? Clin J Pain 21(1): 9-17; discussion 69-72.

Dolce, J.J., Crocker, M.F. \&Doleys, D.M.(1986). Prediction of outcome among chronic pain patients. Behav Res Ther 24(3): 313-9.

Dworkin, R.H., Richlin, D.M., Handlin, D.S. \&Brand, L.(1986). Predicting treatment response in depressed and non-depressed chronic pain patients. Pain 24(3): 343-53. 
Dworkin, R.H., Turk, D.C., Farrar, J.T., Haythornthwaite, J.A., Jensen, M.P., Katz, N.P., Kerns, R.D., Stucki, G., Allen, R.R., Bellamy, N., Carr, D.B., Chandler, J., Cowan, P., Dionne, R., Galer, B.S., Hertz, S., Jadad, A.R., Kramer, L.D., Manning, D.C., Martin, S., McCormick, C.G., McDermott, M.P., McGrath, P., Quessy, S., Rappaport, B.A., Robbins, W., Robinson, J.P., Rothman, M., Royal, M.A., Simon, L., Stauffer, J.W., Stein, W., Tollett, J., Wernicke, J. \&Witter, J.(2005). Core outcome measures for chronic pain clinical trials: IMMPACT recommendations. Pain 113(1-2): 9-19.

Egger, M., Smith, G.D. \&Altman, D.G.(2001). Systematic Reviews in Health Care: Meta-analysis in context. London: BMJ Publishing Group, BMA House.

Feuerstein, M., Menz, L., Zastowney, T.R. \&Barron, B.A.(1994). Chronic pain and disability: Vocational outcomes following multidisciplinary rehabilitation. J Occup Rehabil 4(229-51.

Fredrickson, B.E., Trief, P.M., VanBeveren, P., Yuan, H.A. \&Baum, G.(1988). Rehabilitation of the patient with chronic back pain. A search for outcome predictors. Spine 13(3): 351-3.

Freeman, M.D., Croft, A.C. \&Rossignol, A.M.(1998). "Whiplash associated disorders: redefining whiplash and its management" by the Quebec Task Force. A critical evaluation. Spine 23(9): 1043-9.

Gale, E.N. \&Funch, D.P.(1984). Factors associated with successful outcome from behavioral therapy for chronic temporomandibular joint (TMJ) pain. J Psychosom Res 28(6): 441-8.

Gatchel, R.J.(2001). A biopsychosocial overview of pretreatment screening of patients with pain. Clin J Pain 17(3): 192-9.

Gatchel, R.J.(2004a). Award for distinguished professional contributions to applied research. Am Psychol 59(794-805.

Gatchel, R.J.(2004b). Comorbidity of chronic pain and mental health disorders: the biopsychosocial perspective. Am Psychol 59(8): 795-805.

Gatchel, R.J., Noe, C.E., Pulliam, C., Robbins, H., Deschner, M., Gajraj, N.M. \&Vakharia, A.S.(2002). A preliminary study of multidimensional pain inventory profile differences in predicting treatment outcome in a heterogeneous cohort of patients with chronic pain. Clin J Pain 18(3): 139-43.

Gatchel, R.J., Peng, Y.B., Peters, M.L., Fuchs, P.N. \&Turk, D.C.(2007). The biopsychosocial approach to chronic pain: scientific advances and future directions. Psychol Bull 133(4): 581-624.

Goldberg, R.T. \&Maciewicz, R.J.(1994). Prediction of pain rehabilitation outcomes by motivation measures. Disabil Rehabil 16(1): 21-5.

Grahn, B., Ekdahl, C. \&Borgquist, L.(2000). Motivation as a predictor of changes in quality of life and working ability in multidisciplinary rehabilitation. A two-year follow-up of a prospective controlled study in patients with prolonged musculoskeletal disorders. Disabil Rehabil 22(15): 639-54.

Haazen, I.W.C.J., Vlaeyen, J.W.S., Kole-Snijders, A., van Eek, H. \&van Es, F.D.(1994). Behavioral rehabilitation of chronic low back pain: searching for predictors of treatment outcome. $J$ Rehabil Sci $7(2): 34-43$.

Haldorsen, E.M., Indahl, A. \&Ursin, H.(1998a). Patients with low back pain not returning to work. A $12-$ month follow-up study. Spine 23(11): 1202-7; discussion 1208.

Haldorsen, E.M., Kronholm, K., Skouen, J.S. \&Ursin, H.(1998b). Predictors for outcome of a multi-modal cognitive behavioural treatment program for low back pain patients-a 12-month follow-up study. Eur J Pain 2(4): 293-307.

Hamburgen, M.E., Jennings, C.A., Maruta, T. \&Swanson, D.W.(1985). Failure of a predictive scale in identifying patients who may benefit from a pain management program: follow-up data. Pain 23(3): 253-8.

Harkapaa, K., Jarvikoski, A. \&Estlander, A.M.(1996). Health optimism and control beliefs as predictors for treatment outcome of a multimodal back treatment program. Psychol \& Health 12(123-34.

Harkapaa, K., Jarvikoski, A., Mellin, G., Hurri, H. \&Luoma, J.(1991). Health locus of control beliefs and psychological distress as predictors for treatment outcome in low-back pain patients: results of a 3month follow-up of a controlled intervention study. Pain 46(1): 35-41.

Hartrick, C.T., Kovan, J.P. \&Naismith, P.(2004). Outcome prediction following sympathetic block for complex regional pain syndrome. Pain Practice 4(3): 222-28.

Heikkila, H., Heikkila, E. \&Eisemann, M.(1998). Predictive factors for the outcome of a multidisciplinary pain rehabilitation programme on sick-leave and life satisfaction in patients with whiplash trauma and other myofascial pain: a follow-up study. Clin Rehabil 12(6): 487-96. 
Hildebrandt, J., Pfingsten, M., Saur, P. \&Jansen, J.(1997). Prediction of success from a multidisciplinary treatment program for chronic low back pain. Spine 22(9): 990-1001.

Hudak, P.L., Cole, D.C. \&Haines, A.T.(1996). Understanding prognosis to improve rehabilitation: the example of lateral elbow pain. Arch Phys Med Rehabil 77(6): 586-93.

Hutten, M.M., Hermens, H.J. \&Zilvold, G.(2001). Differences in treatment outcome between subgroups of patients with chronic low back pain using lumbar dynamometry and psychological aspects. Clin Rehabil 15(5): 479-88.

Jarvikoski, A., Harkapaa, K. \&Mellin, G.(1986). Symptoms of psychological distress and treatment effects with low-back pain patients. Pain 25(3): 345-55.

Julkunen, J., Hurri, H. \&Kankainen, J.(1988). Psychological factors in the treatment of chronic low back pain. Follow-up study of a back school intervention. Psychother Psychosom 50(4): 173-81.

Kerns, R.D. \&Haythornthwaite, J.A.(1988). Depression among chronic pain patients: cognitivebehavioral analysis and effect on rehabilitation outcome. J Consult Clin Psychol 56(6): 870-6.

King, S.J., Wessel, J., Bhambhani, Y., Sholter, D. \&Maksymowych, W.(2002). Predictors of success of intervention programs for persons with fibromyalgia. J Rheumatol 29(5): 1034-40.

Kleinke, C.L. \&Spangler, A.S., Jr.(1988). Predicting treatment outcome of chronic back pain patients in a multidisciplinary pain clinic: methodological issues and treatment implications. Pain 33(1): 41-8.

Kraemer, H.C., Wilson, G.T., Fairburn, C.G. \&Agras, W.S.(2002). Mediators and moderators of treatment effects in randomized clinical trials. Arch Gen Psychiatry 59(10): 877-83.

Kuijpers, T., van der Windt, D.A., van der Heijden, G.J. \&Bouter, L.M.(2004). Systematic review of prognostic cohort studies on shoulder disorders. Pain 109(3): 420-31.

Lacroix, J.M., Powell, J., Lloyd, G.J., Doxey, N.C., Mitson, G.L. \&Aldam, C.F.(1990). Low-back pain. Factors of value in predicting outcome. Spine 15(6): 495-9.

Lee, P.W., Chow, S.P., Lieh-Mak, F., Chan, K.C. \&Wong, S.(1989). Psychosocial factors influencing outcome in patients with low-back pain. Spine 14(8): 838-43.

McCracken, L.M., Gross, R.T., Aikens, J. \&Carnrike, C.L., Jr.(1996). The assessment of anxiety and fear in persons with chronic pain: a comparison of instruments. Behav Res Ther 34(11-12): 927-33.

McCracken, L.M. \&Turk, D.C.(2002). Behavioral and cognitive-behavioral treatment for chronic pain: outcome, predictors of outcome, and treatment process. Spine 27(22): 2564-73.

McCreary, C., Turner, J. \&Dawson, E.(1979). The MMPI as a predictor of response to conservative treatment for low back pain. J Clin Psychol 35(2): 278-84.

Michaelson, P., Sjolander, P. \&Johansson, H.(2004). Factors predicting pain reduction in chronic back and neck pain after multimodal treatment. Clin J Pain 20(6): 447-54.

Moore, J.E., Armentrout, D.P., Parker, J.C. \&Kivlahan, D.R.(1986). Empirically derived pain-patient MMPI subgroups: prediction of treatment outcome. J Behav Med 9(1): 51-63.

Morley, S., Williams, A.C. \&Black, S.(2002). A confirmatory factor analysis of the Beck Depression Inventory in chronic pain. Pain 99(1-2): 289-98.

Nelson, D.V., Turner, J.A. \&McCreary, C.(1991). MMPI short forms as predictors of response to conservative treatment for low back pain. J Clin Psychol 47(4): 533-7.

Niemisto, L., Sarna, S., Lahtinen-Suopanki, T., Lindgren, K.A. \&Hurri, H.(2004). Predictive factors for 1year outcome of chronic low back pain following manipulation, stabilizing exercises, and physician consultation or physician consultation alone. J Rehabil Med 36(3): 104-9.

North, R.B., Kidd, D.H., Wimberly, R.L. \&Edwin, D.(1996). Prognostic value of psychological testing in patients undergoing spinal cord stimulation: a prospective study. Neurosurgery 39(2): 301-10; discussion 310-1.

Novy, D.M., Nelson, D.V., Berry, L.A. \&Averill, P.M.(1995). What does the Beck Depression Inventory measure in chronic pain?: a reappraisal. Pain 61(2): 261-70.

Riipinen, M., Niemisto, L., Lindgren, K.A. \&Hurri, H.(2005). Psychosocial differences as predictors for recovery from chronic low back pain following manipulation, stabilizing exercises and physician consultation or physician consultation alone. J Rehabil Med 37(3): 152-8.

Rudy, T.E., Turk, D.C., Kubinski, J.A. \&Zaki, H.S.(1995). Differential treatment responses of TMD patients as a function of psychological characteristics. Pain 61(1): 103-12.

Rudy, T.E., Turk, D.C., Zaki, H.S. \&Curtin, H.D.(1989). An empirical taxometric alternative to traditional classification of temporomandibular disorders. Pain 36(3): 311-20. 
Samwel, H., Slappendel, R., Crul, B.J. \&Voerman, V.F.(2000). Psychological predictors of the effectiveness of radiofrequency lesioning of the cervical spinal dorsal ganglion (RF-DRG). Eur J Pain 4(2): 149-55.

Scholten-Peeters, G.G., Verhagen, A.P., Bekkering, G.E., van der Windt, D.A., Barnsley, L., Oostendorp, R.A. \&Hendriks, E.J.(2003). Prognostic factors of whiplash-associated disorders: a systematic review of prospective cohort studies. Pain 104(1-2): 303-22.

Sinclair, V.G. \&Wallston, K.A.(2001). Predictors of improvement in a cognitive-behavioral intervention for women with rheumatoid arthritis. Ann Behav Med 23(4): 291-7.

Steer, R.A., Beck, A.T. \&Garrison, B., Applications of the Beck Depression Inventory. In: Sartorius, N. \&Ban, T. A. (Eds.), Assessment of Depression, Springer, Heidelberg, 1985, pp. 123-142.

Talo, S., Puukka, P., Rytokoski, U., Ronnemaa, T. \&Kallio, V.(1994). Can treatment outcome of chronic low back pain be predicted? Psychological disease consequences clarifying the issue. Clin J Pain 10(2): 107-21.

ter Kuile, M.M., Spinhoven, P. \&Linssen, A.C.(1995). Responders and nonresponders to autogenic training and cognitive self-hypnosis: prediction of short- and long-term success in tension-type headache patients. Headache 35(10): 630-6.

Tota-Faucette, M.E., Gil, K.M., Williams, D.A., Keefe, F.J. \&Goli, V.(1993). Predictors of response to pain management treatment. The role of family environment and changes in cognitive processes. Clin $\mathrm{J}$ Pain 9(2): 115-23.

Trief, P.M. \&Yuan, H.A.(1983). The use of the MMPI in a chronic back pain rehabilitation program. J Clin Psychol 39(1): 46-53.

Turk, D.C.(1990). Customizing treatment for chronic pain patients: who, what, and why. Clin J Pain 6(4): 255-70.

Turk, D.C.(2005). The potential of treatment matching for subgroups of patients with chronic pain: lumping versus splitting. Clin J Pain 21(1): 44-55; discussion 69-72.

Turk, D.C., Okifuji, A., Sinclair, J.D. \&Starz, T.W.(1998). Differential responses by psychosocial subgroups of fibromyalgia syndrome patients to an interdisciplinary treatment. Arthritis Care Res 11(5): 397-404.

Turk, D.C. \&Rudy, T.E.(1988). Toward an empirically derived taxonomy of chronic pain patients: integration of psychological assessment data. J Consult Clin Psychol 56(2): 233-8.

Turk, D.C. \&Rudy, T.E.(1990). The robustness of an empirically derived taxonomy of chronic pain patients. Pain 43(1): 27-35.

Turner, J.A., Holtzman, S. \&Mancl, L.(2007). Mediators, moderators, and predictors of therapeutic change in cognitive-behavioral therapy for chronic pain. Pain 127(3): 276-86.

Turner, J.A., Robinson, J. \&McCreary, C.P.(1983). Chronic low back pain: predicting response to nonsurgical treatment. Arch Phys Med Rehabil 64(11): 560-3.

van der Hulst, M., Vollenbroek-Hutten, M.M. \&Ijzerman, M.J.(2005). A systematic review of sociodemographic, physical, and psychological predictors of multidisciplinary rehabilitation-or, back school treatment outcome in patients with chronic low back pain. Spine 30(7): 813-25.

van Tulder, M., Furlan, A., Bombardier, C. \&Bouter, L.(2003). Updated method guidelines for systematic reviews in the cochrane collaboration back review group. Spine 28(12): 1290-9.

Vendrig, A.A., Derksen, J.J. \&de Mey, H.R.(1999). Utility of Selected MMPI-2 Scales in the Outcome Prediction for Patients With Chronic Back Pain. Psychol Assess 11(3): 381-85.

Vendrig, A.A., Derksen, J.J. \&de Mey, H.R.(2000). MMPI-2 Personality Psychopathology Five (PSY-5) and prediction of treatment outcome for patients with chronic back pain. J Pers Assess 74(3): 423-38.

Vlaeyen, J.W., Kole-Snijders, A.M., Boeren, R.G. \&van Eek, H.(1995a). Fear of movement/(re)injury in chronic low back pain and its relation to behavioral performance. Pain 62(3): 363-72.

Vlaeyen, J.W.S., Kole-Snijders, A.M.J., Rotteveel, A.M. \&Ruesink, R.(1995b). The role of fear of movement/(re)injury in pain disability. J Occup Rehabil 5(4): 235-52.

Williams, A.C. \&Richardson, P.H.(1993). What does the BDI measure in chronic pain? Pain 55(2): 25966.

Woby, S.R., Roach, N.K., Urmston, M. \&Watson, P.J.(2007). The relation between cognitive factors and levels of pain and disability in chronic low back pain patients presenting for physiotherapy. Eur $\mathrm{J}$ Pain 11(8): 869-77. 


\section{APPENDIX I \\ Check list for methodological and informative quality of predictive prospective studies in patients with chronic pain}

\section{Criteria}

\section{Study Design}

1. Main purpose of the study is psychological predictors of treatment outcome

Patient selection

2. Selection defined in relationship to onset of treatment (inception cohort)

3. Description of source population contains age, gender, setting and type of pain

4. Appropriate description of relevant inclusion and exclusion criteria

\section{Response}

5. Response $\geq 75 \%$

6. Information presented about patient/disease characteristics of non-responders versus responders or no selective response

Follow-up

7. Follow-up at least 3 months after treatment

8. Drop-outs/loss to follow-up $<20 \%$

9. Information presented about completers versus loss to follow-up/drop-outs

Treatment

10. Explicitly described with no co-interventions

11. Treatment is standardized (both for RCT's as for cohort studies)

Predictive factors

12. Measuring instruments are valid and reliable (internal validity)

13. Baseline information of all psychological predictive factors

Outcome

14. Outcome measures are standardized and valid and reliable

15. Are relevant outcome measures used?: pain (reduction), disability, Quality of life, Global Perceived Effect.

16. Baseline information of all relevant outcome measures

Analysis

17. Univariate analysis presented with two by two tables

18. Multivariate analysis with adjusting for confounding

19. Presentation of all multivariate outcome and confidence intervals

Yes $=2$ points, Not clear $=1$ point and No $=0$ points; Maximum of 38 points 


\section{APPENDIX II}

\section{Methodological quality assessment of the predictive studies}

\begin{tabular}{|c|c|c|c|c|c|c|c|c|c|c|c|c|c|c|c|c|c|c|c|c|c|}
\hline Study & A & B & C & $\mathrm{D}$ & $E$ & $\mathrm{~F}$ & G & H & I & $\mathrm{J}$ & $\mathrm{K}$ & $\mathrm{L}$ & M & $\mathrm{N}$ & 0 & $\mathrm{P}$ & Q & $\mathrm{R}$ & $S$ & $\begin{array}{l}\text { Quality } \\
\text { Score }\end{array}$ & $\begin{array}{c}\text { Score } \\
(\%)\end{array}$ \\
\hline Härkäpää et al.(1991) & 2 & 2 & 2 & 2 & 0 & 0 & 2 & 2 & 0 & 1 & 1 & 2 & 2 & 2 & 2 & 2 & 2 & 2 & $L$ & 30 & 79 \\
\hline Niemisto et al. (2004) & 2 & 2 & 2 & 2 & 0 & 0 & 2 & 2 & 0 & 2 & 2 & 2 & 0 & 2 & 2 & 2 & 2 & 2 & 2 & 30 & 79 \\
\hline Vendrig et al. (2000) & 2 & 2 & 2 & 1 & 2 & 0 & 2 & 2 & 1 & 1 & 1 & 2 & 2 & 2 & 2 & 2 & 0 & 2 & 2 & 30 & 79 \\
\hline Rudy et al. (1995) & 2 & 2 & 2 & 2 & 2 & 0 & 2 & 2 & 0 & 1 & 2 & 2 & 2 & 2 & 2 & 2 & 2 & 0 & 0 & 29 & 76 \\
\hline Samwel et al. (2000) & 2 & 2 & 2 & 2 & 2 & 0 & 2 & 2 & 0 & 2 & 2 & 2 & 2 & 2 & 2 & 2 & 1 & 0 & 0 & 29 & 76 \\
\hline Grahn et al. (2000) & 1 & 2 & 2 & 2 & 0 & 0 & 2 & 0 & 0 & 2 & 1 & 1 & 2 & 1 & 2 & 2 & 2 & 2 & 2 & 26 & 68 \\
\hline Julkunen et al. (1988) & 2 & 2 & 1 & 2 & 2 & 0 & 2 & 2 & 0 & 1 & 0 & 2 & 2 & 2 & 2 & 2 & 2 & 0 & 0 & 26 & 68 \\
\hline Michaelson et al. (2004) & 2 & 2 & 2 & 2 & 0 & 0 & 2 & 0 & 2 & 1 & 0 & 2 & 0 & 2 & 2 & 2 & 1 & 2 & 2 & 26 & 68 \\
\hline Vendrig et al. (1999) & 2 & 2 & 2 & 0 & 0 & 0 & 2 & 2 & 2 & 1 & 1 & 2 & 2 & 2 & 2 & 2 & 2 & 0 & 0 & 26 & 68 \\
\hline Talo et al. (1994) & 2 & 2 & 2 & 2 & 2 & 0 & 2 & 2 & 0 & 1 & 2 & 2 & 0 & 2 & 2 & 0 & 0 & 1 & 1 & 25 & 66 \\
\hline King et al. (2002) & 2 & 2 & 2 & 2 & 0 & 1 & 0 & 0 & 2 & 1 & 2 & 2 & 0 & 2 & 2 & 0 & 2 & 1 & 1 & 24 & 63 \\
\hline Riipinen et al. (2005) & 2 & 2 & 1 & 2 & 0 & 0 & 2 & 0 & 0 & 1 & 2 & 2 & 2 & 2 & 2 & 2 & 2 & 0 & 0 & 24 & 63 \\
\hline Burchiel et al. (1995) & 2 & 2 & 2 & 2 & 0 & 0 & 2 & 0 & 0 & 2 & 0 & 2 & 0 & 2 & 2 & 2 & 2 & 1 & 0 & 23 & 61 \\
\hline Clark et al. (1996) & 2 & 2 & 2 & 2 & 2 & 0 & 0 & 0 & 0 & 0 & 2 & 2 & 2 & 2 & 2 & 0 & 1 & 1 & 1 & 23 & 61 \\
\hline Haazen et al. (1994) & 2 & 2 & 2 & 2 & 2 & 0 & 2 & 0 & 0 & 0 & 1 & 2 & 0 & 2 & 2 & 0 & 0 & 2 & 2 & 23 & 61 \\
\hline Hutten et al. (2001) & 2 & 2 & 2 & 2 & 0 & 0 & 0 & 2 & 0 & 1 & 0 & 2 & 2 & 2 & 2 & 2 & 2 & 0 & 0 & 23 & 61 \\
\hline North et al. (1996) & 2 & 2 & 2 & 2 & 0 & 0 & 2 & 0 & 0 & 1 & 2 & 2 & 0 & 2 & 2 & 0 & 0 & 2 & 2 & 23 & 61 \\
\hline TerKuile et al. (1995) & 2 & 2 & 2 & 2 & 0 & 0 & 2 & 0 & 2 & 1 & 2 & 2 & 0 & 2 & 2 & 0 & 2 & 0 & 0 & 23 & 61 \\
\hline Bergstrom et al. (2001) & 2 & 2 & 2 & 2 & 0 & 0 & 2 & 2 & 0 & 0 & 0 & 2 & 2 & 1 & 2 & 0 & 2 & 1 & 0 & 22 & 59 \\
\hline Tota-Faucette et al. (1993) & 2 & 2 & 2 & 2 & 0 & 0 & 0 & 0 & 0 & 0 & 0 & 2 & 0 & 2 & 2 & 2 & 2 & 2 & 2 & 22 & 59 \\
\hline Gatchel et al. (2002) & 2 & 2 & 2 & 2 & 0 & 0 & 0 & 0 & 0 & 1 & 0 & 2 & 2 & 2 & 2 & 2 & 2 & 0 & 0 & 21 & 55 \\
\hline Hartrick et al. (2004) & 2 & 2 & 2 & 0 & 2 & 1 & 2 & 0 & 0 & 0 & 2 & 2 & 0 & 2 & 2 & 0 & 2 & 0 & 0 & 21 & 55 \\
\hline Kerns et al. (1988) & 1 & 2 & 2 & 2 & 0 & 0 & 0 & 0 & 0 & 1 & 1 & 2 & 2 & 2 & 2 & 2 & 2 & 0 & 0 & 21 & 55 \\
\hline Chapman et al. (1994) & 2 & 1 & 1 & 0 & 0 & 2 & 2 & 0 & 0 & 0 & 0 & 2 & 2 & 2 & 2 & 2 & 2 & 0 & 0 & 20 & 53 \\
\hline Härkäpää et al. (1996) & 2 & 2 & 2 & 0 & 0 & 0 & 2 & 0 & 0 & 0 & 0 & 2 & 0 & 2 & 2 & 0 & 2 & 2 & 2 & 20 & 53 \\
\hline Hildebrandt et al. (1997) & 2 & 2 & 2 & 2 & 0 & 0 & 2 & 0 & 0 & 0 & 1 & 2 & 1 & 2 & 2 & 0 & 2 & 0 & 0 & 20 & 53 \\
\hline Moore et al. (1986) & 2 & 2 & 2 & 1 & 0 & 0 & 0 & 0 & 0 & 1 & 0 & 2 & 2 & 2 & 2 & 2 & 2 & 0 & 0 & 20 & 53 \\
\hline Turk et al. (1998) & 2 & 2 & 2 & 1 & 0 & 0 & 0 & 0 & 0 & 1 & 0 & 2 & 2 & 2 & 2 & 2 & 1 & 0 & 0 & 19 & 50 \\
\hline Gale et al. (1984) & 2 & 2 & 2 & 0 & 0 & 0 & 2 & 0 & 0 & 0 & 0 & 2 & 0 & 2 & 2 & 0 & 2 & 2 & 0 & 18 & 47 \\
\hline Aronoff et al. (1982) & 2 & 2 & 1 & 0 & 0 & 0 & 0 & 0 & 0 & 0 & 0 & 2 & 2 & 2 & 2 & 2 & 2 & 0 & 0 & 17 & 45 \\
\hline Kleinke et al. (1988) & 2 & 2 & 2 & 0 & 0 & 0 & 0 & 0 & 0 & 1 & 0 & 2 & 0 & 2 & 2 & 2 & 0 & 1 & 1 & 17 & 45 \\
\hline Turner et al. (1983) & 2 & 2 & 2 & 1 & 0 & 0 & 2 & 0 & 2 & 0 & 0 & 2 & 0 & 2 & 2 & 0 & 0 & 0 & 0 & 17 & 45 \\
\hline McCreary et al. (1979) & 2 & 2 & 1 & 0 & 0 & 0 & 2 & 0 & 0 & 0 & 0 & 2 & 0 & 2 & 2 & 0 & 2 & 0 & 0 & 15 & 39 \\
\hline Nelson et al. (1991) & 2 & 2 & 2 & 0 & 0 & 0 & 2 & 0 & 0 & 0 & 0 & 2 & 0 & 2 & 2 & 0 & 0 & 0 & 0 & 14 & 37 \\
\hline Fredrickson et al. (1988) & 2 & 2 & 2 & 0 & 0 & 0 & 2 & 0 & 0 & 0 & 0 & 2 & 0 & 1 & 2 & 0 & 0 & 0 & 0 & 13 & 34 \\
\hline Trief et al. (1983) & 2 & 2 & 2 & 0 & 0 & 0 & 2 & 2 & 0 & 0 & 0 & 2 & 0 & 0 & 0 & 0 & 0 & 0 & 0 & 12 & 32 \\
\hline Cairns et al. (1984) & 1 & 2 & 2 & 0 & 0 & 0 & 2 & 0 & 0 & 0 & 0 & 2 & 0 & 0 & 0 & 0 & 0 & 0 & 0 & 9 & 24 \\
\hline
\end{tabular}




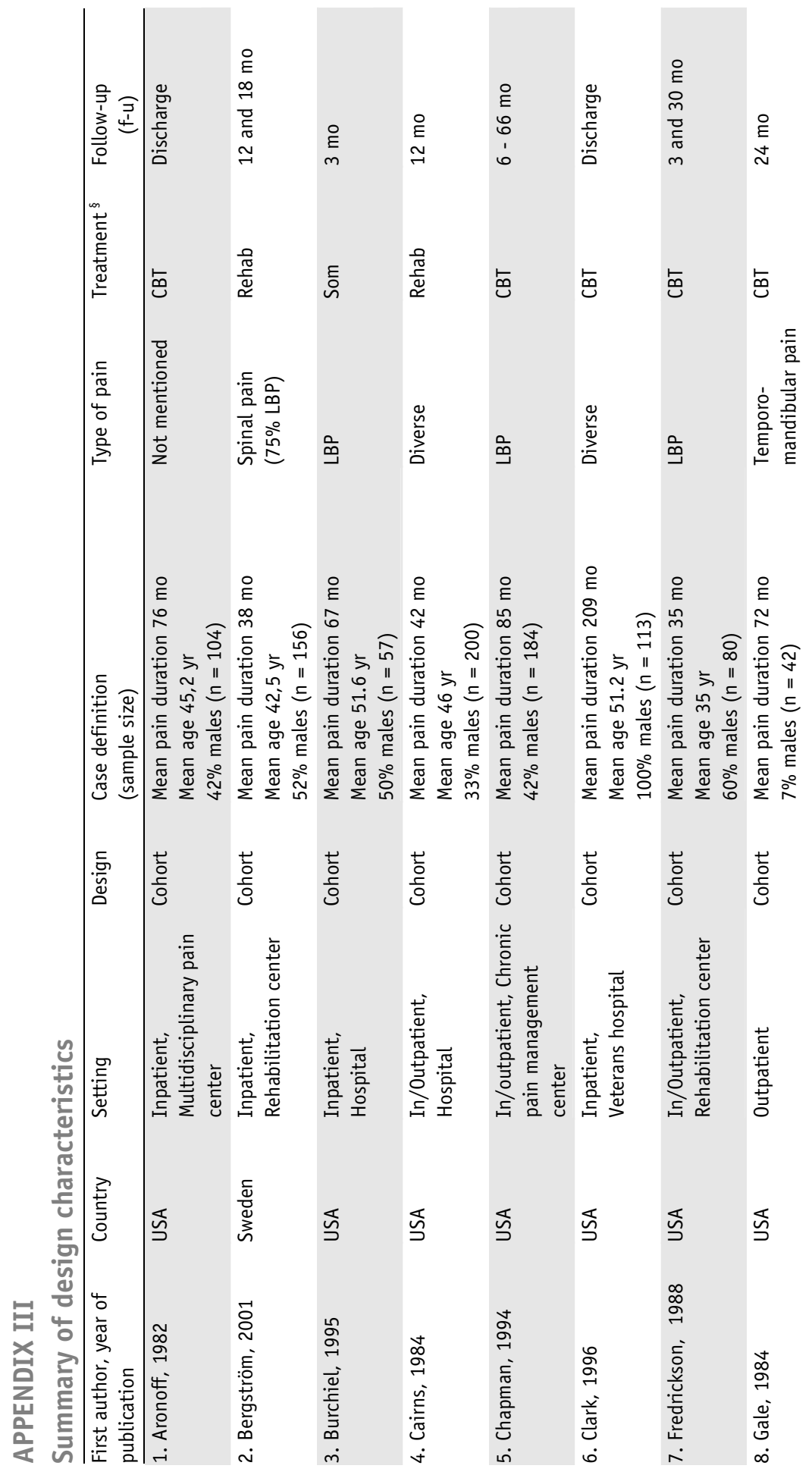




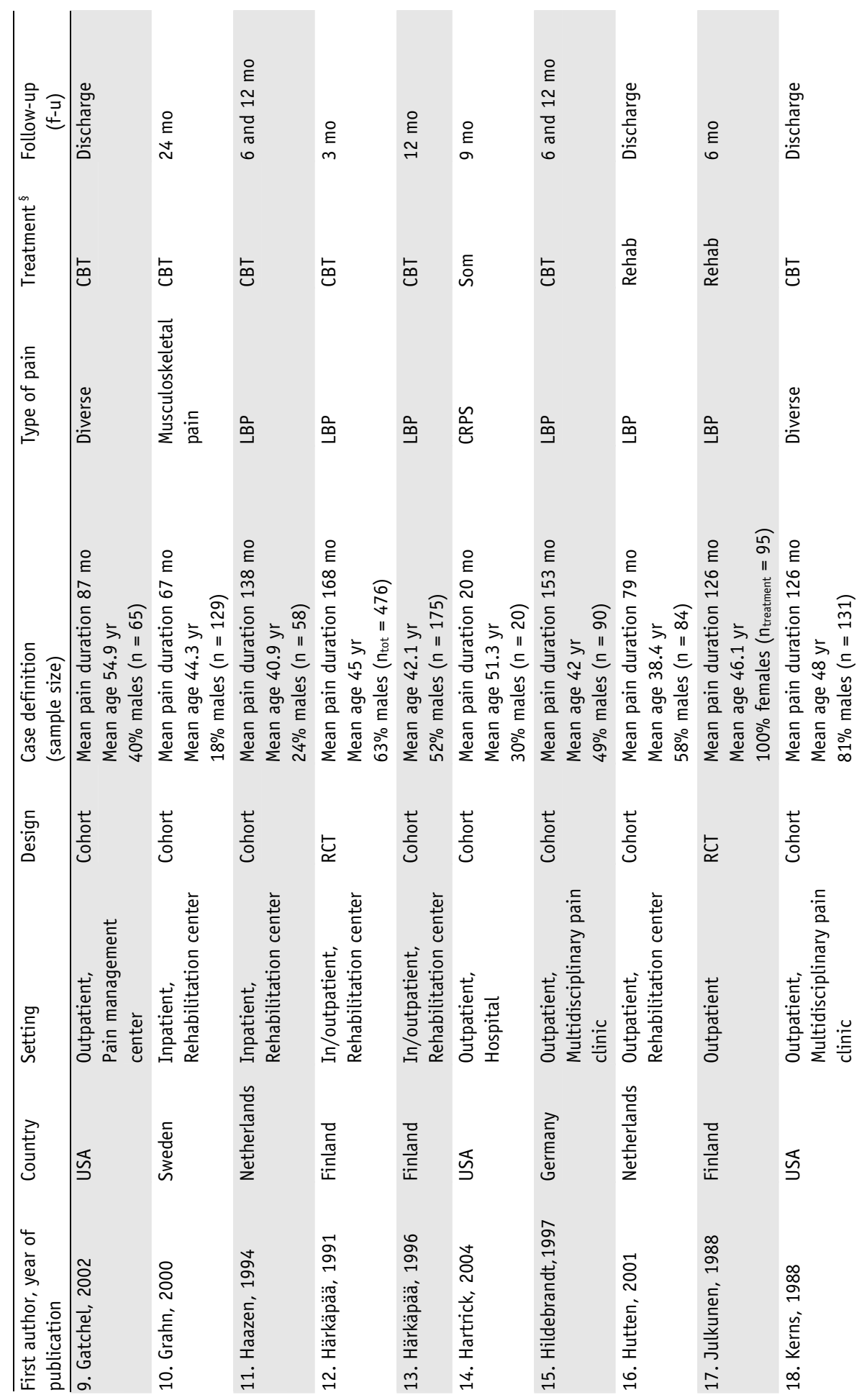




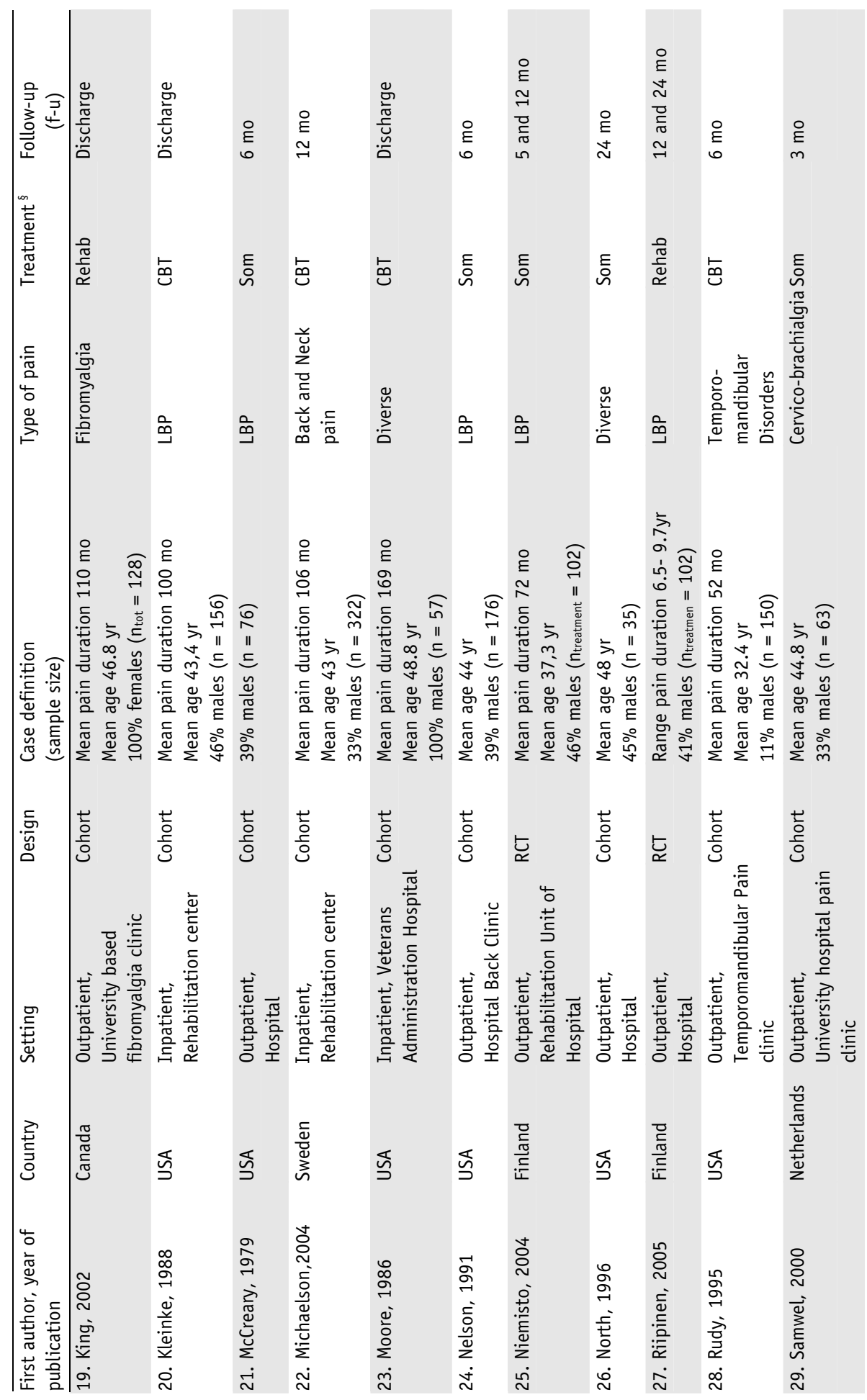




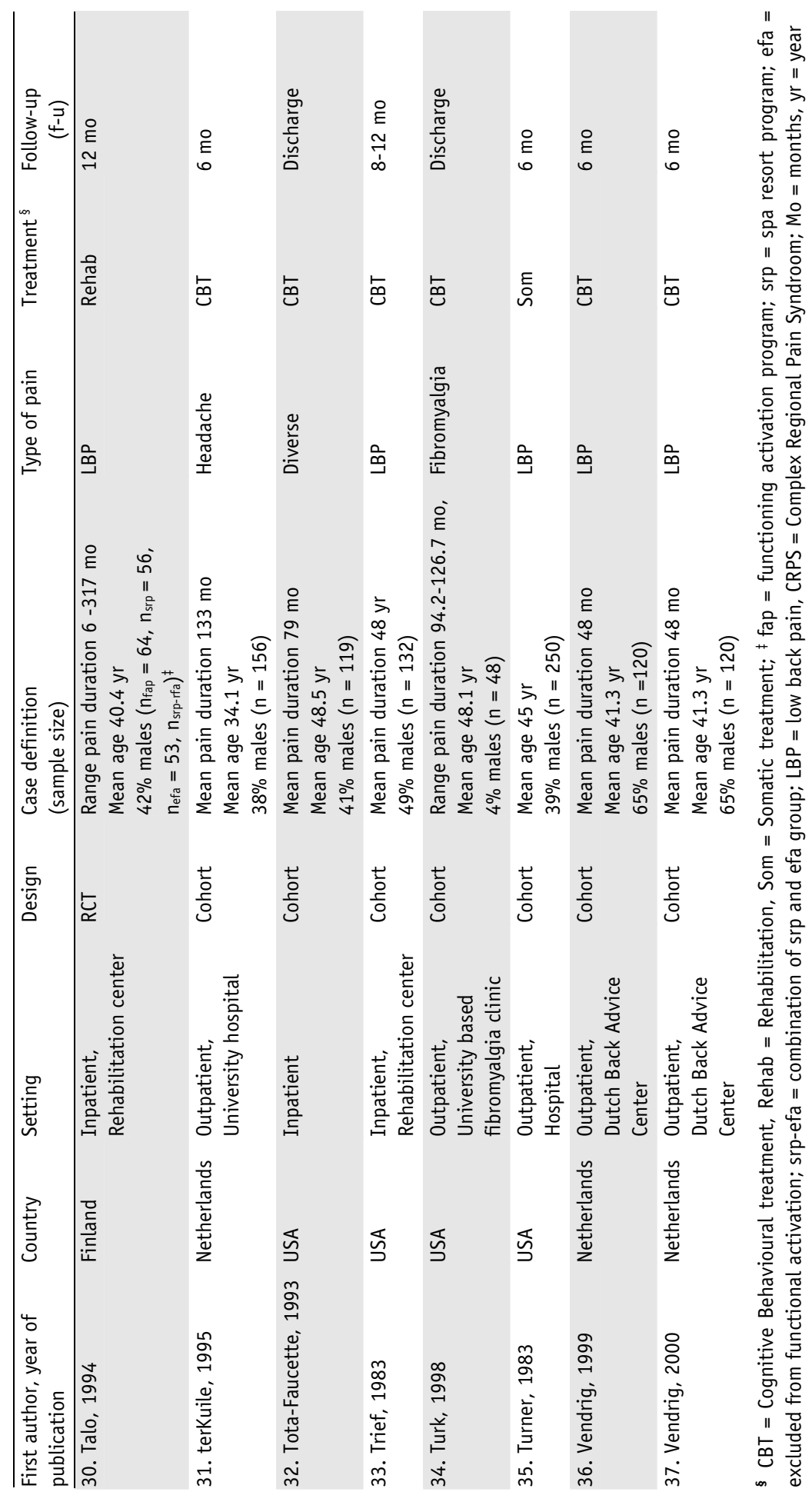




\section{APPENDIX IV \\ Psychological constructs}

\begin{tabular}{|c|c|}
\hline Construct & Instruments \\
\hline Depression & $\begin{array}{l}\text { Minnesota Multiphasic Personality Inventory (MMPI): subscale } \\
\text { depression } \\
\text { Beck Depression Inventory (BDI) } \\
\text { Pilowsky's Depression Questionnaire } \\
\text { Depression Scale } \\
\text { Finnish Depression Questionnaire }\end{array}$ \\
\hline $\begin{array}{l}\text { Somatic focus/ } \\
\text { Hypochondriasis }\end{array}$ & $\begin{array}{l}\text { Minnesota Multiphasic Personality Inventory (MMPI): subscal } \\
\text { hypochondriasis } \\
\text { Hypochondriasis Scale }\end{array}$ \\
\hline Dysfunctional Profile & Multidimenional Pain Inventory (MPI) \\
\hline General distress/ Anxiety & $\begin{array}{l}\text { Taylor Manifest Anxiety Inventory } \\
\text { Zung Anxiety Scale } \\
\text { Symptom Checklist (SCL-90) } \\
\text { Derogatis Affects Balance Scale (DABS) } \\
\text { Hopkins Symptom Checklist } \\
\text { Distress Scale }\end{array}$ \\
\hline Fear-avoidance & $\begin{array}{l}\text { Coping Strategies Questionnaire (CSQ): subscale catastrophizing } \\
\text { Fear-avoidance Beliefs Questionnaire } \\
\text { Pain Coping List (PCL): subscale catastrophizing } \\
\text { Inventory of negative thoughts }\end{array}$ \\
\hline Locus of Control & $\begin{array}{l}\text { Wallston's Health Locus of Control } \\
\text { Health Locus Control Beliefs Questionnaire } \\
\text { Locus of Control Beliefs scale } \\
\text { Belief of chance control of disease scale } \\
\text { Multi Locus of Pain Control Questionnaire }\end{array}$ \\
\hline Motivation & $\begin{array}{l}\text { Minnesota Multiphasic Personality Inventory (MMPI) } \\
\text { Motivation Scale } \\
\text { Motivation Interview }\end{array}$ \\
\hline Optimism & Health Optimism Questionnaire \\
\hline Psychopathology & Minnesota Multiphasic Personality Inventory (MMPI) \\
\hline
\end{tabular}




\section{APPENDIX V}

\section{Constructs outcome measures}

\begin{tabular}{ll}
\hline Construct & Instruments \\
\hline Pain Intensity & Visual Analogue Scale (VAS) \\
& McGill Pain Questionnaire (MPQ) \\
& Neuropathic Pain Scale (NPS) \\
& 6-point scale \\
& Multidimensional Pain Inventory (MPI) \\
& 5-point scale \\
Global Perceived Effect & Oswestry Disability Scale (ODI) \\
Quebec Back pain Disability Scale (QBDS) & Disability Index \\
Risability & Multidimensional Pain Inventory (MPI) \\
& Million Handicap Index (MHI) \\
& Activity Discomfort Scale (ADS) \\
& Short Form-36 (SF-36) \\
& Nottingham Health Profile (NHP) \\
Quality of Life Questionnaire
\end{tabular}


CHAPTER 4

APPENDIX VI

Overall results of outcome for prognostic factors, outcome and treatment

\begin{tabular}{|c|c|c|c|c|c|c|c|c|c|c|}
\hline \multirow[t]{2}{*}{ Prognostic factor } & \multirow[t]{2}{*}{ Outcome } & \multirow[t]{2}{*}{$\begin{array}{l}\text { Cohorts } \\
\text { assessed }\end{array}$} & \multicolumn{2}{|c|}{$\begin{array}{l}\text { Direction } \\
\text { Findings }\end{array}$} & \multirow[t]{2}{*}{$\begin{array}{l}\text { High } \\
\text { quality }\end{array}$} & \multirow[t]{2}{*}{$\begin{array}{l}\text { Low } \\
\text { quality }\end{array}$} & \multirow[t]{2}{*}{$\begin{array}{c}\text { No } \\
\text { findings }\end{array}$} & \multirow[t]{2}{*}{$\begin{array}{l}\text { High } \\
\text { quality }\end{array}$} & \multirow[t]{2}{*}{$\begin{array}{l}\text { Low } \\
\text { quality }\end{array}$} & \multirow[t]{2}{*}{$\begin{array}{l}\text { Level of } \\
\text { evidence }\end{array}$} \\
\hline & & & - & + & & & & & & \\
\hline \multirow[t]{3}{*}{ Depression } & Pain & 10 & $4 / 10$ & & 2 & 2 & $6 / 10$ & 5 & 1 & S- \\
\hline & GPE & 3 & $1 / 3$ & & & 1 & $2 / 3$ & 1 & 1 & I \\
\hline & Disability & 4 & $2 / 4$ & & 2 & & $2 / 4$ & 2 & & S- \\
\hline Somatic Focus/ & Pain & 9 & $3 / 9$ & $1 / 9$ & 2 & 2 & $5 / 9$ & 3 & 2 & I \\
\hline \multirow[t]{2}{*}{ Hypochondriasis } & GPE & 1 & & & & & $1 / 1$ & & 1 & I \\
\hline & Disability & 3 & $1 / 3$ & & 1 & & $2 / 3$ & 2 & & L- \\
\hline General Distress/ & Pain & 6 & $2 / 6$ & $1 / 6$ & 3 & & $3 / 6$ & 3 & & L- \\
\hline \multirow[t]{2}{*}{ General Anxiety } & GPE & 1 & & & & & $1 / 1$ & & 1 & I \\
\hline & Disability & 5 & $2 / 5$ & $1 / 5$ & 3 & & $2 / 5$ & 2 & & L- \\
\hline \multirow[t]{4}{*}{ Fear-Avoidance } & Pain & 4 & $2 / 4$ & & 2 & & $2 / 4$ & 2 & & S- \\
\hline & GPE & 1 & $1 / 1$ & & 1 & & & & & L- \\
\hline & Disability & 1 & & & & & $1 / 1$ & 1 & & I \\
\hline & QOL & 1 & & & & & $1 / 1$ & 1 & & I \\
\hline \multirow[t]{3}{*}{ Locus of Control } & Pain & 1 & & & & & $1 / 1$ & 1 & & L- \\
\hline & GPE & 1 & $1 / 1$ & & & 1 & & & & I \\
\hline & Disability & 3 & $3 / 3$ & & 3 & & & & & S- \\
\hline \multirow[t]{3}{*}{ Motivation } & Pain & 1 & & & & & $1 / 1$ & 1 & & I \\
\hline & GPE & 1 & & $1 / 1$ & & 1 & & & & I \\
\hline & QOL & 1 & & $1 / 1$ & 1 & & & & & L+ \\
\hline \multirow[t]{2}{*}{ Optimism } & Pain & 1 & & $1 / 1$ & 1 & & & & & L+ \\
\hline & Disability & 1 & & $1 / 1$ & 1 & & & & & L+ \\
\hline \multirow[t]{2}{*}{ Psychopathology } & Pain & 2 & & $1 / 2$ & 1 & & $1 / 2$ & 1 & & L+ \\
\hline & Disability & 2 & & $1 / 2$ & 1 & & $1 / 2$ & 1 & & L- \\
\hline \multirow[t]{3}{*}{ Dysfunctional } & Pain & 5 & & $3 / 6$ & 3 & & $2 / 6$ & 2 & & $\mathrm{~S}_{+}$ \\
\hline & Disability & 4 & & $3 / 4$ & 3 & & $1 / 4$ & 1 & & S+ \\
\hline & QOL & 3 & & & & & $3 / 3$ & 3 & & I \\
\hline
\end{tabular}

S- Strong evidence of negative outcome; S+ Strong evidence of positive outcome; L- Limited evidence of negative outcome; L+ Limited evidence of positive outcome; I Evidence inconclusive; ${ }^{1}$ depression measured with the Beck Depression Inventory (BDI) ${ }^{2}$ depression measured with the Minnesota Multiphasic Personality Inventory (MMPI) 


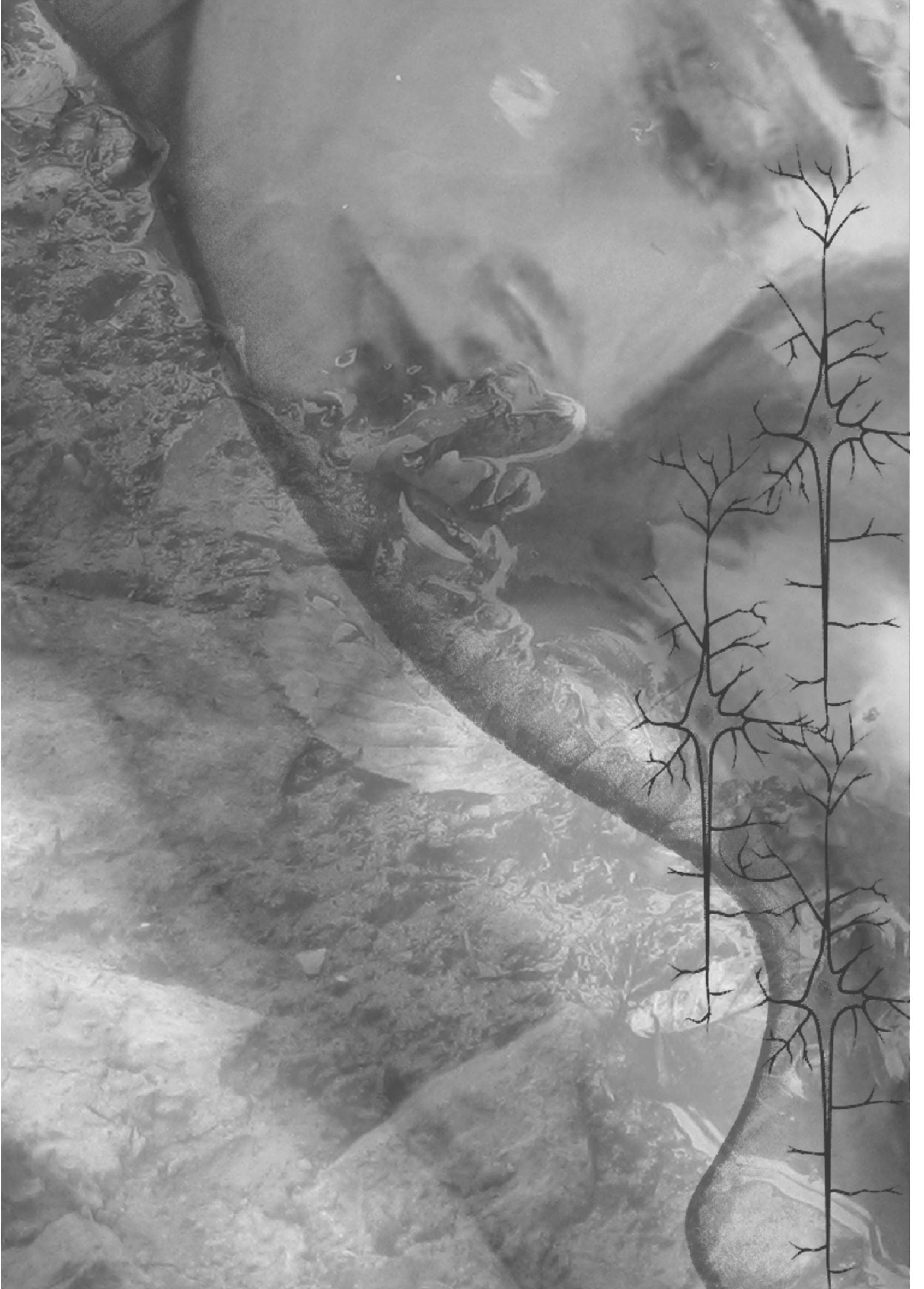




\section{Chapter 5}

Psychological predictors of treatment outcome in a heterogeneous chronic pain population: depression, fearavoidance beliefs or both? A prospective cohort study 


\section{CHAPTER 5}

\section{ABSTRACT}

The objective of this study was to investigate the contribution of depression, fearavoidance variables, and locus of pain control in explaining treatment outcome in a heterogeneous chronic pain population referred to an academic pain centre. In addition, the predictive value for treatment outcome in different diagnosis and treatment groups was investigated.

The population of this prospective cohort study consisted of 248 chronic noncancer pain patients. On initial assessment, all patients completed a standard questionnaire which included demographics, disease variables, and standard assessment instruments on pain (VAS), quality of life (SF-36), pain interference (MPI), and psychological factors. Treatment was subdivided into two subgroups, i.e., patients receiving non-invasive or invasive treatment. Diagnoses were subdivided into five groups, i.e.,neuropathic pain, cervical-related pain, lumbar-related pain, thoracic- and extravertebral-related pain, and other pain. After nine months, a follow-up questionnaire was sent out, which included pain intensity, quality of life, pain interference, and a question about the global perceived effect (GPE) of treatment.

Depression was found to be the most consistent predictor of treatment outcome in the group as a whole, in terms of pain intensity, mental component of quality of life, and pain interference. In addition, depression was predictive of the outcome pain intensity and pain interference in the neuropathic pain group, and of the mental component of quality of life in the lumbar vertebral-related pain group, and pain catastrophizing was predictive of pain intensity in invasive treatment, and external pain control for the mental component of quality of life in noninvasive treatment.

The results seen in the present study may be a first step in the better tailoring of treatments to patients. The ability to identify psychological characteristics of those patients who are likely to obtain insufficient benefit from medical treatment may facilitate the development of alternative treatment approaches tailored to their needs.

\section{INTRODUCTION}

A substantial proportion of chronic pain patients do not obtain sufficient benefit from the treatment they receive for their pain (Vlaeyen \& Morley, 2005). One explanation for the insufficient effect of treatment could be the heterogeneity of patients, which makes it unlikely that all patients benefit from the same treatment (Turk \& Okifuji, 1998). Many patients attending academic pain centres have longlasting pain problems and experience substantial disability and distress. According to biopsychosocial models of chronic pain, pain and disability are not only influenced by somatic pathology, but also by psychological and social factors (Gatchel, 
2001; Waddell, 2006). When pain persists, all aspects of life are affected, which can lead to depression, anger, anxiety, self-preoccupation, and isolation (Gatchel et al., 2007). Moreover, psychological factors may contribute to the variability in the outcome of treatment for pain (Gatchel, 2001). Pre-treatment screening for psychological risk factors in unsuccessful treatment may eventually contribute to improved treatment efficacy. Therefore, it is important to identify these risk factors. The present study focuses on several possible psychological risk factors.

One of the most prominent models nowadays in understanding persistent pain and disability is the fear-avoidance model of pain (Vlaeyen \& Linton, 2000). This model emphasizes the role of cognitive factors (pain catastrophizing) and emotional components (pain-related fear) as key players in chronic pain (Linton, 2000). Other authors have stressed the role of depression as a predisposing factor for chronic pain (Pincus et al., 2002; Pincus et al., 2006). In contrast to the large number of studies that have examined the contribution of fear-avoidance variables in the aetiology and maintenance of chronic pain and disability, relatively few studies have examined their influence on treatment outcome (Tota-Faucette et al., 1993; Hildebrandt et al., 1997; Samwel et al., 2000; King et al., 2002). On the other hand, a large number of studies has examined the influence of depression on treatment outcome (Kerns \& Haythornthwaite, 1988; Burchiel et al., 1995; Hildebrandt et al., 1997; Vendrig et al., 1999; Michaelson et al., 2004). However, two reviews on the moderating effect of psychological variables found only weak evidence of an association between depression and treatment outcome (Feuerstein et al., 1994; van der Hulst et al., 2005). Both these studies were restricted to back pain patients and multidisciplinary or back school treatment. Recently, we conducted a more comprehensive systematic review including studies that examined patients with different types of chronic pain, and various kinds of interventions. In these studies we found consistent evidence of depression, fear-avoidance variables, and locus of pain control as predictors of treatment outcome in terms of pain intensity and disability (Lame et al., in preparation). However, due to the heterogeneity of the studies reviewed, the evidence was based on qualitative analysis only.

Therefore, we designed a prospective cohort study to re-examine the relative contribution of depression, fear-avoidance variables, and locus of pain control in explaining treatment outcome in a heterogeneous chronic pain population referred to an academic pain centre. We specifically focused on the moderating effect of these psychological variables on medical treatment, and excluded multidisciplinary and psychological treatments. These latter treatments are designed to aim, at least in part, at influencing the psychological factors, and therefore may confound moderating and mediating effects (Vlaeyen \& Morley, 2005). Treatment was subdivided in two groups, i.e., patients receiving non-invasive or invasive treatment. In addition, the predictive value of treatment outcome in various diagnosis and treatment 


\section{CHAPTER 5}

groups was investigated. Since pain is a multifactorial problem, we included various outcome variables in order to cover the full breath of the problem (Dworkin et al., 2005).

\section{METHODS}

\section{Setting and participants}

The population in this prospective cohort study consisted of chronic non-cancer pain patients (pain duration $>3$ months) who were referred to an outpatient's clinic for pain and pain management at a university hospital. There were no exclusions in the localization of pain. All new patients underwent the same standard procedure, i.e., they had to fill in a questionnaire on demographics and disease variables, which also included standard assessment instruments on pain, quality of life, and psychological factors. In addition, patients were asked to give written informed consent. The questionnaire was sent to their home address, and patients had to return it completed before their first appointment with the physician. The questionnaire was used as a baseline measure for the current study. After the first consultation with the physician, patients were referred to different therapeutic modalities, based on somatic and psychocognitive diagnostic procedures. Diagnosis and treatment were recorded. The follow-up questionnaire was sent out nine months after the first consultation with the physician, when treatment was expected to be either finished or stabilized. In total, 524 consecutive returned baseline questionnaires were eligible for inclusion. Fifty-eight patients ( $41 \%$ males and $59 \%$ females) did not give their written informed consent for future research. Finally, 466 patients received a follow-up questionnaire.

\section{Outcome measures}

Outcome measures were assessed twice, at baseline and follow-up, with the exception of GPE, which was only assessed at follow-up. Demographics, disease variables. and psychological variables were assessed at baseline only.

Pain intensity. Average pain intensity during the past week was measured using the visual analogue scale (VAS). Patients had to mark their pain on a ten-point VAS, ranging from 0 on the left side ('no pain') to 10 on the right side ('most intense imaginable pain').

Global Perceived Effect (GPE). Patients were asked to record the overall result of treatment on a ten-point visual analogue scale, ranging from 'no effect' $(0)$ to 'total recovery' (10).

Quality of Life (QOL). Quality of life was measured using SF-36. This instrument was developed during the Medical Outcome Studies of the Rand Corporation and 
measures general health and quality of life (Van der Zee et al., 1993). SF-36 includes eight multi-item dimensions: physical functioning, social functioning, role limitations physical, role limitations emotional, vitality, mental health, bodily pain, and general health perception. In order to decrease the number of statistical comparisons, we decided to use the two-dimensional SF-36 model, i.e., the physical and mental component score (Ware et al., 1994; Ware et al., 1995). The psychometric properties of SF-36 are adequate (Van der Zee et al., 1993; Van der Zee et al., 1996).

Pain interference. Patients' perception of the amount of life disruption (e.g., during social or recreational activities) due to their pain was measured with the subscale 'pain interference' of MPI (Kerns et al., 1985). MPI is a 61-item measure and comprises 12 empirically derived subscales. Previous research has demonstrated good reliability and validity in several samples of chronic pain patients (Kerns et al., 1985; Bernstein et al., 1995).

\section{Predictive variables}

Demographic variables. Patients recorded their sex, age, marital status, and highest level of education.

Disease variables. Duration of pain in years and location of pain were recorded.

Depression. Depression was measured with the 21-item Beck Depression Inventory (BDI) (Beck et al., 1961). Each item is associated for a symptom of depression and scored from zero, indicating absence of the symptom, to 3 for the most severe level of that symptom. BDI has shown high internal consistency in several studies. Cronbach's alphas ranged from 0.76 to 0.95 (Beck et al., 1988).

Pain Catastrophizing. Pain catastrophizing was measured with the Dutch version of the Pain Catastrophizing Scale (PCS) (Sullivan et al., 1995; Crombez \& Vlaeyen, 1996). PCS is a 13-item instrument. Items are scored on a five-point Likert scale, ranging from 0 (not at all) to 4 (always), developed to identify catastrophic thoughts or feelings that patients experience in relation to their pain. High scores indicate more catastrophizing thoughts about pain. PCS has good psychometric properties (Crombez et al., 1998; Van Damme et al., 2000; Lame et al., 2008).

Fear of movement/reinjury. Fear of (re)injury due to movement or activity was measured using the 17-item Tampa Scale of Kinesiophobia (TSK) (Miller et al., 1991; Vlaeyen et al., 1995). The items are scored on a four-point Likert scale with scoring possibilities ranging from 1 ('strongly disagree') to 4 ('strongly agree'). The scores on items 4, 8, 12 and 16 are reversed, and total scores range from 17 to 68 . High scores indicate more fear of pain/(re)injury due to movement or activity. The questionnaire has been validated, with sufficient internal consistency $(=0.77)$ and validity (Vlaeyen et al., 1995).

Locus of pain control. Locus of pain control was measured using the 42-item Pain Coping and Cognition List (PCCL). PCCL was developed by the Pain Management and Research Centre, University Hospital Maastricht, the Netherlands (Stomp-van 
den Berg et al., 2001). It is constructed out of the Pain Cognition List (Vlaeyen et al., 1990), Locus of Pain Control questionnaire (Engstrom, 1983), and the Coping Strategies questionnaire (Spinhoven et al., 1994), and includes all the unique information from the original lists. PCCL includes four subscales: pain catastrophizing, pain coping, internal pain control, and external pain control. The questionnaire has good internal consistency and construct validity (Stomp-van den Berg et al., 2001).

\section{Data reduction and statistical analyses}

In order to enable subgroup analysis, patient diagnosis and the treatment received were assembled in broad categories. The diagnoses were collected into five different groups, i.e., neuropathic pain $(n=80)$, cervical vertebral related pain (CVRP) $(n=63)$, lumbar vertebral related pain (LVRP) $(n=79)$, thoracic and extra vertebral related pain $(n=40)$, and other pain $(n=15)$. Neuropathic pain is defined as a complex type of pain, initiated or caused by a primary lesion or dysfunction in the nervous system (International Association for the Study of Pain (IASP)). Vertebral related pain is defined as pain originating from bone structures or the soft tissue of the vertebrae. Extra vertebral related pain included all pain originating from bone structures or soft tissue extra vertebral. Other pain included all pain complaints that could not be included in the other categories (e.g., visceral, vascular pain). The various treatments were collected into two groups, i.e., a non-invasive group $(\mathrm{n}=86)$ and an invasive group $(\mathrm{n}=162)$. Patients in the non-invasive group' were treated with medication and/or TENS. A small portion of this group was additionally treated using podotherapy $(n=3)$, physical therapy $(n=1)$ or rehabilitation $(n=3)$. Patients in the 'invasive group' were treated with radiofrequency techniques (RF) $(n=153)$ or spinal cord stimulation $(n=9)$. Additional treatment was given to a small portion of the RF group, i.e., musculoskeletal medicine $(n=8)$ and rehabilitation $(n=3)$.

All statistical analyses were carried out using the SPSS statistical package for Windows, version 12.0. Differences between the diagnosis groups and the treatment groups were calculated using ANOVA. Post-hoc tests (Gabriel and Hochberg's GT2) were used to specify the differences. Improvement from baseline to follow-up in pain, HRQL, catastrophizing, depression, and fear of movement, were tested using paired-sample t-tests. In order to obtain insight into the clinical importance of the improvement, effect sizes were calculated by converting a t-value into an $r$ value (Rosnow \& Rosenthal, 2005). Linear regression analysis was used to identify predictors of change from baseline to follow-up in pain intensity, the physical and mental quality of life component scores (SF-36), and pain interference, as well as global perceived effect. In order to reduce the number of predictors, we first conducted univariate analysis of the demographic and disease variables. In the final multivariate regression analysis, the significant demographic and disease variables 
were entered together with all psychological variables and pain intensity at baseline. A multivariate analysis for the group of chronic pain patients as a whole was conducted first, using a backward deletion procedure with the criterion $p<0.10$ for keeping a variable in the equation. The set of significant predictive variables resulting from the analysis with the group as a whole, were used for the subsequent multivariate analysis of the diagnostic treatment subgroups. In this way, an identical set of predictors was tested for each subgroup, allowing comparison of the importance of each predictor across diagnostic groups and interventions.

Post hoc, we also explored whether different predictors might emerge for the subgroups by performing additional analyses, during which all psychological predictors were again entered using a backward deletion procedure. Due to their small sample size, the subgroups thoracic and extravertebral related pain and other pain, were excluded from the multivariate analyses of the diagnosis groups. The results from the regression analyses were regarded as being significant with a $p$ value of less than 0.05 .

\section{RESULTS}

\section{Response rate and patient characteristics}

In total, 466 chronic pain patients received a follow-up questionnaire. When no reaction followed within two weeks, a second questionnaire was sent out. After a further two weeks, persistent non-responders were telephoned. Finally, 315 patients $(68 \%)$ returned the follow-up questionnaire. Of these, 38 had no indication of pain treatment and were returned or referred to another specialist. A further 29 patients were treated using cognitive behavioural treatment (CBT) or another psychological intervention, and were excluded from the final cohort. In the end, a total of 248 patients were included in the study. There were no differences regarding demographics, pain duration, pain intensity, pain catastrophizing, fear of movement/(re)injury, or internal and external pain control at baseline, between non-responders, patients not treated, patients in the CBT group, and patients included in the study, with the exception of depression, which was higher in patients referred for CBT or other psychological interventions (18.5, sd 11.5) than in patients included in the study $(13.4$, sd $7.9 ; p=0.02)$. Baseline characteristics are summarized in Table 1. 
CHAPTER 5

Table 1: Baseline characteristics

\begin{tabular}{lll}
\hline Characteristic & & Total Group \\
& & $\mathrm{N}=248$ \\
\hline Gender \% & male & 35 \\
& female & 65 \\
Age yr (SD) [range] & & $52.8(14.0)$ [17-88] \\
Marital status \% & married/living together & 78.7 \\
& unmarried & 7.3 \\
Education \% & divorced & 6.5 \\
& low & 60.2 \\
Pain duration yr (SD) [range] & middle & 26.2 \\
PCCL score mean (SD) & high & 13.3 \\
& & $7.5(8.3)[0.3-42]$ \\
VAS score mean (SD) [range] & internal pain control & $4.1(0.9)$ \\
PCS score mean (SD) [range] & external pain control & $3.4(1.2)$ \\
TSK score mean (SD) [range] & & $7.1(1.8)[0.7-100]$ \\
BDI score mean (SD) [range] & & $29.4(12.6)[0-52]$ \\
SF-36 component summary scores & physical (PCSS) & $40.6(8.0)$ [24-65] \\
MPI mean (SD) & mental (MCSS) & $13.3(7.9)[0-39]$ \\
\hline & interference & $28.5(8.0)$ \\
& & $44.5(11.0)$ \\
& & $4.2(1.2)$ \\
\hline
\end{tabular}

\section{Diagnosis groups and treatment groups}

Baseline characteristics of the different diagnosis and treatment groups are presented in Table 2. Only those patients with cervical vertebral-related pain had a higher quality of life score with regard to the physical component, compared to patients suffering from lumbar vertebral-related pain. No other baseline differences were found between the diagnosis groups. No baseline differences were found between the two treatment groups. 


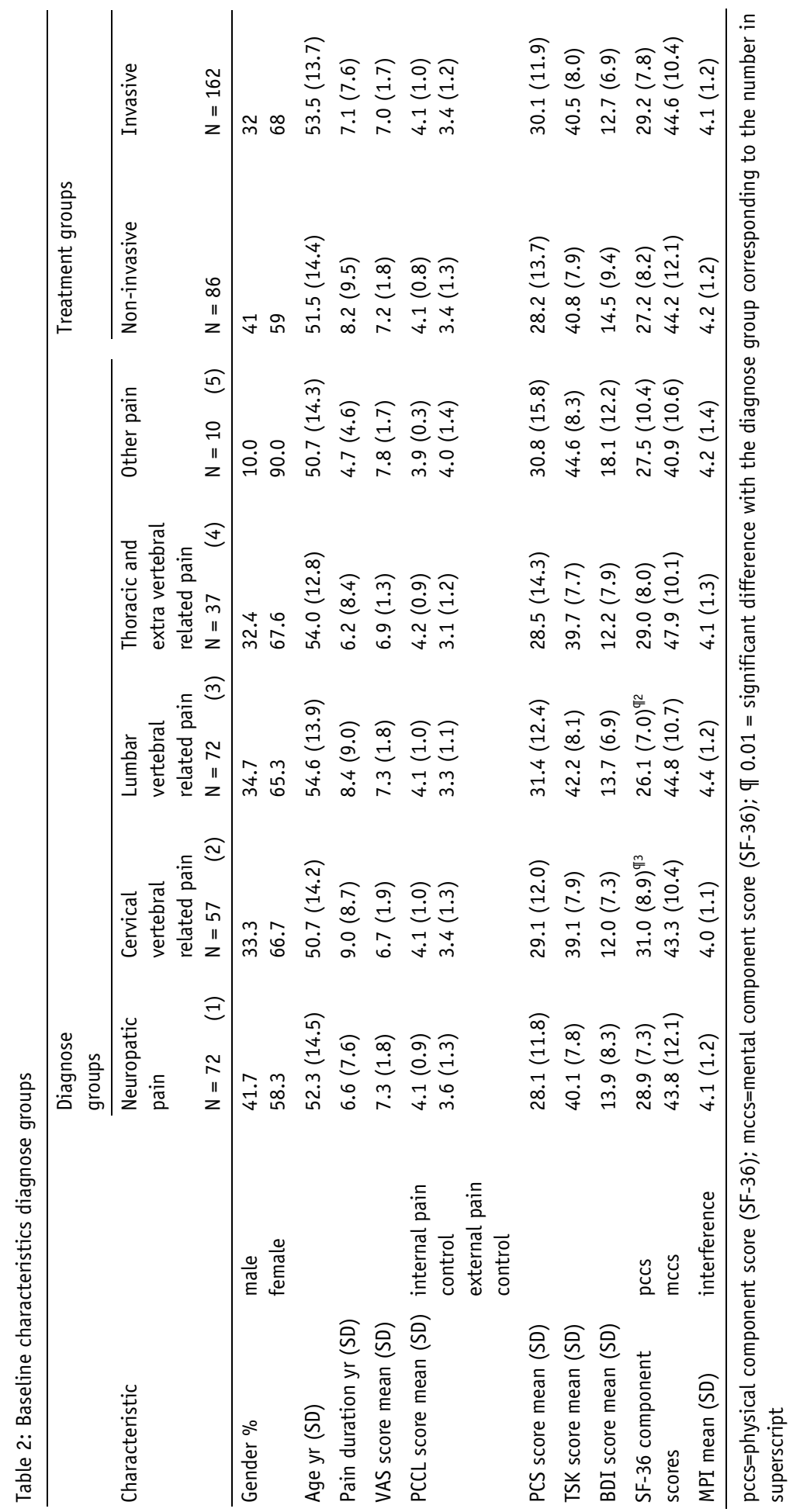




\section{CHAPTER 5}

\section{Treatment effect}

The changes in the variables from baseline to follow-up are summarized in Table 3. For the group as a whole, all outcome variables, with the exception of the mental component of quality of life, improved from baseline to follow-up. There were some minor differences in the effects of treatment within the diagnosis groups. No significant treatment effects were observed in the 'other pain' group. However, it should be noted that this group only included ten patients. The SF-36 mental component score improved in the neuropathic pain group, but the SF-36 physical component score was not improved after treatment. Treatment effect was similar for the invasive and non-invasive treatment group.

Table 3: Change scores from baseline to follow-up in the group as a whole.

\begin{tabular}{lccccccccc}
\hline & $\begin{array}{c}\text { Baseline } \\
\text { Mean(sd) }\end{array}$ & $\begin{array}{c}\text { Follow-up } \\
\text { Mean(sd) }\end{array}$ & $\begin{array}{c}\text { Mean } \\
\text { difference }\end{array}$ & sd & t & df & p value & Effect size \\
\hline VAS & $7.1(1.8)$ & $5.4(2.7)$ & 1.68 & 2.8 & 9.28 & 233 & $<0.0001$ & 0.5 \\
SF-36: Physical component score & $28.6(8.2)$ & $31.8(8.9)$ & -3.22 & 8.8 & -4.95 & 181 & $<0.0001$ & 0.4 \\
SF-36: Mental component score & $44.5(11.0)$ & $45.3(13.4)$ & -0.82 & 11.8 & -0.94 & 181 & 0.35 & 0.07 \\
MPI: Pain interference & $4.2(1.2)$ & $3.6(1.5)$ & 0.54 & 1.3 & 6.32 & 242 & $<0.0001$ & 0.4 \\
\hline
\end{tabular}

\section{Predictors of treatment outcome}

None of the demographic variables or pain duration contributed significantly to the prediction of the different outcome measures after treatment, and therefore these variables were not included in the final regression model. Five separate analyses were conducted using pain catastrophizing, fear of movement/(re)injury, depression, internal and external pain control as independent variables, and each of the five outcomes as dependent variables. The results of the regression analysis for the group as a whole are shown in Table 4. Depression was found to be the most consistent predictor of treatment outcome, reaching significance for the outcome pain intensity, the mental component of quality of life, and pain interference, while a trend was seen for GPE. Only for the physical component of quality of life, did depression not seem to be related to treatment outcome. Other significant predictors in the group as a whole were baseline pain intensity, external and internal pain control. However, each of these predictors only reached significance for one dependent variable, casting doubt on the robustness of these findings.

Next, the same set of variables for a particular outcome variable reaching significance in the group as a whole was also tested for its predictive value in the diagnostic and treatment subgroups (Tables 4 and 5). By and large, the same results were found in the three separately tested diagnosis groups. Depression reached 
significance for the outcome pain intensity and pain interference in the neuropathic pain group, and for the mental component of quality of life in the lumbar vertebral-related pain group. The predictive power within the cervical-related pain group seemed to be less. No clear differences were apparent in the two treatment groups with regard to the strength of the associations between depression and outcome. 


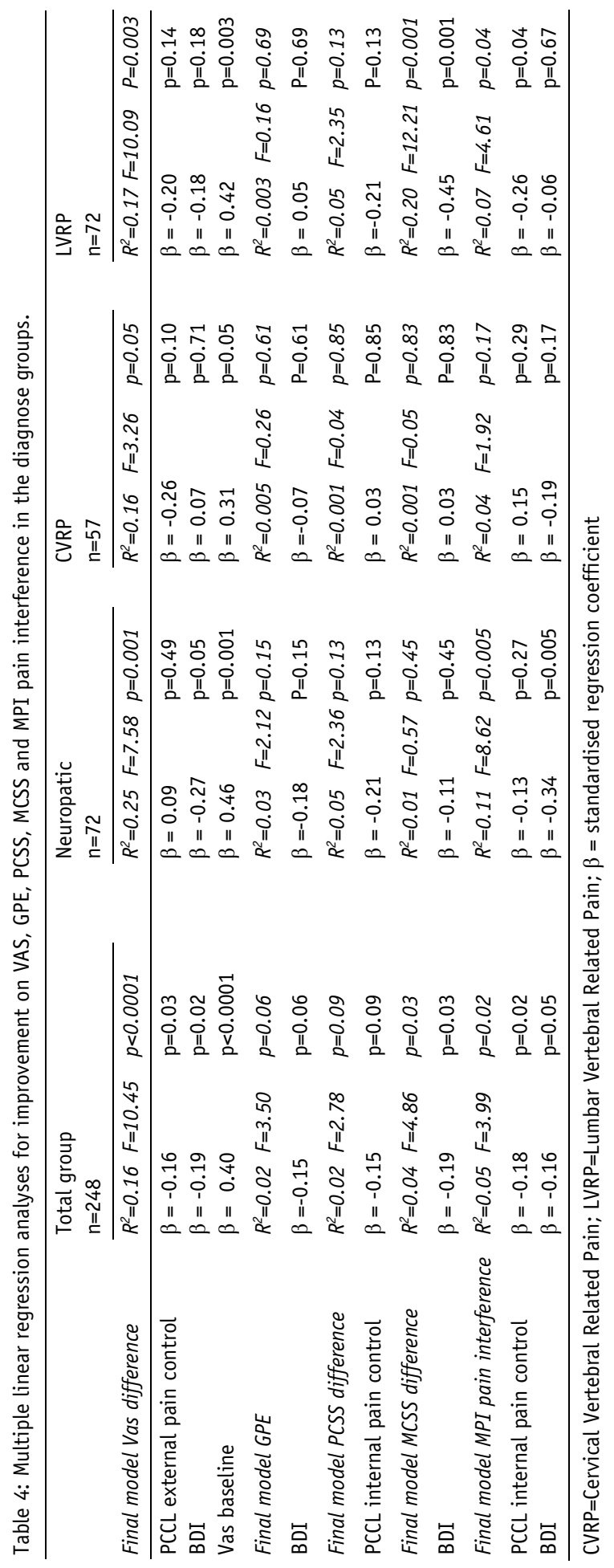




\section{Post Hoc analyses diagnosis and treatment groups}

The main analysis enabled us to examine the consistency of predictors across diagnosis groups and treatments. However, this analytic approach was not sensitive to detecting differential predictive associations in the various subgroups. Therefore, post hoc, we conducted additional analyses within each subgroup and for each outcome, entering all psychological variables as independent variables (backward deletion procedure). Since the sample sizes in the diagnosis subgroups are rather small, and the number of analyses rather large, and in order to avoid type I error, only those associations that reach significance for at least two of the outcomes within one of the diagnosis subgroups will be presented. According to this criterion, no additional predictive psychological factors were found. The sample sizes in the treatment groups enable us to present associations that reach significance per outcome variable. Pain catastrophizing was shown to be predictive of pain intensity in the invasive treatment group $(\beta=-0.27, p=0.006)$, and external pain control was predictive of the mental component of quality of life in the non-invasive treatment group $(\beta=-0.34, p=0.03)$. 


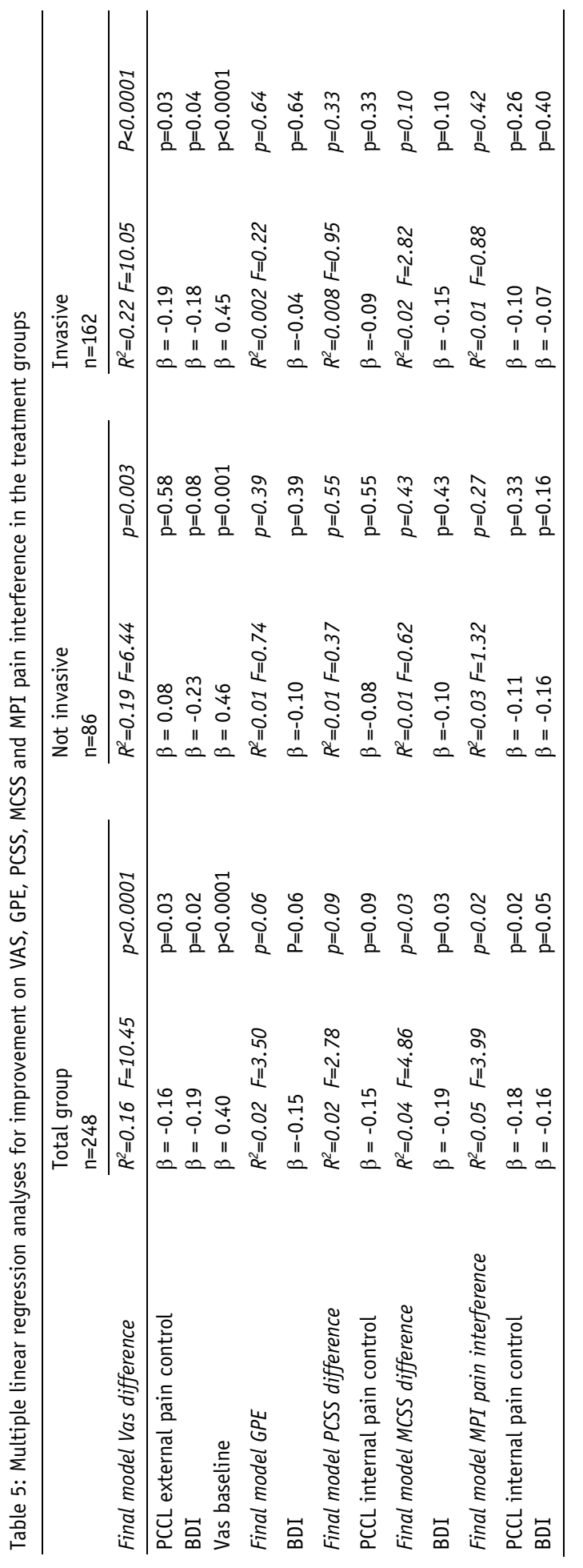




\section{DISCUSSION}

In this prospective cohort study, we found support for depression as the most consistent predictor of negative treatment outcome in terms of pain intensity, pain interference, psychological functioning, and global perceived effect, across diagnostic groups and type of intervention in a heterogeneous chronic pain population. Moreover, within the neuropathic pain group, depression appeared to be the most consistent predictor of negative outcome in various variables. Not all associations reached significance within the subgroup analyses, which could mainly be a statistical power problem. With regard to the beta-coefficients, the association between depression and outcome was, by and large, the same within the various groups. Post hoc analyses showed that pain catastrophizing was predictive of negative invasive treatment outcome in terms of pain intensity, and that external pain control was predictive of negative non-invasive treatment outcome in terms of the mental component of quality of life.

The consistent predictive value of depression on treatment outcome in the present study, is in accordance with the results of a recent systematic review (Lame et al., in preparation). It is remarkable that, in this review, inconsistencies were found in the results seen with the various assessment tools for measuring depression. BDI was unrelated to treatment outcome (Kerns \& Haythornthwaite, 1988; Burchiel et al., 1995; Michaelson et al., 2004), whereas the MMPI depression scale ${ }^{3}$ appeared to be responsible for the consistent findings of depression as predictor of treatment outcome (McCreary et al., 1979; Turner et al., 1983; Burchiel et al., 1995; Vendrig et al., 1999). In contrast, the findings in the present study support the predictive value of depression for treatment outcome in chronic pain when measured with BDI as well. It has been suggested that, in chronic pain patients, BDI scores may be artificially inflated because of their high scores on items reflecting physical symptoms, which may not be indicative of depression, but are simply symptoms of the illness (Moore et al., 1998). However, when we removed the physical items from the total score, the results reported earlier remained unchanged. This pattern is consistent with previous findings in which it was suggested that somatic items are valid indicators of the depression construct (Turk \& Okifuji, 1994; Geisser et al., 1997; Wilson et al., 2001; Harris \& D'Eon, 2007). Other factors that could have biased the results, such as sample size, severity of depressive symptoms and heterogeneity of the pain complaints, did not differ from studies that found no predictive value for depression measured with BDI. Therefore, even though the review did not find an association between BDI scores and treatment outcome, the results of the present study indicate that BDI can be used as a pre-treatment screening tool for chronic pain patients.

3 Minnesota Multiphasic Personality Inventory 
Subgroup analyses revealed a similar predictive value of depression across the diagnostic groups, although, due to restricted sample size, many of the associations did not reach significance within the subgroups. Despite the similarity between diagnostic groups, the association of depression and outcome seemed strongest in neuropathic pain patients. Neuropathic pain is a devastating chronic condition with intractable and severe pain (Gilron et al., 2006). The prevalence of depression in neuropathic pain patients is high (Gustorff et al., 2008). Moreover, not only depression, but also other psychological factors, have been suggested to contribute towards the development of chronic neuropathic pain (Haythornthwaite \& Benrud-Larson, 2000; Leo, 2006), and were found to affect functioning (Twilling, 1998). Although it has been suggested that psychological factors should be considered in the assessment and treatment of chronic neuropathic pain conditions, no evidence of the predictive value of psychological factors on treatment outcome in neuropathic pain has yet been reported. To our knowledge, our study is the first that actually found an association between pre-treatment depression and treatment outcome in neuropathic pain patients.

The predicted association between pre-treatment pain catastrophizing and invasive treatment outcome in terms of pain intensity was in accordance with results found by Samwel et al. (2000). Those authors concluded that pain catastrophizing was able to predict the negative outcome of radiofrequency lesions in a population of patients with chronic cervicobrachialgia, in terms of pain intensity. However, recently, the contribution of pain catastrophizing as a predictive variable of spinal cord stimulation outcome in chronic Complex Regional Pain Syndrome type I (CRPS-I) could not be confirmed (Lame et al., in revision). It was suggested that the results found in this special group were due to patients' belief that CRPS is untreatable and would deteriorate progressively (Bruehl \& Chung, 2006). Pain catastrophizing may be secondary to the seriousness of the complaints and the repeated failure of previous treatments.

The present study has several strengths. It includes a large sample of chronic pain patients $(n=248)$, several psychological predictors are included, taken from evidence available from previous studies, and their influence is assessed on five different outcome variables. Nevertheless, several limitations should be mentioned. Firstly, since the design of this study was uncontrolled, it has still to be proved whether the outcome results were based predominantly on treatment procedures, confounding variables, or were simply due to the influence of time. The influence of time seems to be of minor importance, since all patients suffer from persistent pain conditions for a long time, so that spontaneous recovery is deemed to be unlikely. Secondly, some caution is warranted when interpreting improvement of the outcome measures. One method for determining clinically important changes in outcome is based on the effect size. A 0.50 effect size (i.e., one-half of the standard deviation) may be a reasonable criterion in the investigation of clinically 
important changes (Dworkin et al., 2008). In this study, only change in pain intensity reached an effect size of 0.5 . The other outcome measures that significantly changed had only low effect sizes (0.4). On the other hand, these moderate effect sizes replicate the suboptimal treatment efficacy found in previous studies, and possibly reflect the heterogeneity of results across patients. This may also underline the importance of pre-treatment psychological screening, in order to distinguish between good treatment responders and those patients that may need another or additional interventional approach. Based on the present results, depression seems to be a major target for a such screening. A final limitation that should be mentioned is that, despite the identification of significant predictor variables, their association with outcome in terms of explained variance was rather weak. However, methodological control and standardization of the cohort had to be sacrificed, given that subjects were patients in an actual treatment programme (i.e., not one designed solely for research purposes).

In conclusion, the results seen in the present study may be a first step in the better tailoring of treatment to patient. The ability to be able to identify the psychological characteristics of patients who are not likely to benefit sufficiently from medical treatment, may facilitate the development of alternative treatment approaches tailored to their specific needs. Future research should focus on matching treatment to individual patient. In the case of patients with high levels of depression, this could mean that a physician should refrain from offering medical treatment alone, but should also offer patients additional treatment for their depression. 


\section{REFERENCES}

Beck, A.T., Steer, R.A. \&Garbin, M.G.(1988). Psychometric properties of the Beck Depression Inventory: twenty-five years of evaluation. Clin Psych Rev 8(77-100.

Beck, A.T., Ward, C.H., Mendelson, M., Mock, J. \&Erbaugh, J.(1961). An inventory for measuring depression. Arch Gen Psychiatry 4(561-71.

Bernstein, I.H., Jaremko, M.E. \&Hinkley, B.S.(1995). On the utility of the West Haven-Yale Multidimensional Pain Inventory. Spine 20(8): 956-63.

Bruehl, S. \&Chung, 0.Y.(2006). Psychological and behavioral aspects of complex regional pain syndrome management. Clin J Pain 22(5): 430-7.

Burchiel, K.J., Anderson, V.C., Wilson, B.J., Denison, D.B., Olson, K.A. \&Shatin, D.(1995). Prognostic factors of spinal cord stimulation for chronic back and leg pain. Neurosurgery $36(6)$ : 1101-10; discussion 1110-1.

Crombez, G., Eccleston, C., Baeyens, F. \&Eelen, P.(1998). When somatic information threatens, catastrophic thinking enhances attentional interference. Pain 75(2-3): 187-98.

Crombez, G. \&Vlaeyen, J.W.S.(1996). The Pain Catastrophizing Scale. unpublished Dutch/Flemisch translation.

Dworkin, R.H., Turk, D.C., Farrar, J.T., Haythornthwaite, J.A., Jensen, M.P., Katz, N.P., Kerns, R.D., Stucki, G., Allen, R.R., Bellamy, N., Carr, D.B., Chandler, J., Cowan, P., Dionne, R., Galer, B.S., Hertz, S., Jadad, A.R., Kramer, L.D., Manning, D.C., Martin, S., McCormick, C.G., McDermott, M.P., McGrath, P., Quessy, S., Rappaport, B.A., Robbins, W., Robinson, J.P., Rothman, M., Royal, M.A., Simon, L., Stauffer, J.W., Stein, W., Tollett, J., Wernicke, J. \&Witter, J.(2005). Core outcome measures for chronic pain clinical trials: IMMPACT recommendations. Pain 113(1-2): 9-19.

Dworkin, R.H., Turk, D.C., Wyrwich, K.W., Beaton, D., Cleeland, C.S., Farrar, J.T., Haythornthwaite, J.A., Jensen, M.P., Kerns, R.D., Ader, D.N., Brandenburg, N., Burke, L.B., Cella, D., Chandler, J., Cowan, P., Dimitrova, R., Dionne, R., Hertz, S., Jadad, A.R., Katz, N.P., Kehlet, H., Kramer, L.D., Manning, D.C., McCormick, C., McDermott, M.P., McQuay, H.J., Patel, S., Porter, L., Quessy, S., Rappaport, B.A., Rauschkolb, C., Revicki, D.A., Rothman, M., Schmader, K.E., Stacey, B.R., Stauffer, J.W., von Stein, T., White, R.E., Witter, J. \&Zavisic, S.(2008). Interpreting the clinical importance of treatment outcomes in chronic pain clinical trials: IMMPACT recommendations. J Pain 9(2): 105-21.

Engstrom, D., Cognitive behavioral therapy methods in chronic pain treatments. In: Bonica, J. J. (Ed.), Advances in pain research and therapy., Raven Press, New York, 1983, pp. 829-38.

Feuerstein, M., Menz, L., Zastowney, T.R. \&Barron, B.A.(1994). Chronic pain and disability: Vocational outcomes following multidisciplinary rehabilitation. J Occup Rehabil 4(229-51.

Gatchel, R.J.(2001). A biopsychosocial overview of pretreatment screening of patients with pain. Clin J Pain 17(3): 192-9.

Gatchel, R.J., Peng, Y.B., Peters, M.L., Fuchs, P.N. \&Turk, D.C.(2007). The biopsychosocial approach to chronic pain: scientific advances and future directions. Psychol Bull 133(4): 581-624.

Geisser, M.E., Roth, R.S. \&Robinson, M.E.(1997). Assessing depression among persons with chronic pain using the Center for Epidemiological Studies-Depression Scale and the Beck Depression Inventory: a comparative analysis. Clin J Pain 13(2): 163-70.

Gilron, I., Watson, C.P., Cahill, C.M. \&Moulin, D.E.(2006). Neuropathic pain: a practical guide for the clinician. Cmaj 175(3): 265-75.

Gustorff, B., Dorner, T., Likar, R., Grisold, W., Lawrence, K., Schwarz, F. \&Rieder, A.(2008). Prevalence of self-reported neuropathic pain and impact on quality of life: a prospective representative survey. Acta Anaesthesiol Scand 52(1): 132-6.

Harris, C.A. \&D'Eon, J.L.(2007). Psychometric properties of the Beck Depression Inventory-Second Edition (BDI-II) in individuals with chronic pain. Pain.

Haythornthwaite, J.A. \&Benrud-Larson, L.M.(2000). Psychological aspects of neuropathic pain. Clin J Pain 16(2 Suppl): S101-5.

Hildebrandt, J., Pfingsten, M., Saur, P. \&Jansen, J.(1997). Prediction of success from a multidisciplinary treatment program for chronic low back pain. Spine 22(9): 990-1001. 
Kerns, R.D. \&Haythornthwaite, J.A.(1988). Depression among chronic pain patients: cognitivebehavioral analysis and effect on rehabilitation outcome. J Consult Clin Psychol 56(6): 870-6.

Kerns, R.D., Turk, D.C. \&Rudy, T.E.(1985). The West Haven-Yale Multidimensional Pain Inventory (WHYMPI). Pain 23(4): 345-56.

King, S.J., Wessel, J., Bhambhani, Y., Sholter, D. \&Maksymowych, W.(2002). Predictors of success of intervention programs for persons with fibromyalgia. J Rheumatol 29(5): 1034-40.

Lame, I.E., Geurts, J., Kessels, A.G., Peters, M.L., Koke, A., Kleef, M. \&Patijn, J.(in preparation). A Systematic Review of Psychological Predictors of Treatment Outcome in Chronic Non-cancer Pain.

Lame, I.E., Peters, M.L., Kessels, A.G., Kleef, M. \&Patijn, J.(2008). Test-retest stability of the Pain Catastrophizing Scale and the Tampa Scale for Kinesiophobia in chronic pain over a longer period of time. J Health Psych 13(6): 819-825.

Lame, I.E., Peters, M.L., Patijn, J., Kessels, A.G., Geurts, J. \&van Kleef, M.(in revision). Can the outcome of spinal cord stimulation in chronic CRPS-I patients be predicted by catastrophizing thoughts? Anaesth \& Analg.

Leo, R.J.(2006). Treatment considerations in neuropathic pain. Curr Treat Options Neurol 8(5): 389-400.

Linton, S.J.(2000). A review of psychological risk factors in back and neck pain. Spine 25(9): 1148-56.

McCreary, C., Turner, J. \&Dawson, E.(1979). The MMPI as a predictor of response to conservative treatment for low back pain. J Clin Psychol 35(2): 278-84.

Michaelson, P., Sjolander, P. \&Johansson, H.(2004). Factors predicting pain reduction in chronic back and neck pain after multimodal treatment. Clin J Pain 20(6): 447-54.

Miller, R.P., Kori, S.H. \&Todd, D.D.(1991). The Tampa Scale for Kinesiophobia. unpublished report.

Moore, M.J., Moore, P.B. \&Shaw, P.J.(1998). Mood disturbances in motor neurone disease. J Neurol Sci 160 Suppl 1(S53-6.

Pincus, T., Burton, A.K., Vogel, S. \&Field, A.P.(2002). A systematic review of psychological factors as predictors of chronicity/disability in prospective cohorts of low back pain. Spine 27(5): E109-20.

Pincus, T., Vogel, S., Burton, A.K., Santos, R. \&Field, A.P.(2006). Fear avoidance and prognosis in back pain: a systematic review and synthesis of current evidence. Arthritis Rheum 54(12): 3999-4010.

Rosnow, R.L. \&Rosenthal, R.(2005). Beginning behavioural research: a conceptual primer. Englewood Cliffs, NJ: Pearson/Prentice Hall.

Samwel, H., Slappendel, R., Crul, B.J. \&Voerman, V.F.(2000). Psychological predictors of the effectiveness of radiofrequency lesioning of the cervical spinal dorsal ganglion (RF-DRG). Eur J Pain 4(2): 149-55.

Spinhoven, P., ter Kuile, M.M. \&Linssen, A.C.G.(1994). Coping met Pijn Vragenlijst (CPV) handleiding/experimentele versie. Lisse: Swets \& Zeitlinger.

Stomp-van den Berg, S.G.M., Vlaeyen, J., ter Kuile, M.M., Spinhoven, P., van Breukelen, G. \&KoleSnijders, A.M.,(2001). Pijn coping en cognitie lijst (PCCL), Meetinstrumenten chronische pijn, Maastricht, 2001.

Sullivan, M.J.L., Bishop, S.R. \&Pivik, J.(1995). The Pain Catastrophizing Scale: Development and Validation. Psych Assess 7(4): 524-32.

Tota-Faucette, M.E., Gil, K.M., Williams, D.A., Keefe, F.J. \&Goli, V.(1993). Predictors of response to pain management treatment. The role of family environment and changes in cognitive processes. Clin J Pain 9(2): 115-23.

Turk, D.C. \&0kifuji, A.(1994). Detecting depression in chronic pain patients: adequacy of self-reports. Behav Res Ther 32(1): 9-16.

Turk, D.C. \&Okifuji, A.(1998). Direction in prescriptive chronic pain management based on diagnostic characteristics of the patient. Am Pain Soc Bull 8(5-11.

Turner, J.A., Robinson, J. \&McCreary, C.P.(1983). Chronic low back pain: predicting response to nonsurgical treatment. Arch Phys Med Rehabil 64(11): 560-3.

Twilling, L.L.,(1998). Dissertation abstract: Affective predictors of response to oral opioid therapy in chronic neuropathic pain., Pacific Graduate School of Psychology, US, 1998.

Van Damme, S., Crombez, G., Vlaeyen, J., Goubert, L., Van den Broeck, A. \&Van Houdenhove, B.(2000). De Pain Catastrophizing Scale: psychometrische karakteristieken en normering. Gedragstherapie 3(211-22. 


\section{CHAPTER 5}

van der Hulst, M., Vollenbroek-Hutten, M.M. \&Ijzerman, M.J.(2005). A systematic review of sociodemographic, physical, and psychological predictors of multidisciplinary rehabilitation-or, back school treatment outcome in patients with chronic low back pain. Spine 30(7): 813-25.

Van der Zee, K., Sanderman, R. \&Heyink, J.(1993). De psychometrische kwaliteiten van de MOS 36-item Short Form Health Survey (SF-36) in een Nederlandse populatie. T Soc Gez 71(183-91.

Van der Zee, K., Sanderman, R., Heyink, J. \&Haes, d.H.(1996). Psychometric qualities of the Rand 36item health survey 1.0: a multidimensional measure of general health status. Int J Behav Med 3(104-22.

Vendrig, A.A., Derksen, J.J. \&de Mey, H.R.(1999). Utility of Selected MMPI-2 Scales in the Outcome Prediction for Patients With Chronic Back Pain. Psychol Assess 11(3): 381-85.

Vlaeyen, J.W., Geurts, S.M., Kole-Snijders, A.M., Schuerman, J.A., Groenman, N.H. \&van Eek, H.(1990). What do chronic pain patients think of their pain? Towards a pain cognition questionnaire. $\mathrm{Br} J \mathrm{Clin}$ Psychol 29 (Pt 4) (383-94.

Vlaeyen, J.W., Kole-Snijders, A.M., Boeren, R.G. \&van Eek, H.(1995). Fear of movement/(re)injury in chronic low back pain and its relation to behavioral performance. Pain 62(3): 363-72.

Vlaeyen, J.W. \&Linton, S.J.(2000). Fear-avoidance and its consequences in chronic musculoskeletal pain: a state of the art. Pain $85(3): 317-32$.

Vlaeyen, J.W. \&Morley, S.(2005). Cognitive-behavioral treatments for chronic pain: what works for whom? Clin J Pain 21(1): 1-8.

Waddell, G.(2006). Preventing incapacity in people with musculoskeletal disorders. Br Med Bull 7778(55-69.

Ware, J.E., Jr., Kosinski, M., Bayliss, M.S., McHorney, C.A., Rogers, W.H. \&Raczek, A.(1995). Comparison of methods for the scoring and statistical analysis of SF-36 health profile and summary measures: summary of results from the Medical Outcomes Study. Med Care 33(4 Suppl): AS264-79.

Ware, J.E., Kosinski, M. \&Keller, S.K.,(1994). SF-36 Physical and Mental Health Summary Scales: A User's Manual., Boston, MA: The Health Institute., 1994.

Wilson, K.G., Mikail, S.F., D’Eon, J.L. \&Minns, J.E.(2001). Alternative diagnostic criteria for major depressive disorder in patients with chronic pain. Pain 91(3): 227-34. 


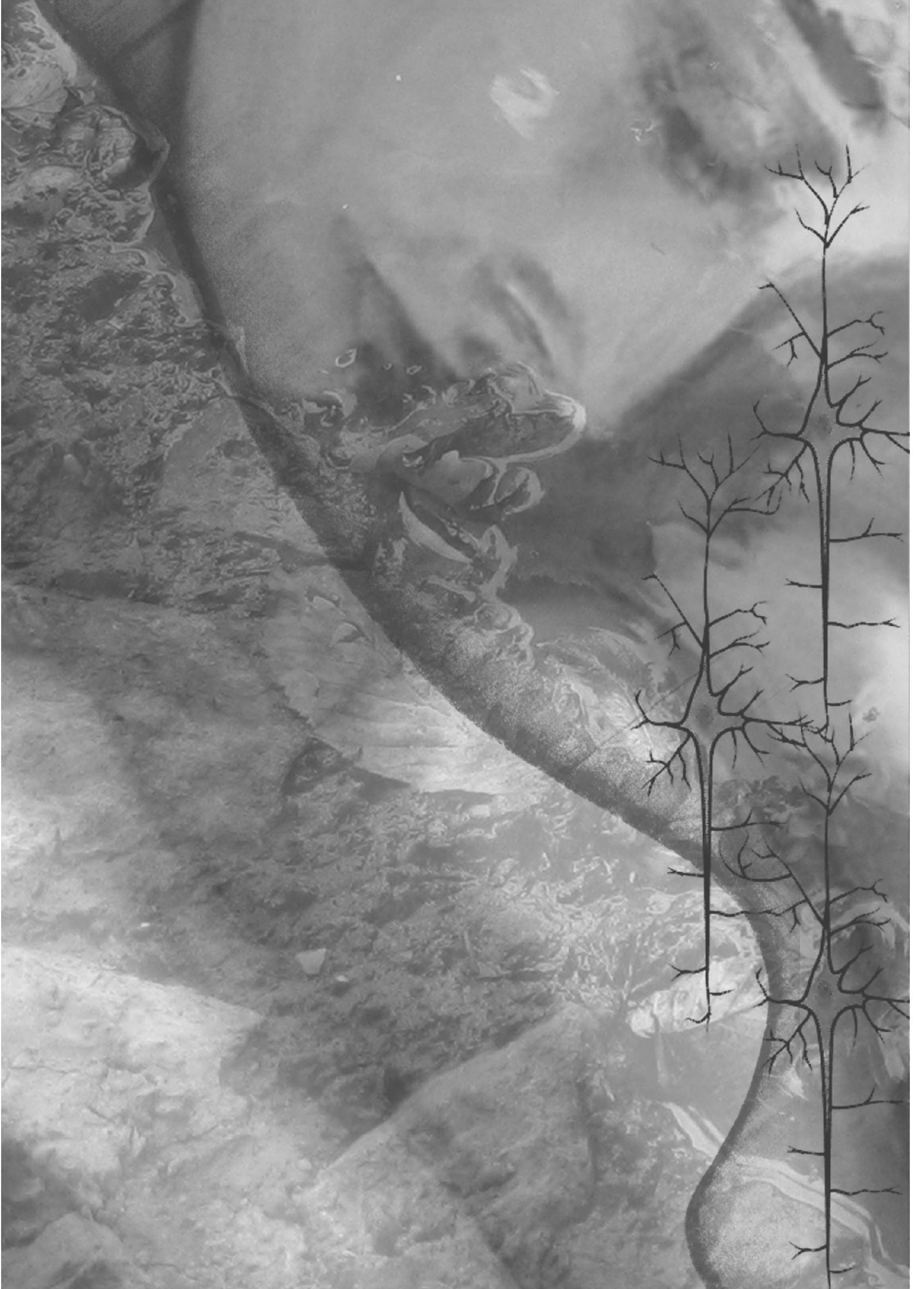




\section{Chapter 6}

Can the outcome of spinal cord stimulation in chronic CRPS-I patients be predicted by catastrophizing thoughts?

Inge Lamé, Madelon Peters, Jacob Patijn, Alfons Kessels, José Geurts, Maarten van Kleef 


\section{ABSTRACT}

The aim of the present study was to examine whether pain catastrophizing is a predictor of Spinal Cord Stimulation (SCS) outcome in patients with Complex Regional Pain Syndrome type I (CRPS-I). Thirty-two patients with chronic CRPS-I participated in this prospective cohort study, and received permanent SCS after a positive response to test stimulation. Baseline assessment was performed before test stimulation, and included questions on demographic variables, disease information, pain intensity (VAS), Pain Catastrophizing Scale (PCS), and health-related quality of life (SF-36). Follow-up assessment was performed nine months after final implantation, and included pain intensity, global perceived effect (GPE), and health-related quality of life. Successful SCS outcome was defined as a reduction of pain intensity of at least $50 \%$ or a 'much improved' or 'total pain relief' on GPE.

After nine months, $38 \%$ of the patients had a successful outcome in terms of reduced pain intensity, and $53 \%$ in terms of GPE. In addition, improvements were apparent for several of the domains of health-related quality of life. However, no evidence was found for the predictive value of catastrophizing on the efficacy of SCS in terms of reduction of pain intensity, GPE, or health-related quality of life.

This study showed that the efficacy of SCS in terms of reduction of pain intensity, GPE and quality of life, in a well-defined chronic CRPS-I population, was not predicted by pain catastrophizing. Therefore, we concluded that a high level of pain catastrophizing in CRPS-I patients is not a contra-indication for SCS treatment.

\section{INTRODUCTION}

Complex Regional Pain Syndrome (CRPS) is characterized by extreme pain and dysfunction of the sympathetic nervous system. It is usually restricted to one region of the body, typically an extremity. CRPS is usually initiated after a traumatic injury or surgical intervention in a limb. Two different types can be distinguished: CRPS-I (formerly known as reflex sympathetic dystrophy) and CRPS-II (formerly known as causalgia). The yearly incidence of CRPS in the Netherlands is 26.2 per 100,000 inhabitants (95\% CI: 23.0-29.7), with the highest incidence occurring between 61 and 70 years of age (de Mos et al., 2007). A substantial portion (approximately 20\%) of patients with acute CRPS go on to develop a chronic condition. Although the syndrome is relatively rare, it can be seen as a significant medical condition (Stanton-Hicks et al., 1998; Geertzen et al., 2006).

Treatment for CRPS primarily focuses on restoration of function in the affected limb. One of the treatment options is spinal cord stimulation (SCS), which is particularly recommended for patients with CRPS who show a poor response to conservative treatment (Stanton-Hicks et al., 1998; Stanton-Hicks et al., 2002; Lee \& Pilitsis, 2006). SCS has been seen to be effective in CRPS in terms of pain relief 
and improvement of quality of life (Lee \& Pilitsis, 2006; Stanton-Hicks, 2006; Taylor, 2006; Cruccu et al., 2007). However, despite evidence of its efficacy, there are still various unresolved issues. Firstly, the long-term efficacy of SCS is still under debate (Turner et al., 2004; Kumar et al., 2006). Secondly, and most importantly for the present study, not all patients profit from this procedure to the same degree (Taylor et al., 2006). Better selection of patients may avoid unnecessary costs and suffering (Kumar et al., 2006). The actual implantation is usually preceded by trial stimulation, and only patients with a positive response to trial stimulation receive permanent SCS. However, this selection procedure does not guarantee long-term success (Cruccu et al., 2007), and may be supplemented by additional criteria. Prognostic studies on pre-implantation predictor variables for successful outcome are needed in order to establish these criteria and guide clinical decision-making.

Prognostic variables for the efficacy of SCS that have emerged from previous studies include dual versus single lead stimulators, site of placement, number of previous operations, and duration of pain before implantation (Taylor et al., 2006; Kumar \& Wilson, 2007). Demographic variables were not consistently associated with outcome. It has also been suggested that psychological factors may play a role in determining the long-term efficacy of SCS (Doyles, 2006). So far, only a few studies have examined whether psychological factors influence treatment outcome, and the results are inconclusive (North et al., 1996; Doyles, 2006; Taylor et al., 2006). This study focuses on the role of one specific psychological factor that may be predictive of outcome in SCS, i.e., pain catastrophizing. Recently Bruehl \& Chung (2006) suggested that pain catastrophizing may be critically involved in the maintenance of the primary features of CRPS, and that these dysfunctional cognitions should be addressed before implementing medical treatment strategies. Catastrophic cognition and incorrect beliefs about the meaning of pain are indeed common in CRPS patients (Bruehl et al., 1996). Because of the intensity of the pain and the somatic symptoms characteristic of CRPS (e.g., allodynia), patients with CRPS may be especially inclined to assume that pain signals damage (Bruehl \& Chung, 2006). Catastrophic misinterpretations of pain could be a primary contributor to disuse and, in the end, may have a deleterious effect on CRPS itself, as well as on its responsiveness to treatment (Bruehl \& Chung, 2006).

The present study examines whether pain catastrophizing is indeed a predictor of SCS outcome in patients with CRPS-I. Pain catastrophizing was measured before implantation and outcome in terms of pain reduction, global perceived effect and health related quality of life were assessed 9 months post implantation. We hypothesized that high catastrophizing patients would have a less successful longterm outcome. 


\section{MATERIAL AND METHODS}

\section{Patient selection}

Participants in this prospective cohort study were selected from the CRPS population at the outpatient's clinic for Pain and Pain management at the University Hospital Maastricht, the Netherlands. Patients were eligible for inclusion if they met the diagnostic criteria for CRPS established by the International Association for the Study of Pain, with impaired function and symptoms beyond the area of trauma (Merskey \& Bogduk, 1994). Additional inclusion criteria were: 1 . Symptoms limited to one hand or one foot, with the entire hand or foot being affected. 2 . Disease duration of at least six months. 3. No long-term benefits from standard therapy (six months of physical therapy, sympathetic blockade, transcutaneous electrical nerve stimulation, and pain medication). 4. A mean pain intensity of at least 5 on a visual analogue scale (VAS) from 0 (no pain) to 10 (worst possible pain), measured using a four-day pain diary.

Patients were excluded from participation if they were suffering from Raynaud's disease, current or previous neurological abnormalities other than CRPS, other conditions affecting the diseased or contralateral extremity, a blood-clotting disorder, or if they used an anticoagulant drug or a cardiac pacemaker. The study complied with the provisions of the Declaration of Helsinki with regard to research involving human subjects, and was approved by the medical ethics committee of Maastricht University Hospital in Maastricht, the Netherlands. All patients gave their written informed consent.

\section{Test stimulation and implantation}

Firstly, all patients underwent test stimulation for one week. Only patients showing a positive response after test stimulation received permanent SCS. A positive response to test stimulation was defined as a decrease in pain intensity on VAS by at least $50 \%$ during the last four days of the testing period, or a score of at least 6 (much improved) on a seven-point Likert scale measuring global perceived effect (GPE) (Likert, 1932). For details of the test stimulation technique and permanent implantation, see Kemler et al. (2000).

\section{Measures}

Demographic variables. Patients' sex, age, marital status, and highest level of education were recorded.

Disease variables. Duration of pain in months and location of the pain (arm versus leg) were recorded. 
Pain intensity. Pain intensity was scored on a visual analogue scale (VAS), with endpoint 'no pain' and 'worst possible pain'.

Global perceived effect. GPE was measured on a seven-point scale (1: worst ever; 2: much worse; 3: worse; 4: no change; 5: improved; 6: much improved; 7: total pain relief).

Quality of Life. Quality of life was measured using SF-36. This instrument was developed during the Medical Outcome Studies of the Rand Corporation and measures general health and quality of life (Van der Zee et al., 1993). SF-36 encompasses eight domains of health-related quality of life: physical functioning (PF), social functioning (SF), role limitations physical (RF), role limitations emotional (RE), mental health $(\mathrm{MH})$, vitality (VI), bodily pain (BP), and general health perception (GH). All raw scale scores are linearly converted to a 0-100 scale. Higher scores indicate a higher level of quality of life. The psychometric properties of SF-36 are adequate (Van der Zee et al., 1993; Van der Zee et al., 1996; Essink-Bot et al., 1997; Aaronson et al., 1998).

Pain catastrophizing. Pain catastrophizing was measured with the Dutch version of the Pain Catastrophizing Scale (PCS). PCS is a 13-item instrument. Items are scored on a five-point Likert scale, ranging from 0 (not at all) to 4 (always), developed in order to identify catastrophic thoughts or feelings that patients experience in relation to their pain. PCS has good psychometric properties (Crombez et al., 1998; Van Damme et al., 2000; Lame et al., 2008).

\section{Procedure}

Before their first appointment with the physician, eligible patients received a questionnaire package by mail, which they had to return. The questionnaire package included questions on demographic variables, disease information, and pain intensity, PCS, and SF-36. Then, the patients received test implantation for one week, and when successful, permanent SCS followed immediately thereafter. Follow-up assessment was performed nine months after final implantation. Patients received a questionnaire package by mail, containing questions on pain intensity, GPE, and SF-36.

\section{Statistical analysis}

Pain intensity was calculated by averaging VAS measured over four days, three times a day. Successful outcome was defined as an improvement of VAS of at least $50 \%$ (Forouzanfar et al., 2003). In addition, for GPE, successful outcome was defined as a score of 6 or 7 (i.e., 'much improved' or 'total pain relief').

Changes in pain and the health-related quality of life domains from baseline to follow-up were tested using paired-sample $t$-tests. Logistic regression analysis was used to identify predictors of the dichotomous outcome variables successful pain 


\section{CHAPTER 6}

relief and successful global perceived effect. As potential predictors, we examined demographic variables, pain duration, pain location, pain intensity at baseline, and pain catastrophizing. In order to reduce the number of predictors, we first conducted univariate analysis, using t-tests for continuous and 2 analysis for categorical variables. Variables that differentiated between patients with or without successful outcome in the univariate analysis, were subsequently included in the logistic regression analysis. In order not to miss a potentially important predictor, we used a significance level of 0.10 for these preliminary analyses. Pain catastrophizing was considered our crucial predictor variable, and was always entered in the regression.

Linear regression analysis was used to identify predictors of changes in healthrelated quality of life from baseline to nine months' follow-up. Significant variables from the previous univariate analysis, together with pain catastrophizing, were entered as independent variables. Moreover, the analyses for each domain were controlled for baseline level of quality of life for that domain. All data were analyzed using the SPSS Statistical Package, version 12.0, for Windows. We used a significance level of 0.05 for the logistic and linear regression analyses.

\section{RESULTS}

\section{Description of population}

Between January 2000 and September 2006, all CRPS-I patients who were eligible for SCS were referred to our pain clinic. Following the inclusion and exclusion criteria, 58 patients were considered for SCS. Of these, $26(45 \%)$ did not receive permanent SCS for the following reasons: insufficient pain reduction after test stimulation ( $n=14)$, low pain intensity on the day of test stimulation $(n=2)$, no paresthesias following test stimulation $(n=2)$, refusal of permanent implantation $(n=3)$, and psychological problems $(n=2)$. No follow-up assessment was available in three patients. Thus, the final study population consisted of 32 patients with chronic CRPS-I. The baseline characteristics are summarized in Table 1. 
Table 1: Baseline characteristics of the CRPS patients

\begin{tabular}{lll}
\hline Characteristic & & $\mathrm{N}=32$ \\
\hline Gender \% & male & 21.2 \\
& female & 78.8 \\
Age yr (SD) [range] & & $38.9(10.5)[15-58]$ \\
Pain duration yr (SD) [range] & & $4.5(3.3)[0,5-16]$ \\
Location of pain \% & arm & 46.9 \\
& leg & 53.1 \\
Marital status \% & married & 75.0 \\
& unmarried & 12.5 \\
Education \% & divorced & 6.3 \\
& lower vocational education & 46.9 \\
VAS score mean (SD) [range] & secondary education & 53.1 \\
PCS score mean (SD) [range] & & $75.6(14.3)[5.0-10.0]$ \\
Rand-36 domains & & $31.0(10.2)[2.0-47.0]$ \\
Mean(SD)[range] & physical function & $28.8(24.6)[0-90.0]$ \\
& social function & $41.3(27.9)[0-100]$ \\
& role limitations physical & $7.5(18.7)[0-75.0]$ \\
& role limitation emotional & $59.5(44.8)[0-100]$ \\
& mental health & $57.8(22.9)[0-96.0]$ \\
& vitality & $39.3(20.9)[5.0-75.0]$ \\
& bodily pain & $12.5(12.8)[0-34.7]$ \\
& general health perception & $50.5(15.8)[25.0-85.0]$ \\
\hline
\end{tabular}

$\mathrm{Yr}=$ year; $\mathrm{SD}=$ standard deviation; $\mathrm{VAS}=\mathrm{visual}$ analogue scale; $\mathrm{PCS}=$ pain catastrophizing scale

\section{SCS outcome at follow-up}

Pain relief of at least $50 \%$ on VAS was reported by 12 patients (38\%). Successful outcome on GPE (much improved or total pain relief) was reported by 17 patients $(53 \%)$. In addition, ten patients $(31 \%)$ reported a slight improvement, three $(9 \%)$ reported no change, and two $(6 \%)$ worsening of their condition. Table 2 shows average pain intensity and the scores on the SF-36 domains at baseline (preimplantation) and at follow-up. Pain intensity was significantly reduced from baseline to follow-up. In addition, nine months after SCS, patients scored significantly higher on the SF-36 domains social functioning, role limitations physical, mental health, vitality, and bodily pain. 


\section{CHAPTER 6}

Table 2: Pain and quality of life outcome measures

\begin{tabular}{lrcrc}
\hline Measuring instrument & $\begin{array}{l}\text { Baseline score } \\
\text { Mean (SD) }\end{array}$ & $\begin{array}{l}\text { Follow-up score } \\
\text { Mean (SD) }\end{array}$ & P value & $\begin{array}{l}\text { 95\% confidence } \\
\text { interval of mean } \\
\text { difference }\end{array}$ \\
\hline $\begin{array}{l}\text { Pain intensity (VAS) } \\
\text { SF-36: }\end{array}$ & $7.6(1.4)$ & $4.2(2.6)$ & $<0.0001$ & $2.4-4.2$ \\
$\quad$ Physical functioning & $28.8(24.6)$ & $34.3(29.1)$ & $\mathrm{ns}$ & $-15.4-4.4$ \\
Social functioning & $41.3(27.9)$ & $56.3(26.9)$ & 0.02 & $-27.4--2.4$ \\
Role limitations physical & $7.5(18.7)$ & $26.7(38.8)$ & 0.007 & $-32.7--5.6$ \\
Role limitations emotional & $59.5(44.8)$ & $64.3(47.1)$ & $\mathrm{ns}$ & $-30.1-20.5$ \\
Mental health & $57.8(22.9)$ & $68.6(20.1)$ & 0.02 & $-19.6--2.0$ \\
Vitality & $39.3(20.9)$ & $51.1(20.5)$ & 0.02 & $-21.2--2.4$ \\
Bodily pain & $12.5(12.8)$ & $42.2(24.8)$ & $<0.0001$ & $-37.8--21.7$ \\
General health & $50.5(15.8)$ & $45.9(21.7)$ & $\mathrm{ns}$ & $-2.5-11.8$ \\
\hline
\end{tabular}

ns $=$ non significant; VAS $=$ Visual analogue scale

Table 3: Univariate analyses for success on pain intensity and GPE

\begin{tabular}{|c|c|c|c|c|c|c|c|c|}
\hline \multirow[b]{3}{*}{ Predictor } & \multicolumn{3}{|c|}{ Pain intensity } & \multirow[b]{3}{*}{$\mathrm{P}$} & \multicolumn{4}{|l|}{ GPE } \\
\hline & \multirow{2}{*}{$\begin{array}{l}\text { Succesful } \\
n\end{array}$} & \multicolumn{2}{|l|}{ Not Succesful } & & \multirow{2}{*}{$\begin{array}{c}\text { Succesful } \\
n\end{array}$} & \multirow{2}{*}{$\begin{array}{l}\text { Not Succesful } \\
n\end{array}$} & \multirow{2}{*}{$\chi$} & \multirow[b]{2}{*}{$\mathrm{P}$} \\
\hline & & $\mathrm{n}$ & $\chi$ & & & & & \\
\hline \multicolumn{9}{|l|}{ Gender } \\
\hline Male & 2 & 5 & 0.305 & 0.68 & 4 & 3 & 0.058 & 1.00 \\
\hline Female & 10 & 15 & & & 13 & 12 & & \\
\hline \multicolumn{9}{|l|}{ Education } \\
\hline High & 4 & 13 & 3.020 & 0.14 & 9 & 8 & 0.000 & 1.00 \\
\hline Low & 8 & 7 & & & 8 & 7 & & \\
\hline \multicolumn{9}{|l|}{ Localization } \\
\hline Hand & 6 & 9 & 0.075 & 1.00 & 9 & 6 & 0.536 & 0.50 \\
\hline \multirow[t]{2}{*}{ Foot } & 6 & 11 & & & 8 & 9 & & \\
\hline & Mean $(s d)$ & Mean $(s d)$ & $\mathrm{t}$ & & Mean $(s d)$ & Mean (sd) & $\mathrm{t}$ & \\
\hline Age & $40.5(9.9)$ & $38.2(10.6)$ & -0.62 & 0.54 & $40.8(9.8)$ & $37.1(10.7)$ & -1.02 & 0.32 \\
\hline Pain duration years & $5.3(4.6)$ & $4.0(2.2)$ & -1.08 & 0.29 & $5.4(4.0)$ & $3.5(2.0)$ & -1.74 & 0.09 \\
\hline Pain intensity & $7.6(1.6)$ & $7.5(1.3)$ & -0.06 & 0.95 & $7.5(1.4)$ & $7.6(1.5)$ & 0.12 & 0.90 \\
\hline Pain catastrophizing & $34.4(4.9)$ & $29.0(12.0)$ & 1.50 & 0.15 & $30.1(10.4)$ & $32.1(10.2)$ & 0.55 & 0.59 \\
\hline
\end{tabular}

\section{Prognostic factors}

Table 3 summarizes the results of the univariate analysis to identify variables associated with successful outcome in terms of pain intensity and GPE. The demographic variables were not predictive of any of the outcome measures. The results show that only pain duration was predictive of success according to GPE. Thereafter, multivariate logistic regression analyses were performed in order to predict 
successful pain relief and successful global perceived effect, with pain duration and pain catastrophizing as the two independent variables. The regression model did not reach significance for either pain intensity or for GPE. Pain catastrophizing appeared to be unrelated to the outcome of SCS in terms of pain relief and GPE.

Table 4 presents the multivariate regression analysis for the eight domains of SF36. All the regression models included pain duration and the baseline score of the relevant SF-36 domain as control variables, and catastrophizing as the crucial variable in the final model. On follow-up, pain duration was found to be a significant predictor of social functioning and bodily pain. Moreover, for physical role limitations, vitality, and general health, there was a non-significant trend towards the association between pain duration and outcome. Patients with a longer duration of pain before SCS seemed to profit more in term of various aspects of healthrelated quality of life. Pain catastrophizing was not predictive of any of the SF-36 domains on follow-up.

Post hoc, we also tested whether any of the other demographic or pain-related variables were associated with outcome, when these were entered instead of pain catastrophizing, but no consistent predictive effect of any of these variables was found. Only education appeared to be related to general health on follow-up ( $\beta=$ $0.32 ; p=0.04)$, with patients with a higher education having better general health on follow-up. 
Table 4: Multivariate regression analyses for the domains of the Sf-36

\begin{tabular}{|c|c|c|c|c|c|c|}
\hline Dependent & Summary & $y$ of the & model & Predictors & & \\
\hline $\begin{array}{l}\text { Physical } \\
\text { Functioning-fu }\end{array}$ & $\mathrm{R}^{2}=0.28$ & $F=3.36$ & $p=0.03$ & $\begin{array}{l}\text { Pain duration } \\
\text { Physical functioning baseline } \\
\text { Catastrophizing }\end{array}$ & $\begin{array}{l}\beta=-0.01 \\
\beta=0.56 \\
\beta=-0.11\end{array}$ & $\begin{array}{l}p=0.96 \\
p=0.005 \\
p=0.55\end{array}$ \\
\hline $\begin{array}{l}\text { Social } \\
\text { Functioning-fu }\end{array}$ & $\mathrm{R}^{2}=0.20$ & $F=2.26$ & $p=0.10$ & $\begin{array}{l}\text { Pain duration } \\
\text { Social functioning baseline } \\
\text { Catastrophizing }\end{array}$ & $\begin{array}{l}\beta=0.39 \\
\beta=0.17 \\
\beta=-0.01\end{array}$ & $\begin{array}{l}p=0.03 \\
p=0.34 \\
p=0.94\end{array}$ \\
\hline $\begin{array}{l}\text { Role limitations } \\
\text { physical-fu }\end{array}$ & $\mathrm{R}^{2}=0.26$ & $F=3.11$ & $p=0.04$ & $\begin{array}{l}\text { Pain duration } \\
\text { Role limitations physical baseline } \\
\text { Catastrophizing }\end{array}$ & $\begin{array}{l}\beta=0.32 \\
\beta=0.31 \\
\beta=0.18\end{array}$ & $\begin{array}{l}p=0.07 \\
p=0.09 \\
p=0.29\end{array}$ \\
\hline $\begin{array}{l}\text { Role limitations } \\
\text { emotional-fu }\end{array}$ & $\mathrm{R}^{2}=0.03$ & $F=0.28$ & $p=0.84$ & $\begin{array}{l}\text { Pain duration } \\
\text { Role limitations emotional baseline } \\
\text { Catastrophizing }\end{array}$ & $\begin{array}{l}\beta=0.13 \\
\beta=-0.05 \\
\beta=-0.12\end{array}$ & $\begin{array}{l}p=0.55 \\
p=0.81 \\
p=0.56\end{array}$ \\
\hline Mental Health-fu & $\mathrm{R}^{2}=0.24$ & $F=2.76$ & $p=0.06$ & $\begin{array}{l}\text { Pain duration } \\
\text { Mental health baseline } \\
\text { Catastrophizing }\end{array}$ & $\begin{array}{l}\beta=0.23 \\
\beta=0.44 \\
\beta=0.21\end{array}$ & $\begin{array}{l}p=0.19 \\
p=0.03 \\
p=0.29\end{array}$ \\
\hline Vitality-fu & $\mathrm{R}^{2}=0.19$ & $F=1.97$ & $p=0.15$ & $\begin{array}{l}\text { Pain duration } \\
\text { Vitality baseline } \\
\text { Catastrophizing }\end{array}$ & $\begin{array}{l}\beta=0.34 \\
\beta=0.41 \\
\beta=0.08\end{array}$ & $\begin{array}{l}p=0.09 \\
p=0.05 \\
p=0.68\end{array}$ \\
\hline Bodily Pain-fu & $R^{2}=0.36$ & $F=5.28$ & $p=0.005$ & $\begin{array}{l}\text { Pain duration } \\
\text { Bodily pain baseline } \\
\text { Catastrophizing }\end{array}$ & $\begin{array}{l}\beta=0.41 \\
\beta=0.47 \\
\beta=0.06\end{array}$ & $\begin{array}{l}p=0.01 \\
p=0.005 \\
p=0.72\end{array}$ \\
\hline General Health-fu & $\mathrm{R}^{2}=0.37$ & $F=4.81$ & $p=0.009$ & $\begin{array}{l}\text { Pain duration } \\
\text { General health baseline } \\
\text { Catastrophizing }\end{array}$ & $\begin{array}{l}\beta=0.28 \\
\beta=0.59 \\
\beta=-0.02\end{array}$ & $\begin{array}{l}p=0.09 \\
p=0.002 \\
p=0.93\end{array}$ \\
\hline
\end{tabular}

$\mathrm{fu}=$ follow-up

\section{DISCUSSION}

The present study examined whether pain catastrophizing is a predictor of SCS outcome in patients with CRPS-I. The results of this study showed that the efficacy of SCS in terms of reduction of pain intensity, GPE, and quality of life in a welldefined chronic CRPS-I population was not predicted by pain catastrophizing. Pain duration appeared to be predictive of quality of life, i.e., patients with a longer duration of pain profited more from SCS.

Previously, it has been suggested that pain catastrophizing may contribute to a negative emotional state, which is an important factor in the maintenance of CRPS and the response to treatment (Bruehl \& Chung, 2006). So far, the influence of pain catastrophizing on the outcome of treatment in CRPS had not yet been examined. However, there is evidence from other pain conditions that pre-intervention pain catastrophizing predicts postoperative pain after abdominal surgery (Granot \& Ferber, 2005) and after total knee arthroplasy (Roth et al., 2007). More pertinent to the present study is the fact that a few studies have examined the influence of 
pain catastrophizing on the treatment of chronic pain conditions. Two studies found pain catastrophizing to be a negative predictor of treatment efficacy: it reduced the patient's subjective rating of success after multidisciplinary treatment for low back pain (Hildebrandt et al., 1997), and was related to less pain reduction after radiofrequency lesions of the cervical spinal dorsal ganglion in cervicobrachialgia (Samwel et al., 2000). Another study found no association between pain catastrophizing and outcome of high frequency transcutaneous electrical nerve stimulation (TENS) in a chronic outpatient pain population (Oosterhof et al., 2007).

In the present study we were unable to find any evidence of the hypothesized influence of pain catastrophizing on the outcome of SCS in CRPS patients. It should be noted that the mean PCS score in this study was rather high (mean = 31 ), showing that CRPS patients display a significant degree of pain catastrophizing. Indeed, compared to other chronic pain populations, where a median of 22 or 25 was found, in the present population, 78\% $(n=25)$ of patients obtained a score higher than 25 (Van Damme et al., 2002). It can be hypothesized that the absence of effect results from the fact that almost all patients scored in the high catastrophizing range. It can also be proposed that, in this population in particular, catastrophizing may be secondary to the seriousness of the complaints and the repeated failure of previous treatment, leading patients to believe that CRPS is an untreatable and progressively deteriorating condition (Bruehl \& Chung, 2006). The main duration of pain was fairly long and possibly in less chronic patients, the predictive value of pain catastrophizing could be present. Nevertheless, our results demonstrate that SCS could have long-term positive effects in CRPS-I patients, despite high levels of pain catastrophizing.

Quality of life is an upcoming issue in chronic disease conditions (Kemler \& de Vet, 2000). With regard to the impact of catastrophizing on quality of life, findings in a large community sample with different pain subgroups and pain-free persons (Severeijns et al., 2002), and in a chronic pain population (Lame et al., 2005), indicated that catastrophizing most prominently affects the mental and social aspects of quality of life. In the present study, we also found that pain catastrophizing was most closely related to mental health at baseline $(r=-0.47)$. However, there was no prospective relationship between pain catastrophizing and changes in quality of life after treatment. The only prospective relationship found in this study was between pain duration and social functioning and bodily pain on follow-up. In the case of pre- to post-intervention changes in physical role limitations, vitality, and general health, a trend towards an association with pain duration was found. Patients suffering pain for a longer period of time showed greater improvement with regard to these aspects of quality of life. This is in contrast with a previous study that found an inverse relationship between time from onset of 


\section{CHAPTER 6}

first CRPS symptoms and efficacy of SCS (Kumar \& Wilson, 2007). At present, we do not have an explanation for these converging results.

Several limitations of this study must be acknowledged. For example, we collected our data via the post, which may have biased the results. Moreover, we focused on a single psychological variable as a predictor of outcome. Although the selection of this variable was guided by theoretical considerations, and was based on the prior suggestion that pain catastrophizing is of critical importance in the maintenance of the primary features of CRPS (Bruehl \& Chung, 2006), future studies could also include other potentially important contenders (i.e., kinesiophobia, depression). This study has also several strengths. Firstly, there was a very high response rate, because the questionnaire had to be returned before a first medical appointment could be made. Secondly, we used a well-defined CRPS-I population. Finally, we had a fairly long follow-up period (nine months) and could therefore really assess the predictors of the long-term efficacy of SCS.

This was the first study to test the assumption that pain catastrophizing may negatively affect the responsiveness to treatment in CRPS. More specifically, we assessed its influence on long-term outcome after SCS. We found no evidence for the predictive value of pain catastrophizing for SCS outcome in terms of pain intensity, GPE, and quality of life in patients with CRPS-I. Therefore, we conclude that a high level of pain catastrophizing in CRPS-I patients is not a contraindication for SCS treatment. 


\section{REFERENCES}

Aaronson, N.K., Muller, M., Cohen, P.D., Essink-Bot, M.L., Fekkes, M., Sanderman, R., Sprangers, M.A., te Velde, A. \&Verrips, E.(1998). Translation, validation, and norming of the Dutch language version of the SF-36 Health Survey in community and chronic disease populations. J Clin Epidemiol 51(11): 1055-68.

Bruehl, S. \&Chung, 0.Y.(2006). Psychological and behavioral aspects of complex regional pain syndrome management. Clin J Pain 22(5): 430-7.

Bruehl, S., Husfeldt, B., Lubenow, T.R., Nath, H. \&Ivankovich, A.D.(1996). Psychological differences between reflex sympathetic dystrophy and non-RSD chronic pain patients. Pain 67(1): 107-14.

Crombez, G., Eccleston, C., Baeyens, F. \&Eelen, P.(1998). When somatic information threatens, catastrophic thinking enhances attentional interference. Pain 75(2-3): 187-98.

Cruccu, G., Aziz, T.Z., Garcia-Larrea, L., Hansson, P., Jensen, T.S., Lefaucheur, J.P., Simpson, B.A. \&Taylor, R.S.(2007). EFNS guidelines on neurostimulation therapy for neuropathic pain. Eur J Neurol 14(9): 952-70.

de Mos, M., de Bruijn, A.G., Huygen, F.J., Dieleman, J.P., Stricker, B.H. \&Sturkenboom, M.C.(2007). The incidence of complex regional pain syndrome: a population-based study. Pain 129(1-2): 12-20.

Doyles, D.(2006). Psychological factors in spinal cord stimulation therapy: brief review and discussion. Neurosurg Focus 21(1-6.

Essink-Bot, M.L., Krabbe, P.F., Bonsel, G.J. \&Aaronson, N.K.(1997). An empirical comparison of four generic health status measures. The Nottingham Health Profile, the Medical Outcomes Study 36item Short-Form Health Survey, the COOP/WONCA charts, and the EuroQol instrument. Med Care 35(5): 522-37.

Forouzanfar, T., Weber, W.E., Kemler, M. \&van Kleef, M.(2003). What is a meaningful pain reduction in patients with complex regional pain syndrome type 1? Clin J Pain 19(5): 281-5.

Geertzen, J.H.B., Perez, R.S.G.M., Dijkstra, P.U., Kemler, M.A. \&Rosenbrand, C.J.G.M.,(2006). Complex Regional Pain Syndrome type I Guidelines, Van Zuiden communications BV, Alphen aan den Rijn, 2006.

Granot, M. \&Ferber, S.G.(2005). The roles of pain catastrophizing and anxiety in the prediction of postoperative pain intensity: a prospective study. Clin J Pain 21(5): 439-45.

Hildebrandt, J., Pfingsten, M., Saur, P. \&Jansen, J.(1997). Prediction of success from a multidisciplinary treatment program for chronic low back pain. Spine 22(9): 990-1001.

Kemler, M.A., Barendse, G.A., van Kleef, M., de Vet, H.C., Rijks, C.P., Furnee, C.A. \&van den Wildenberg, F.A.(2000). Spinal cord stimulation in patients with chronic reflex sympathetic dystrophy. N Engl J Med 343(9): 618-24.

Kemler, M.A. \&de Vet, H.C.(2000). Health-related quality of life in chronic refractory reflex sympathetic dystrophy (complex regional pain syndrome type I). J Pain Symptom Manage 20(1): 68-76.

Kumar, K., Hunter, G. \&Demeria, D.(2006). Spinal cord stimulation in treatment of chronic benign pain: challenges in treatment planning and present status, a 22-year experience. Neurosurgery 58(3): 481-96; discussion 481-96.

Kumar, K. \&Wilson, J.R.(2007). Factors affecting spinal cord stimulation outcome in chronic benign pain with suggestions to improve success rate. Acta Neurochir Suppl 97(Pt 1): 91-9.

Lame, I.E., Peters, M.L., Kessels, A.G., Kleef, M. \&Patijn, J.(in press). Test-retest stability of the Pain Catastrophizing Scale and the Tampa Scale for Kinesiophobia in chronic pain over a longer period of time. J Health Psych.

Lame, I.E., Peters, M.L., Vlaeyen, J.W., Kleef, M. \&Patijn, J.(2005). Quality of life in chronic pain is more associated with beliefs about pain, than with pain intensity. Eur J Pain 9(1): 15-24.

Lee, A.W. \&Pilitsis, J.G.(2006). Spinal cord stimulation: indications and outcomes. Neurosurg Focus 21(6): E3.

Likert, R.(1932). A Technique for the measurement of attitudes. Arch Psych 22(140.

Merskey, H. \&Bogduk, N.(1994). Classification of chronic pain: descriptions of chronic pain syndromes and definitions of pain terms. Seattle: IASP press. 40-2 pp. 


\section{CHAPTER 6}

North, R.B., Kidd, D.H., Wimberly, R.L. \&Edwin, D.(1996). Prognostic value of psychological testing in patients undergoing spinal cord stimulation: a prospective study. Neurosurgery 39(2): 301-10; discussion 310-1.

Oosterhof, J., Samwel, H.J., de Boo, T.M., Wilder-Smith, 0.H., Oostendorp, R.A. \&Crul, B.J.(2007). Predicting outcome of TENS in chronic pain: A prospective, randomized, placebo controlled trial. Pain.

Roth, M.L., Tripp, D.A., Harrison, M.H., Sullivan, M. \&Carson, P.(2007). Demographic and psychosocial predictors of acute perioperative pain for total knee arthroplasty. Pain Res Manag 12(3): 185-94.

Samwel, H., Slappendel, R., Crul, B.J. \&Voerman, V.F.(2000). Psychological predictors of the effectiveness of radiofrequency lesioning of the cervical spinal dorsal ganglion (RF-DRG). Eur J Pain 4(2): $149-55$.

Severeijns, R., van den Hout, M.A., Vlaeyen, J.W. \&Picavet, H.S.(2002). Pain catastrophizing and general health status in a large Dutch community sample. Pain 99(1-2): 367-76.

Stanton-Hicks, M.(2006). Complex regional pain syndrome: manifestations and the role of neurostimulation in its management. J Pain Symptom Manage 31(4 Suppl): S20-4.

Stanton-Hicks, M., Baron, R., Boas, R., Gordh, T., Harden, N., Hendler, N., Koltzenburg, M., Raj, P. \&Wilder, R.(1998). Complex Regional Pain Syndromes: guidelines for therapy. Clin J Pain 14(2): 155-66.

Stanton-Hicks, M.D., Burton, A.W., Bruehl, S.P., Carr, D.B., Harden, R.N., Hassenbusch, S.J., Lubenow, T.R., Oakley, J.C., Racz, G.B., Raj, P.P., Rauck, R.L. \&Rezai, A.R.(2002). An updated interdisciplinary clinical pathway for CRPS: report of an expert panel. Pain Pract 2(1): 1-16.

Taylor, R.S.(2006). Spinal cord stimulation in complex regional pain syndrome and refractory neuropathic back and leg pain/failed back surgery syndrome: results of a systematic review and metaanalysis. J Pain Symptom Manage 31(4 Suppl): S13-9.

Taylor, R.S., Van Buyten, J.P. \&Buchser, E.(2006). Spinal cord stimulation for complex regional pain syndrome: a systematic review of the clinical and cost-effectiveness literature and assessment of prognostic factors. Eur J Pain 10(2): 91-101.

Turner, J.A., Loeser, J.D., Deyo, R.A. \&Sanders, S.B.(2004). Spinal cord stimulation for patients with failed back surgery syndrome or complex regional pain syndrome: a systematic review of effectiveness and complications. Pain 108(1-2): 137-47.

Van Damme, S., Crombez, G., Bijttebier, P., Goubert, L. \&Van Houdenhove, B.(2002). A confirmatory factor analysis of the Pain Catastrophizing Scale: invariant factor structure across clinical and nonclinical populations. Pain 96(3): 319-24.

Van Damme, S., Crombez, G., Vlaeyen, J., Goubert, L., Van den Broeck, A. \&Van Houdenhove, B.(2000). De Pain Catastrophizing Scale: psychometrische karakteristieken en normering. Gedragstherapie 3(211-22.

Van der Zee, K., Sanderman, R. \&Heyink, J.(1993). De psychometrische kwaliteiten van de MOS 36-item Short Form Health Survey (SF-36) in een Nederlandse populatie. T Soc Gez 71(183-91.

Van der Zee, K., Sanderman, R., Heyink, J. \&Haes, d.H.(1996). Psychometric qualities of the Rand 36item health survey 1.0: a multidimensional measure of general health status. Int J Behav Med 3(104-22. 


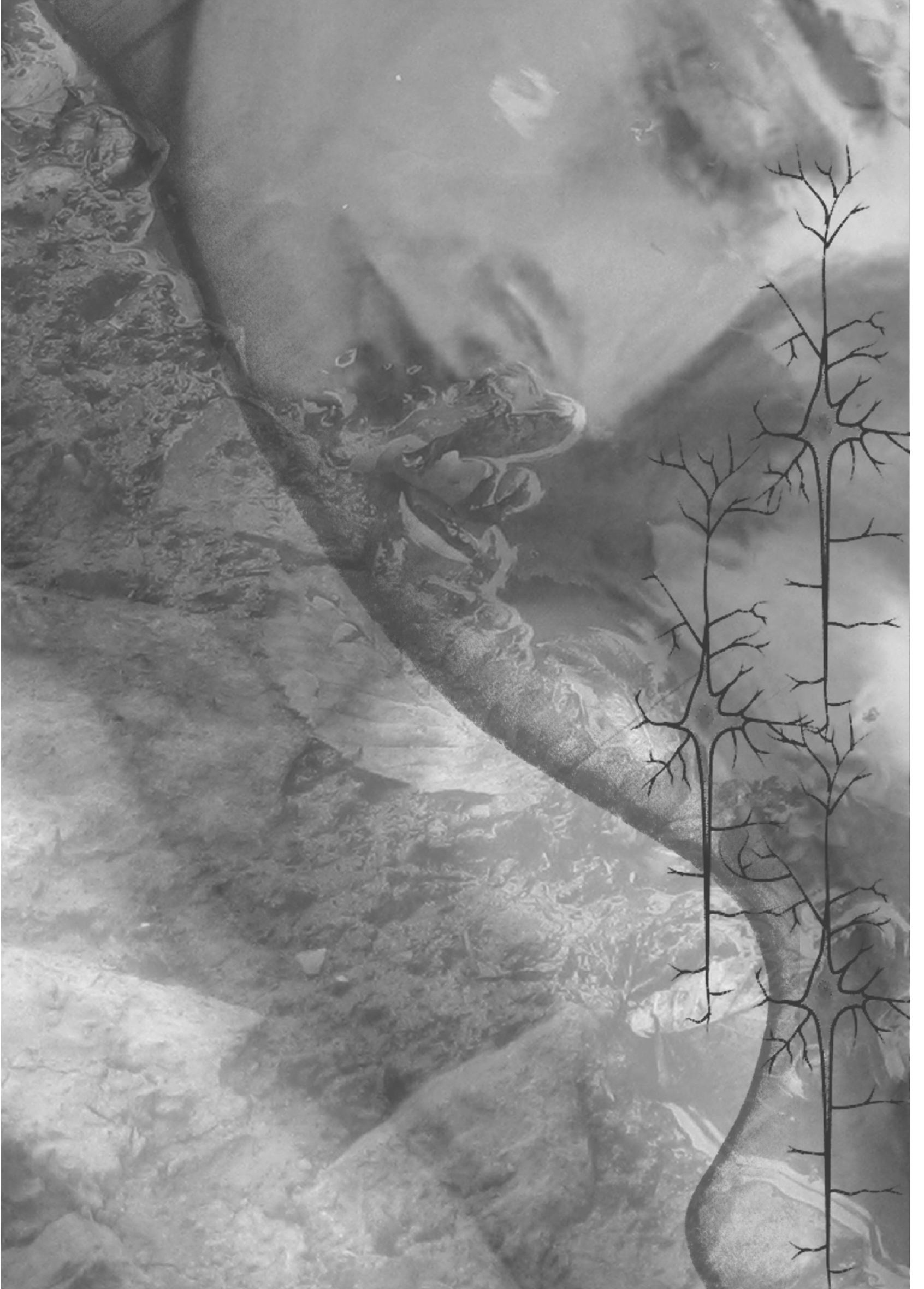




\section{Chapter 7}

\section{General discussion}




\section{INTRODUCTION}

The objective of this thesis was to examine whether psychological variables are predictive of treatment outcome in a heterogeneous chronic pain population referred to an academic pain centre. This final chapter presents a summary and discussion of the main findings, strengths and limitations, and the clinical relevance and recommendations for future research.

\section{RESULTS OF THE STUDIES}

The research questions formulated in Chapter 1 led to several results, which are listed below.

- Heterogeneous chronic pain patients visiting a pain clinic score significantly low on all eight quality of life domains compared to other chronic pain populations (Chapter 2).

- Pain catastrophizing appears to be the most prominent predictor of the mental components of quality of life (Chapter 2).

- The total scores on the Pain Catastrophizing Scale (PCS) and on the Tampa Scale for Kinesiophobia (TSK) appeared to be stable over time intervals that reflect common practice in pain clinics (Chapter 3 ).

- A systematic review of the predictors of treatment outcome in chronic pain shows that depression and fear avoidance are consistent predictors of changes in pain intensity, and that depression and locus of pain control are consistent predictors of changes in disability after treatment (Chapter 4). With regard to the various treatment groups, depression is shown to be a consistent predictor of somatic treatment outcome in terms of pain intensity.

- Depression appears to be the most consistent predictor of medical treatment outcome in terms of pain intensity, global perceived effect, mental component of quality of life, and pain interference, in a heterogeneous chronic pain population. High depression scores predicted poorer treatment outcome (Chapter 5).

- With regard to various diagnosis groups, depression was shown to be a consistent predictor of a less beneficial outcome of medical treatment in chronic neuropathic pain, in terms of pain intensity and pain interference. Pain catastrophizing was shown to be associated with a less beneficial outcome of invasive treatment in terms of pain intensity (Chapter 5 ).

- Pain catastrophizing was not predictive of the outcome of spinal cord stimulation (SCS) in terms of global perceived effect (GPE), quality of life (Q0L), or the reduction of pain intensity, in chronic Complex Regional Pain Syndrome patients type I (CRPS-I) (Chapter 6). 


\section{DISCUSSION OF THE MAIN RESULTS}

In general, treatment of chronic pain is moderately successful (Vlaeyen \& Morley, 2005), and the results from our academic pain centre are no exception. Patients referred to academic pain centres have usually been suffering from pain for a long time, sometimes with unknown aetiology. A first step in the process of improving treatment outcome is to examine which factors are predictive of insufficient treatment outcome. In particular, this thesis focused on the psychological factors associated with treatment outcome. Before tackling the main question of the prediction of the results of treatment, we first discuss the results with regard to the characteristics of our population.

\section{Characteristics of the population}

As expected, the level of quality of life in patients at our academic pain centre was extremely low (Chapter 2). Quality of life was shown to be low in all physical and mental domains, even lower than in other chronic pain populations, i.e., migraine and cancer pain (Aaronson et al., 1998). Most striking low levels of quality of life were found for low back pain patients and patients with widespread pain. Moreover, both pain intensity and pain catastrophizing were negatively associated with the level of quality of life. In line with other studies, the contribution of pain catastrophizing exceeded that of pain intensity, and was most prominent in the mental components of quality of life (social functioning, mental health, vitality, and general health). Pain coping, internal, and external pain control were of minor importance. However, a psychological factor closely related to pain catastrophizing, i.e., pain-related fear, was not included in the study. Pain-related fear, such as catastrophizing, has been shown to be an important predictor of pain intensity in chronic low back pain (CLBP) (Fishbain et al., 1997; Rush et al., 2000; Peters et al., 2005). In CLBP patients, pain-related fear has been found to be an even stronger predictor of pain intensity than catastrophizing (McCracken et al., 1996; Peters et al., 2005). Evidence of the contribution of pain-related fear to the level of quality of life in low back pain is limited (Kovacs et al., 2004; Kovacs et al., 2005a; Kovacs et al., 2005b; Kovacs et al., 2007). In our cross-sectional study of predictors of quality of life (Chapter 2), we only included pain catastrophizing as a possible predictive factor of quality of life, because we focused on a broad, heterogeneous population of pain patients. Most studies that find evidence of the role of pain-related fear in chronic pain have focused on musculoskeletal pain complaints, such as CLBP. Pain-related fear may be less relevant for complaints outside the musculoskeletal system.

Therefore, this cross-sectional study showed that the population seen in our academic pain centre is severely impaired. Moreover, many patients have undergone previous treatment for their pain, without apparent success. Reviewing the overall 
treatment response rate in this patient group, as found in the prospective study described in Chapter 5, it would appear that treatment was successful in $38 \%$ of the total population across diagnoses and the various medical treatments that were applied. Treatment success was defined as an improvement in pain intensity (measured with VAS) of at least 30\% (Farrar et al., 2001; Dworkin et al., 2008; Ostelo et al., 2008). Considering the severity of the population, a treatment response of $38 \%$ can be regarded as relatively successful. Nevertheless, it is clear that $62 \%$ of chronic pain patients do not benefit sufficiently from treatment, and there is still much room for improvement. Therefore, it is important to identify the factors that have a negative impact on the results of treatment, in order to be able to better select patients that have the best chances of successful treatment.

\section{Which psychological predictors of treatment outcome can be identified in a heterogeneous chronic pain population?}

\section{a. Test-retest stability PCS and TSK}

Two widely used assessment tools for the measurement of pain catastrophizing and pain-related fear are PCS and TSK. TSK was developed specifically to measure fear of movement/(re)injury. When using these instruments as pre-treatment screening measures in our pain population, it was essential to know whether they were stable over time, especially over longer periods of time. As already stated in the general introduction to this thesis, waiting lists are common at academic pain centers, and the interval between first administering the instrument and the first consultation with the physician can run into months. We were specifically interested in PCS, which has been shown to be an important factor in the level of quality of life. Although the interval between the two assessment times varied between 14 and 135 days, with a mean of 52 , both instruments possessed sufficient testretest stability over extended periods of time (Chapter 3 ). Therefore, we concluded that the use of PCS and TSK was justified in the following research.

\section{b. Psychological predictors of treatment outcome}

The major aim of this study was to search for predictors of (specifically medical) treatment outcome in a chronic pain population referred to an academic pain centre. One of the main variables focused on was pain catastrophizing, since our first study indicated that catastrophizing was high in our patient population and also because it was related to quality of life. According to at least one previous study (Samwel et al., 2000), it may also be a negative factor for outcome after somatic treatment. Before conducting our primary study on the predictors of treatment outcome, we first conducted a systematic review to see what other factors of outcome had been identified previously (Chapter 4). Fear-avoidance variables were found to be important factors, but additionally we found support for the predictive value of depression and pain control. In particular, depression was shown to be a consistent predictor of somatic treatment modalities. Therefore, we included fear- 
avoidance variables, depression, and pain control in our prospective cohort study (Chapter 5). By and large, the results of this study supported the findings in the review. Depression was found to be the most consistent predictor of negative medical treatment outcome in terms of pain intensity, psychological functioning, and global perceived effect, across diagnosis groups and type of intervention in a heterogeneous chronic pain population. Moreover, depression appeared to be a consistent negative predictor of pain intensity and pain interference after treatment in a neuropathic pain group. Other psychological factors which were examined, i.e., pain catastrophizing, fear of movement/(re)injury, internal and external pain control, were of minor importance or were unrelated to the diagnosis groups. However, with regard to the different treatment groups, pain catastrophizing was shown to be a negative predictor of changes in pain intensity after invasive treatment. Following this result, we conducted a prospective study focusing on a more specific and homogeneous pain population seen at our academic pain centre, namely patients with chronic CRPS-I (Chapter 6). These patients are often eligible for invasive treatment, such as spinal cord stimulation treatment aimed at pain reduction. Only those patients showing pain reduction of at least $50 \%$ after a oneweek test period received definitive implantation. The inclusion of patients with a definitive implantation was time-consuming, and during this time, the set-up of the pre-treatment screening list was changed. Unfortunately, this precluded us from including a measurement of depression and pain-related fear in the study because data on depression and pain-related fear could not be obtained from all patients. Thus, this study specifically examined pain catastrophizing as a predictive factor of the outcome of SCS. We found that pain catastrophizing was not predictive of SCS outcome in terms of pain intensity, GPE, or quality of life in CRPS-I patients. This is in apparent contrast with the results of our prospective cohort study, in which we found that pain catastrophizing was predictive of outcome after invasive treatment. On the other hand, neither did we find any association of pain catastrophizing with neuropathic pain in our prospective cohort study. It can be speculated that pain catastrophizing is a predictive factor of invasive treatment outcome in musculoskeletal pain problems, but not in neuropathic pain conditions.

\section{STRENGTHS AND LIMITATIONS}

Most of the strengths and limitations of the various studies have already been reported in the discussion sections of the previous chapters. This general discussion will only describe the overall strengths and limitations of this thesis.

This thesis focused on a comprehensive research in the area of psychological predictors of treatment outcome, more particularly after medical interventions. As far as we know, the study presented in Chapter 5 is the first to examine five psycho- 
logical predictors and five outcome measures of medical treatment in a heterogeneous chronic pain population. The results provide insight into the importance of specific psychological factors in a heterogeneous chronic pain population. Although the associations within the different diagnosis groups were mostly insignificant, the results suggested that the predictive power of depression for treatment outcome was relatively sound across the various diagnoses.

Some of the limitations of our studies should also be mentioned. Firstly, as already discussed above, we were not able to include measures of pain-related fear and depression in our prospective study of CRPS-I patients. That was particularly unfortunate because our prospective cohort study indicated that depression was a major predictor of outcome, in neuropathic pain patients as well. Secondly, our choice of predictive factors is certainly not exhaustive. It was based on earlier literature on this topic and we very likely omitted some interesting predictive psychological factors.

\section{CLINICAL IMPLICATIONS AND FUTURE RESEARCH}

The results of this thesis provide interesting information for clinicians treating patients with persistent pain complaints. Overall, we can conclude that some psychological factors are important in the prediction of the outcome of medical treatment, i.e., depression and pain catastrophizing, although the latter may be more applicable in some patient groups than others. These results could be a first step in the better tailoring of treatment to patient. When patients engage in exaggerated negative thoughts about their pain, or are very depressed, no good response to medical treatment is evident. One possible approach could be to address these negative thoughts and/or depression first, in order to optimize the effect of treatment. Multidisciplinary treatment approaches, with both psychological and medical treatment, might be appropriate. Future research should look into how the development of these alternative treatment approaches can be tailored to a patient's needs. The next step would be to investigate whether the effects of medical treatment can indeed be improved if the depression is treated, either before or together with medical treatment.

\section{CONCLUSIONS}

We have attempted to conduct a comprehensive overview of the psychological predictive factors of the effects of medical treatment. Our study population consisted of patients referred to an academic pain centre, with a long history of pain complaints. We used theory-based psychological predictive factors, standardized assessment tools, and multiple theory-based outcome measures. We investigated predictive factors across diagnosis and treatment groups. 
The findings in this study revealed that depression is an important factor in the prediction of treatment outcome in a chronic pain population and in various specific diagnosis groups. Invasive treatment outcome is negatively influenced by high levels of pain catastrophizing. These interesting results should be used to stimulate future research into discovering how these factors could be incorporated into the treatment process in order to establish a better outcome. 


\section{REFERENCES}

Aaronson, N.K., Muller, M., Cohen, P.D., Essink-Bot, M.L., Fekkes, M., Sanderman, R., Sprangers, M.A., te Velde, A. \&Verrips, E.(1998). Translation, validation, and norming of the Dutch language version of the SF-36 Health Survey in community and chronic disease populations. J Clin Epidemiol 51(11): 1055-68.

Dworkin, R.H., Turk, D.C., Wyrwich, K.W., Beaton, D., Cleeland, C.S., Farrar, J.T., Haythornthwaite, J.A., Jensen, M.P., Kerns, R.D., Ader, D.N., Brandenburg, N., Burke, L.B., Cella, D., Chandler, J., Cowan, P., Dimitrova, R., Dionne, R., Hertz, S., Jadad, A.R., Katz, N.P., Kehlet, H., Kramer, L.D., Manning, D.C., McCormick, C., McDermott, M.P., McQuay, H.J., Patel, S., Porter, L., Quessy, S., Rappaport, B.A., Rauschkolb, C., Revicki, D.A., Rothman, M., Schmader, K.E., Stacey, B.R., Stauffer, J.W., von Stein, T., White, R.E., Witter, J. \&Zavisic, S.(2008). Interpreting the clinical importance of treatment outcomes in chronic pain clinical trials: IMMPACT recommendations. J Pain 9(2): 105-21.

Farrar, J.T., Young, J.P., Jr., LaMoreaux, L., Werth, J.L. \&Poole, R.M.(2001). Clinical importance of changes in chronic pain intensity measured on an 11-point numerical pain rating scale. Pain 94(2): 149-58.

Fishbain, D.A., Cutler, R., Rosomoff, H.L. \&Rosomoff, R.S.(1997). Chronic pain-associated depression: antecedent or consequence of chronic pain? A review. Clin J Pain 13(2): 116-37.

Kovacs, F., Abraira, V., Cano, A., Royuela, A., Gil del Real, M.T., Gestoso, M., Mufraggi, N., Muriel, A. \&Zamora, J.(2007). Fear avoidance beliefs do not influence disability and quality of life in Spanish elderly subjects with low back pain. Spine 32(19): 2133-8.

Kovacs, F.M., Abraira, V., Zamora, J. \&Fernandez, C.(2005a). The transition from acute to subacute and chronic low back pain: a study based on determinants of quality of life and prediction of chronic disability. Spine 30(15): 1786-92.

Kovacs, F.M., Abraira, V., Zamora, J., Teresa Gil del Real, M., Llobera, J., Fernandez, C., Bauza, J.R., Bauza, K., Coll, J., Cuadri, M., Duro, E., Gili, J., Gestoso, M., Gomez, M., Gonzalez, J., Ibanez, P., Jover, A., Lazaro, P., Llinas, M., Mateu, C., Mufraggi, N., Muriel, A., Nicolau, C., Olivera, M.A., Pascual, P., Perello, L., Pozo, F., Revuelta, T., Reyes, V., Ribot, S., Ripoll, J. \&Rodriguez, E.(2004). Correlation between pain, disability, and quality of life in patients with common low back pain. Spine 29(2): 206-10.

Kovacs, F.M., Muriel, A., Abriaira, V., Medina, J.M., Castillo Sanchez, M.D. \&Olabe, J.(2005b). The influence of fear avoidance beliefs on disability and quality of life is sparse in Spanish low back pain patients. Spine 30(22): E676-82.

McCracken, L.M., Gross, R.T., Aikens, J. \&Carnrike, C.L., Jr.(1996). The assessment of anxiety and fear in persons with chronic pain: a comparison of instruments. Behav Res Ther 34(11-12): 927-33.

Ostelo, R.W., Deyo, R.A., Stratford, P., Waddell, G., Croft, P., Von Korff, M., Bouter, L.M. \&de Vet, H.C.(2008). Interpreting change scores for pain and functional status in low back pain: towards international consensus regarding minimal important change. Spine 33(1): 90-4.

Peters, M.L., Vlaeyen, J.W. \&Weber, W.E.(2005). The joint contribution of physical pathology, painrelated fear and catastrophizing to chronic back pain disability. Pain 113(1-2): 45-50.

Rush, A.J., Polatin, P. \&Gatchel, R.J.(2000). Depression and chronic low back pain: establishing priorities in treatment. Spine 25(20): 2566-71.

Samwel, H., Slappendel, R., Crul, B.J. \&Voerman, V.F.(2000). Psychological predictors of the effectiveness of radiofrequency lesioning of the cervical spinal dorsal ganglion (RF-DRG). Eur J Pain 4(2): 149-55.

Vlaeyen, J.W. \&Morley, S.(2005). Cognitive-behavioral treatments for chronic pain: what works for whom? Clin J Pain 21(1): 1-8. 


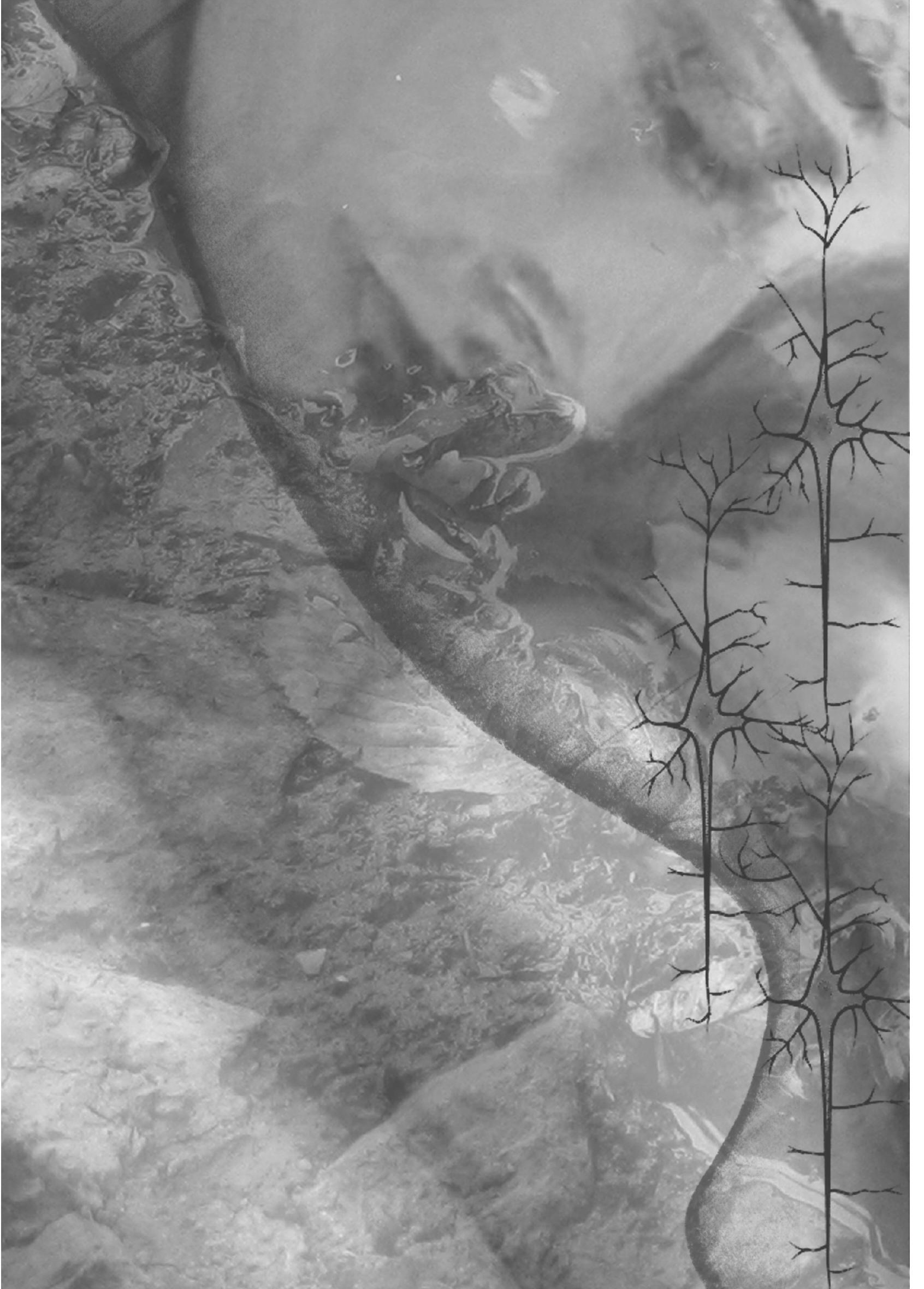




\section{Chapter 8}

\section{Summary}

Samenvatting 


\section{SUMMARY}

Chronic pain is a very common health problem, with musculoskeletal pain as one of the leading categories. Especially patients who are referred to an Academic Pain Centre have a long history of pain complaints, mostly with many psychological consequences. The treatment of this specific patient group often is unsuccessful. It is assumed that both somatic and psychological variables are inevitable related to the efficacy of treatment. Although many chronic pain patients are treated in a multidisciplinary setting (i.e. a combination of behavioural, physical, occupational and medication therapy), the available evidence about psychological factors that have influence on treatment outcome does not allow to draw conclusions on/about the most promising therapy.

In this thesis a first step is undertaken to the understanding of specific psychological factors that are involved in the efficacy of treatment outcome in a chronic pain population of an Academic pain centre.

Chapter $\mathbf{1}$ is an introductory chapter and first describes the relevance of a multidisciplinary approach in treating patients with chronic pain complaints. A short overview of the development from unimodal treatment approaches, like somatic treatment and behavioural treatments, to multidisciplinary treatment programs according to the biopsychosocial model, is given. Second, the theoretical background of psychological factors in chronic pain is described. Psychological factors have shown to be key players in the transition from acute to chronic pain and might be of influence on treatment outcome in chronic pain. The underlying fearavoidance model is discussed. Finally, this introductory chapter concludes with the research questions and the framework of this thesis.

In order to give direction to the search of psychological predictive factors of treatment outcome in chronic pain, we first examined the health status of our Academic Pain Centre population and psychological variables that were predictive of quality of life in a cross-sectional study, which is presented in Chapter 2. We were mainly interested in the impact of demographic and fear-avoidance variables on different aspects of quality of life. This information will shed light on the role of psychological factors in the perseverance of pain complaints and how this influences quality of life aspects. The results conclude that this specific chronic pain population has extreme low values on all quality of life aspects, even lower than other chronic pain populations, i.e. migraine and cancer pain. Moreover, pain catastrophizing negatively influenced the mental components of quality of life (social functioning, mental health, vitality and, general health) and even exceeded the impact of pain intensity on quality of life status. The results of this study yield room for research on psychological variables, like pain catastrophizing, as predictors of treatment outcome. 
In Chapter 3 we investigated the test-retest stability of two commonly used assessment instruments in measuring fear-avoidance variables, i.e. the Pain Catastrophizing Scale and the Tampa Scale for Kinesiophobia. Although both scales already revealed good test-retest stability, no data were available about the stability over an extended period of time in patients with chronic pain complaints. We specifically were interested in the stability over longer period of times, because this reflects time intervals that are common practice in Academic Pain Centres. Both instruments possessed sufficient test-retest stability over extended time intervals and therefore are justified to use as assessment measures in the prospective studies presented in chapter 5 and 6 .

In order to evaluate the current status of psychological predictive variables of treatment outcome in chronic pain, it is imperative to conduct a comprehensive review of the existing literature. Chapter $\mathbf{4}$ systematically reviews the existing evidence on psychological predictors of treatment outcome in all manifestations of chronic pain. The most prominent predictive factors with strong evidence were depression, fear-avoidance, and locus of control. Depression and fear-avoidance were negatively associated with pain intensity after treatment, whereas depression and a low pain control were negatively associated with disability after treatment. Patients who meet the dysfunctional profile were predisposed to have better outcome on the level of pain intensity and disability. Regarding the different treatment groups, i.e. somatic, rehabilitation, and cognitive-behavioural treatment, the results were inconclusive. The suggested interaction of the predictive factor with type of treatment was not substantiated by the results of this review. A detailed description of the various elements of a cognitive-behavioural treatment approach mostly was insufficient, so that it remained unclear if specific psychological factors were treated. It is concluded from this review that psychological factors are involved in the efficacy of treatment outcome in chronic pain. These valuable results are a first step in the process of better tailoring treatments to individual patients.

Chapter 5 presents the results of a prospective cohort study to examine the relative contribution of depression, fear-avoidance variables (pain catastrophizing and pain-related fear) and locus of control in an Academic Pain Centre population. This study focussed on medical treatment, excluding multidisciplinary and psychological treatments. Treatment was subdivided in two groups, i.e. non-invasive or invasive treatments. Multivariate regression analyses show that high levels of depression in the total group were associated with less pain reduction and pain interference, and less improvement on the mental component of quality of life. In addition, high levels of depression predicted less pain reduction after treatment in a neuropathic pain group. When regarding both treatment groups, we found that highly catastrophizing patients have less pain reduction after invasive treatment. It is concluded that the results of this study may provide us with tools for screen- 


\section{CHAPTER 8}

ing of chronic pain patients with insufficient prognosis for beneficial treatment outcome.

Following the results in chapter 5, we investigated the association between pain catastrophizing and the outcome of spinal cord stimulation in a specific and homogeneous chronic pain population, namely patients with Complex Regional Pain Syndrome type I (CRPS-I). The results of this prospective cohort study are presented in Chapter 6. Thirty-two patients were included for spinal cord stimulation. It was hypothesized that high catastrophizing patients would have a less successful outcome, in terms of pain reduction, improvement on quality of life or global perceived effect, nine months after implantation. Unexpectedly, pain catastrophizing did not predict spinal cord stimulation outcome in this specific pain group. Although the mean score of pain catastrophizing was high, a substantial part $(38 \%)$ of the patients reported at least fifty percent pain relief, which underlines the efficacy of spinal cord simulation in CRPS-I despite high levels of pain catastrophizing. We conclude that a high level of pain catastrophizing in CRPS-I patients is not a contra-indication for spinal cord stimulation.

Chapter $\mathbf{7}$ is the final chapter and provides a summary of the results of this thesis, followed by a general discussion of the main findings. We conclude that depression is an important factor in the prediction of treatment outcome in chronic pain patients. Also, pain catastrophizing is a negative predictor of invasive treatment outcome. However, pain catastrophizing did not predict spinal cord stimulation outcome in a CRPS-I population. Further, the strengths and limitations of the studies are discussed. Finally, some clinical implications and recommendations for future research are given. 


\section{SAMENVATTING}

Chronische pijn is een veelvoorkomend gezondheidsprobleem, waarbij muskuloskeletale pijn een van de belangrijkste categorieën is. Vooral patiënten die naar een Academisch Pijn Centrum worden verwezen hebben een lange geschiedenis met pijnklachten, vaak met bijkomende psychologische problematiek. De behandeling van deze specifieke patiëntengroep verloopt veelal zonder succes. Inmiddels is het therapeutisch uitgangspunt dat zowel somatische als psychologische componenten dienen worden behandeld om een optimaal effect van de behandeling te bereiken. Alhoewel veel chronische pijnpatiënten multidisciplinair worden behandeld, d.m.v. een combinatie van gedragstherapie en een medische behandeling, is de beschikbare evidentie over de impact van psychologische factoren op de effectiviteit van de behandeling nog niet voldoende uitgekristalliseerd.

In deze thesis wordt de eerste stap gezet naar het identificeren van specifieke psychologische factoren, die van belang zijn voor de effectiviteit van de behandeling van chronische pijnpatiënten in een Academisch Pijn Centrum.

Hoofdstuk 1 is een inleidend hoofdstuk en beschrijft allereerst het belang van een multidisciplinaire benadering bij de behandeling van chronische pijnpatiënten. In een kort overzicht wordt de ontwikkeling van een unimodale benadering van de behandeling, waarbij één discipline betrokken is, naar de multidisciplinaire behandelingsprogramma's, waarbij het Bio-Psycho-Sociale model als uitgangspunt geldt, beschreven. Ten tweede, wordt de theoretische achtergrond van psychologische factoren en chronische pijn besproken. Psychologische factoren spelen een belangrijke rol bij de transitie van acute naar chronische pijn en zijn mogelijk van invloed op de effectiviteit van de behandeling van chronische pijnpatiënten. Het onderliggende Vrees-Vermijdings model wordt besproken. Tenslotte eindigt het hoofdstuk met de vier onderzoeksvragen en een beschrijving van de verschillende hoofdstukken in deze thesis.

Om enige richting te kunnen geven aan ons onderzoek naar de voorspellende waarde van psychologische factoren op de effectiviteit van de behandeling, hebben we allereerst de gezondheidsstatus van de populatie pijnpatiënten in onze Academische pijnkliniek onderzocht, hetgeen wordt beschreven in Hoofdstuk 2. Tevens worden d.m.v. cross-sectionele analyses de voorspellende waarde van psychologische factoren op de kwaliteit van leven van deze populatie gepresenteerd. In dit onderzoek zijn wij met name geïnteresseerd in de impact van vreesvermijdings variabelen op de verschillende aspecten van de kwaliteit van leven. Deze informatie geeft inzicht in de rol die psychologische factoren kunnen spelen bij het voortbestaan van pijnklachten en hoe dit de kwaliteit van leven aspecten beïnvloedt. Uit de resultaten blijkt dat deze specifieke pijnpopulatie extreem lage waarden scoort op alle kwaliteit van leven aspecten, zelfs lager dan andere chronische pijnpopulaties, zoals een populatie migraine patiënten en patiënten met 
chronische kankerpijn. Bovendien worden de mentale componenten van de kwaliteit van leven (sociaal functioneren, mentale gezondheid, vitaliteit en de algemene gezondheid) negatief beïnvloedt door patiënten die veel catastroferen over hun pijn. Catastroferen over de pijn heeft zelfs een grotere invloed op de kwaliteit van leven dan de mate van pijn zelf. De resultaten van deze studie geven ruimte aan verder onderzoek naar psychologische factoren, zoals catastroferen over de pijn, als voorspellers van de effectiviteit van de behandeling.

In Hoofdstuk 3 worden de resultaten beschreven van de analyses van het onderzoek naar de test-hertest stabiliteit van twee veelgebruikte pijnvragenlijsten bij het meten van Vrees-Vermijdings variabelen, namelijk de Pijn Catastroferen Schaal en de Tampa Schaal voor Kinesiofobie. Alhoewel uit eerder onderzoek is gebleken dat de test-hertest stabiliteit goed is, zijn geen gegevens beschikbaar over de stabiliteit van deze lijsten met een langere periode tussen de 2 metingen bij een chronische pijnpopulatie. Uit de praktijk blijkt, dat een vragenlijst wordt ingevuld weken, soms zelfs maanden voordat een eerste consult met de arts plaatsvindt. De vraag rijst of de eerder ingevulde lijst op dit latere tijdstip nog representatief is. Beide instrumenten blijken voldoende test-hertest stabiliteit te bezitten over een langere periode. Uit deze studie wordt geconcludeerd dat het gebruik van de twee lijsten in de prospectieve studies van hoofdstuk 5 en 6 gerechtvaardigd is.

Om de huidige status van de voorspellende waarde van psychologische factoren op de effectiviteit van de behandeling te evalueren, is het noodzakelijk om een uitgebreide literatuurstudie uit te voeren. In Hoofdstuk $\mathbf{4}$ wordt de bestaande evidentie over dit onderwerp besproken in alle uitingen van chronische pijn. De meest prominent aanwezige factoren met een sterke evidentie zijn depressie, vreesvermijding en pijncontrole. Depressie en vrees-vermijding beïnvloeden de pijnintensiteit na de behandeling negatief. Zowel depressiviteit als het hebben van weinig controle over de pijn hebben een negatieve invloed op de beperking na de behandeling. Patiënten die in het 'dysfunctionele' profiel vallen hebben minder pijn en beperkingen na de behandeling. Wanneer wordt gekeken of de invloed van psychologische variabelen afhankelijk is van het type behandeling (somatisch, revalidatie en cognitief-gedragsmatig) komen er geen duidelijke verschillen aan het licht. Veelal ontbreekt een gedetailleerde beschrijving van met name de verschillende elementen van een cognitief-gedragsmatige benadering, zodat onduidelijk blijft in hoeverre bepaalde specifieke psychologische factoren worden behandeld. De conclusie van deze studie luidt dat factoren als depressie, vreesvermijding en pijncontrole zijn betrokken bij de effectiviteit van de behandeling van chronische pijnpatiënten. Deze waardevolle resultaten zijn een eerste stap in het proces van het verbeteren van de toewijzing van patiënten in een individueel afgestemd behandelingsplan. 
Hoofdstuk 5 presenteert de resultaten van een prospectieve cohort studie naar de bijdrage van depressie, vrees-vermijdings variabelen (catastroferen over pijn en pijn-gerelateerde vrees) en pijncontrole in de effectiviteit van de behandeling in een Academisch Pijn Centrum. Deze studie richt zich op een medische behandeling, zonder multidisciplinaire en psychologische behandeling. De behandeling wordt ingedeeld in twee groepen, namelijk de niet-invasieve en de invasieve groep. Uit multivariate regressieanalyses volgt dat depressiviteit in de totale groep verbonden is met minder afname in pijn en pijn interferentie en minder toename in de mentale componenten van kwaliteit van leven. Tevens voorspelt depressie een minder grote afname van de pijn na de behandeling in een groep patiënten met neuropatische pijn. Patiënten die veel catastroferen over hun pijn hebben een minder grote afname van de pijn na een invasieve behandeling. De resultaten van deze studie kunnen een handvat zijn voor het screenen van patiënten met chronische pijn, zeker als bekend is dat deze patiënten een slechtere prognose voor de effectiviteit van de behandeling hebben.

Hoofdstuk 6 beschrijft de resultaten van een prospectieve cohort studie, waarin het verband tussen catastroferen over pijn en de effectiviteit van ruggenmergstimulatie bij patiënten met een complex regionaal pijnsyndroom type I (CRPS-I) wordt getest. In de studie worden 32 CRPS-I patiënten toegelaten voor ruggenmergstimulatie. De hypothese luidt dat patiënten die veel catastroferen over hun pijn minder succes van de behandeling zullen hebben negen maanden na de implantatie, op het gebied van pijnvermindering en verbetering van kwaliteit van leven. Echter onverwacht blijkt dat catastroferen over de pijn geen voorspellende waarde heeft voor de effectiviteit van ruggenmergstimulatie bij CRPS-I patiënten. Ondanks dat het gemiddelde niveau van catastroferen hoog is, heeft $38 \%$ van de patiënten ten minste $50 \%$ pijnvermindering ten gevolge van de ruggenmergstimulatie. Daaruit blijkt dat een hoog niveau van catastroferen bij CRPS-I patiënten geen contra-indicatie vormt voor behandeling met ruggenmergstimulatie.

Hoofdstuk 7 is het laatste hoofdstuk van deze thesis en geeft een samenvatting van de resultaten uit de verschillende studies, wat wordt gevolgd door een algemene discussie van de belangrijkste bevindingen. In het algemeen concluderen we dat depressie een belangrijke factor is bij het voorspellen van de effectiviteit van de behandeling bij chronische pijnpatiënten. Tevens, heeft catastroferen over de pijn een negatieve impact op de effectiviteit van invasieve behandelingen. Echter, bij CRPS-I patiënten heeft catastroferen geen invloed op de behandeling met ruggenmergstimulatie. Verder worden de sterke punten en de beperkingen van de thesis besproken. Tenslotte worden de klinische implicaties en aanbevelingen voor de toekomst besproken. 


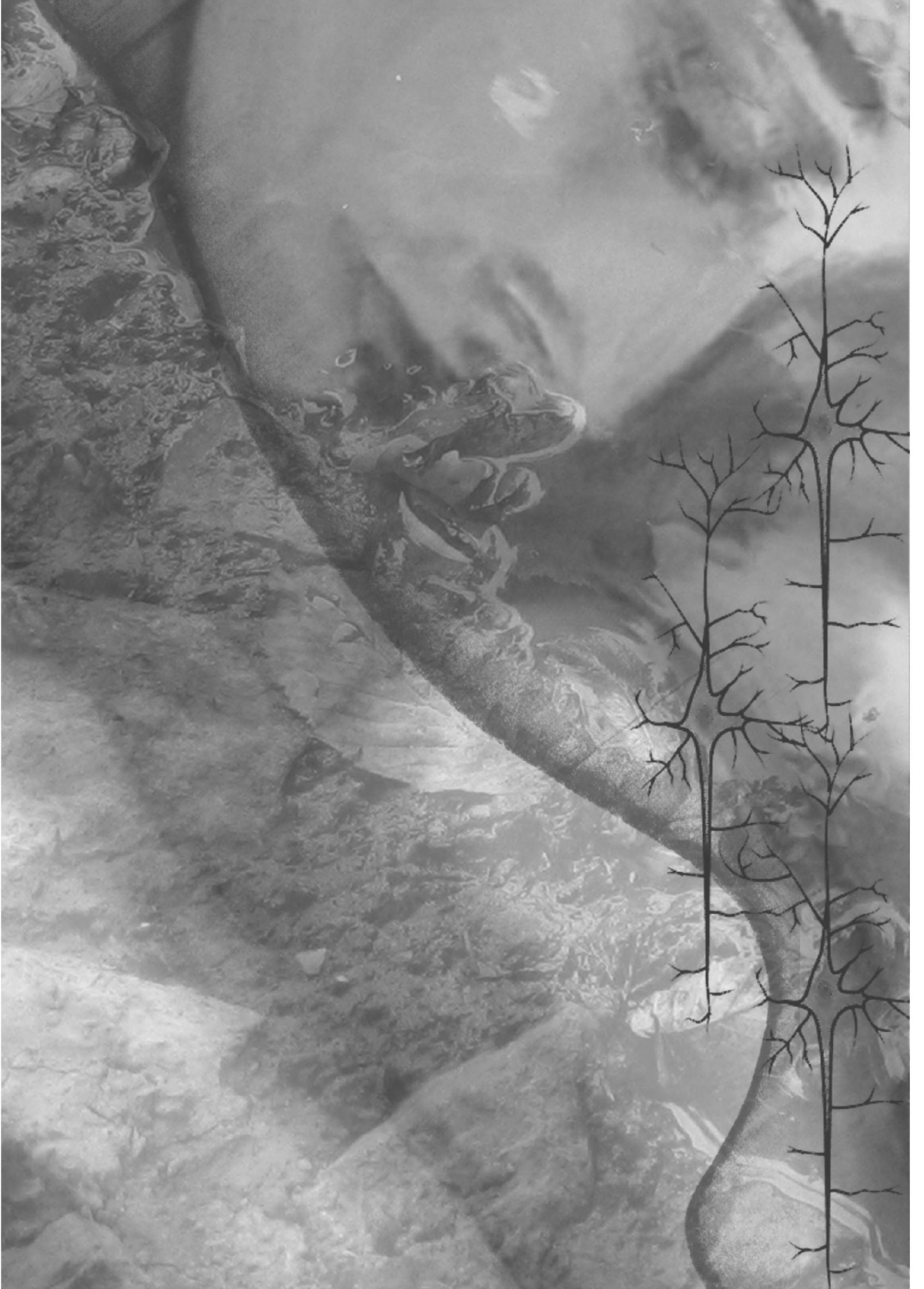




\section{Dankwoord}




\section{DANKWOORD}

Afscheid nemen doet pijn! Het gevoel is sterker als je een proefschrift afrondt en al een paar jaar op afstand woont. Het echte afscheid gaat nu eigenlijk pas plaatsvinden. Met pijn in mijn hart en niet zonder hier, op deze bladzijden iedereen die mij op wat voor een manier dan ook heeft bijgestaan tijdens het promotietraject, te bedanken.

Allereerst gaat mijn welgemeende dank uit naar mijn promotoren en copromotor, prof. Maarten van Kleef, prof. Madelon Peters en dr. Jaap Patijn.

Maarten, jij bent mijn begeleider vanaf het eerst uur. Ik kan me de dag dat je me vroeg om dit promotietraject in te gaan nog heugen als de dag van gisteren. Ik, een veertiger en moeder van 2 kinderen, gaat mij dit wel lukken! Ik ben je nu dankbaar dat je mij de kans hebt geboden om deze leerzame weg in te slaan. Ondanks de tegenslagen in mijn naaste omgeving en de verhuizing naar Rotterdam, waardoor ik ettelijke maanden vertraging heb opgelopen, is het me gelukt mijn proefschrift af te ronden. Jij hebt de grote lijnen uitgestippeld en creatieve oplossingen bedacht.

Madelon, jij bent voor mij een groot voorbeeld als onderzoeker en als mens. De vele gesprekken die wij hebben gevoerd zijn voor mij van onschatbare waarde. Je heldere analytische manier van denken en je kritische noot bij elk hoofdstuk hebben ervoor gezorgd dat het proefschrift is zoals het nu is.

Jaap, als clinicus heb jij de praktijkkant van dit proefschrift altijd benadrukt. Recht door zee, als rasechte Rotterdammers onder elkaar, wees je mij op wetenschappelijke valkuilen waarin ik dreigde te vallen. Een warm schouderklopje in moeilijke tijden heeft me altijd goed gedaan.

De leden van de beoordelingscommissie: prof. dr. Van 0s, prof. dr. Vissers, prof. dr. Vissser-van de Walle, prof. dr. Metsemakers en prof. dr. Vles, wil ik bedanken voor de bereidwilligheid om tijd vrij te maken in de zomervakantie voor het doornemen en goedkeuren van mijn proefschrift.

Mijn speciale dank gaat uit naar de patiënten van de polikliniek pijnbestrijding, die waarschijnlijk wéér een vragenlijst in moesten vullen en dit altijd trouw bleven doen. Zonder de bereidwilligheid van deze patiënten geen proefschrift!

Op de werkvloer heb ik vele collega's die ik zou willen bedanken. De collega's van het PKC, mijn werkplek, hebben ervoor gezorgd dat ik een geweldige tijd heb gehad. Sandra Reijnders, voor jou een speciaal woordje van dank. Jij was voor mij de rots in de branding op het secretariaat. Jouw hulp en adviezen hebben het voor mij een stuk gemakkelijker gemaakt. Albere Köke, jij stond echt altijd voor me 
klaar en bent een heel fijne collega geweest. Wij hebben het langst samengewerkt, hebben veel gelachen en ook professioneel heb je een steentje bijgedragen aan dit proefschrift. José Geurts, je bent niet zo heel lang mijn collega geweest, maar hebt me op vele manieren bijgestaan. Jouw gedrevenheid en enthousiasme bij het meelezen van de artikelen van de review en het eindeloze geduld als ik weer eens een paar artikelen niet kon downloaden en ik jou moest vragen dit voor mij te doen, vind ik bewonderenswaardig. Ik vind het fijn dat wij onze samenwerking kunnen afsluiten met jou als paranimf aan mijn zijde. Marjan de Rijke, al woon je nu in Zeeland, het heeft me goed gedaan om jou als collega gehad te hebben. Het wekelijks bikkelen op de racefiets in het heuvelland en het uitstapje tot diep in de nacht met carnaval, zullen een blijvende goede herinnering zijn. Nelleke en Rachel, jullie aanwezigheid tijdens de vele bezoekjes aan het PKC heeft me goedgedaan.

De dames van de polikliniek pijnbestrijding, Emilienne en Claire, maar ook Jetty, Esther, Lucy, Rosina en Peter, jullie hebben een fantastische bijdrage geleverd aan het verzamelen van de patiëntgegevens. Het was altijd een 'uitje' om even bij jullie langs te gaan.

Fons Kessels, ik heb gemerkt dat je nooit te oud bent om te leren. Mijn statistische kennis is mede dank zij jou in de loop der jaren verbeterd. Jij hebt veel bijgedragen aan de statistiek, die zo nodig is bij elk wetenschappelijk onderzoek. Bedankt hiervoor!

Wilma Lardenoije, bedankt voor de bereidwilligheid om mij de nodige informatie over de ESES patiënten te verstrekken. Resy van den Broeck, je hulp bij het opsturen van mijn eerste artikel naar het European Journal of Pain en allerlei praktische zaken, heb ik zeer gewaardeerd.

Jan van Zundert, mijn dank voor de fijne samenwerking in al die jaren, de borrel als weer één van je artikelen was goedgekeurd en voor je kritisch commentaar op mijn ESES artikel.

Prof dr. Johan Vlaeyen, bedankt voor je adviezen over mijn eerste artikel en de verhelderende gesprekken die wij door de jaren heen hebben gehad.

De dames van het secretariaat anesthesie, Hermina, Patrice, Thea en Hanny, ook bij jullie kon ik altijd terecht als ik hulp nodig had.

Een evenzeer belangrijk aspect is de morele steun !

Van mijn vrienden wil ik er een paar in het bijzonder noemen. De Millenniumgroep, Ellen, Rens, Annelies, Theo, Ella en Rob, jullie onvoorwaardelijke steun en vriendschap is heel bijzonder. Gelukkig woon ik nu weer wat dichterbij en kunnen we veel gezellige etentjes en uitstapjes maken en de draad van het sporten weer op- 
pakken. Wilma, mijn lieve vriendin, jij hebt altijd in mij geloofd en samen hebben we heel wat meegemaakt. Door dik en dun, zo wil ik het omschrijven! Anja, mijn lieve paranimf, jouw wijze woorden werken altijd! Ik voel me gesterkt je straks aan mijn zijde te hebben. 0ok in Maastricht heb ik een thuishaven. Patrice, jouw deur stond en hopelijk staat, altijd voor mij open. Ik heb heel wat nachtjes bij jullie geslapen als ik weer eens een paar dagen in Maastricht was.

Lieve ma, een schoonmoeder uit duizenden. Bedankt voor alle hulp die ik zo hard nodig had als mijn afwezigheid in het gezin weer eens een feit was. Lieve mama, jij hebt mijn promotie niet meer mee mogen maken. Lieve pa en Maryse, jullie huis stond altijd voor mij open als ik mij een paar dagen terug wilde trekken. Pierre en Angélique, mijn broer en zus, jullie hebben ook al die jaren meegeleefd.

Mijn allerliefste Jan, Renée en Tim, aan jullie draag ik dit proefschrift op. Jullie hebben mijn grillen met veel liefde doorstaan en zonder jullie steun was het niet gelukt. Daar ben ik jullie heel dankbaar voor. Dit boek wordt eindelijk gesloten... 
About the author 


\section{ABOUT THE AUTHOR}

Ingrid Elisabeth (Inge) Lamé was born on January 15, 1961 in Rotterdam, The Netherlands. She attended the secondary school at the Comenius College in Capelle a/d Ijssel from 1973 to 1980 . From 1980 to 1984 she studied Physical Therapy at the Academy of Physical Therapy in Rotterdam. She has worked as a physical therapist at the physical therapy practice 'Schiedam-Zuid', situated in Schiedam, for ten years. In 1987 she started her study at the faculty of Human Movement Sciences of the Vrije Universiteit in Amsterdam, while working as a physical therapist. She obtained her diploma of Master of Sciences, specialized in Physiology and Psychology, in 1995. Her daughter Renée was born in January 1993.

From December 1995 till August 1997 she moved with her family to Wayne, New Jersey, USA. Her son Timothy Jan was born in October 1996. In August 1998 she moved to Maastricht. She started her career as a scientist at the Pain Management and Research Centre, University Hospital in Maastricht in February 2000. She started her doctoral research in November 2002 and prepared this PhD thesis under supervision of Prof. M. Van Kleef, Prof. M. Peters and Dr. J. Patijn.

Inge Lamé is married to Jan Rotmans, professor in Transition Management at the Erasmus Universiteit Rotterdam. 


\section{PUBLICATIONS}

Van Suijlekom, H.A., Lamé, I.E., Stomp-van den Berg, S.G.M., Kessels, A.G., Weber, W.E.J. (2003) Quality of life of patients with cervicogenic headache: A comparison with control subjects and patients with migraine or tension-type headache. Headache, 43 (10), 1034-1041

Van Zundert, J., Lamé, I.E., de Louw, A., Jansen, J., Kessels, A.G., Patijn, J., van Kleef, M. (2003) Percutaneous pulsed radiofrequency treatment of the cervical dorsal root ganglion in the treatment of chronic cervical pain syndromes: A clinical audit. Neuromodulation, 6 (1), 6-14

Lamé, I.E., Weber, W.E.J. (2005) Catastrophising pain behaviour in sarcoidosis patients. The Pain Clinic, 17 (4), 351-355

Lamé, I.E., Peters, M.L., Vlaeyen, J.W. van Kleef, M., Patijn, J. (2005) Quality of life in chronic pain is more associated with beliefs about pain, than with pain intensity . European Journal of Pain, 9 (1), $15-24$

Haspeslagh, S.R., van Suijlekom, H.A., Lamé, I.E., Kessels, A.G., van Kleef, M., Weber, W.E. (2006) Randomised controlled trial of cervical radiofrequency lesions as a treatment for cervicogenic headache. BMC Anesthesiology, 6 (1), 1-11

Van Zundert, J., Patijn, J., Kessels, A., Lamé, I.E., van Suijlekom, H., van Kleef, M. (2007) Pulsed radiofrequency adjacent to the cervical dorsal root ganglion in chronic cervical radicular pain: A double blind sham controlled randomized clinical trial. Pain, 127 (1-2), 173-182

Peters, M.L., Patijn, J., Lamé, I.E. (2007) Pain assessment in younger and older pain patients: psychometric properties and patient preference of five commonly used measures of pain intensity. Pain Medicine, 8 (7), 601-610

Lamé, I.E., Peters, M.L., Kessels, A.G., van Kleef, M., Patijn, J. (2008) Test-retest stability of the Pain Catastrophizing Scale and the Tampa Scale for Kinesiophobia in Chronic Pain over a Longer Period of Time. Journal of Health Psychology, 13 (6), $820-826$ 